DOE/ER--10614-1

DE82 013037

\title{
Theory and Tests of Two-Phase Turbines
}

\section{David G. Elliott}

March 15, 1982

Prepared for

U.S. Department of Energy

Through an agreement with

National Aeronautics and Space Administration

by

Jet Propulsion Laboratory

California Institute of Technology

Pasadena, California 


\section{DISCLAIMER}

This report was prepared as an account of work sponsored by an agency of the United States Government. Neither the United States Government nor any agency Thereof, nor any of their employees, makes any warranty, express or implied, or assumes any legal liability or responsibility for the accuracy, completeness, or usefulness of any information, apparatus, product, or process disclosed, or represents that its use would not infringe privately owned rights. Reference herein to any specific commercial product, process, or service by trade name, trademark, manufacturer, or otherwise does not necessarily constitute or imply its endorsement, recommendation, or favoring by the United States Government or any agency thereof. The views and opinions of authors expressed herein do not necessarily state or reflect those of the United States Government or any agency thereof. 
Two-phase turbines open the possibility of new types of power cycles operating with extremely wet mixtures of steam and water, organic fluids, or immiscible liquids and gases. Possible applications are geothermal power, waste-heat recovery, refrigerant expansion, solar conversion, transportation turbine engines, and engine bottoming cycles.

A theoretical model for two-phase impulse turbines was developed. Apparatus was constructed for testing one- and two-stage turbines (using speed decrease from stage to stage). Turbines were tested with water-and-nitrogen mixtures and Refrigerant 22. Nozzle efficiencies were 0.78 (measured) and 0.72 (theoretical) for water-and-nitrogen mixtures at a water/nitrogen mixture ratio of 68 , by mass; and 0.89 (measured) and 0.84 (theoretical) for Refrigerant 22 expanding from 0.02 quality to 0.28 quality. Blade efficiencies (shaft power before windage and bearing loss divided by nozzle jet power) were 0.63 (measured) and 0.71 (theoretical) for water-and-nitrogen mixtures and 0.62 (measured) and 0.63 (theoretical) for Refrigerant 22 with a single-stage turbine, and 0.70 (measured) and 0.85 (theoretical) for water-and-nitrogen mixtures with a two-stage turbine. 


\section{DISCLAIMER}

Portions of this document may be illegible in electronic image products. Images are produced from the best available original document. 


\section{ACKNOWLEDGMENT}

The two-phase turbine research was supported from May 1977 to September 1980 by the Department of Energy (DOE), Division of Geothermal Energy, Hydrothermal Technology Branch, Clifton B. McFarland, Chief, under Interagency Agreement EG-78-A-30-1026 (NASA Task Order RD 152, Amendment 130), "Analysis Support in Geothermal Cycles and Expanders." The turbine research continued with support from the DOE Division of Advanced Energy Projects, Dr. Ryszard Gajewski, Director, under Interagency Agreement DE-AI01-80ER10614 (NASA Task Order RD 152, Amendment 266), "Two-Phase Turbines for Efficient Waste Recovery."

This report is the final report on the work for the Division of Geothermal Energy and the midterm report on the work for the Division of Advanced Energy Projects.

The turbine research was conducted in the Acoustics, Fluid Dynamics, and Heat Transfer Group (Paul F. Massier, Supervisor) of the Energy and Materials Research Section (Dr. Robert F. Landel, Manager). Support in organizing the project and coordinating with NASA and DOE was provided by G.W. Meisenholder, Manager of Transportation Programs at JPL. Special acknowledgment is due P.R. Miller, Manager of Conservation and Fossil Energy Systems at NASA, for assistance in securing support for the research and handling contractual arrangements. 
I. INTRODUCTION .......................... 1

II. BACKGROUND ...........................

III. APPLICATIONS ... . . . . . . . . . . . . . 4

A. Saturated Water Turbines . . . . . . . . . . . 4

B. Organic-Fluid Turbines . . . . . . . . . . . . . 4

C. Wet-to-Dry Cycle .................... 12

D. Two-Component Cycle . . . . . . . . . . . . . . 15

IV. NOZZLES ........................ 19

A. Construction ........................ 19

B. Nozzle Program ...................... 22

c. Performance Definitions ................. . 24

D. Lll Steam-and-Water Data . . . . . . . . . . . 26

E. Water-and-Nitrogen Data ................... 27

F. Refrigerant-22 Data . . . . . . . . . . . . . 32

G. LlL Tutbine Nozzle .................... 32

H. Wet-To-Dry Nozzle ................... 37

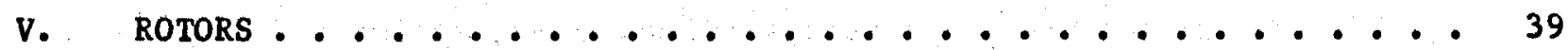

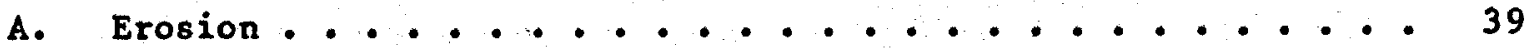

B. Liquid Path . . . . . . . . . . . . . . . . 40

C. Rotor Program ................................. 47

D. Rotor Test Apparatus . . . . . . . . . . . . . 51

E. Measurement Procedure . . . . . . . . . . . . . . 54

F. Water-and-Nitrogen Turbine Data . . . . . . . . . . 54

G. Refrigerant-22 Turbine Data . . . . . . . . . . . 56

H. Lll steam-and-Water Turbine Data ............. 60

I. Staging Method ...................... 61

J. First-Stage Rotor Data ............... . . 65 
K. Two-Stage Turbine Data ...................

L. Divergence and Stagnation Losses ...............

L. Divergence and stagnation hosses $0^{\circ} \cdot 0^{\circ} \cdot 0^{\circ} \cdot 0^{\circ} \cdot$

N. Turbine Performance Examples. . . . ............

vI. CONCLUSION ..........................

A. Analysis Capability . . . . . . . . . . . . . 96

B. Application Prospects . . . . . . . . . . . . 96

APPENDIXES

A. ROTOR MODEL . . . . . . . . . . . . . . . 99

B. SEPARATOR TURBINE MODEL . . . . . . . . . . . . . 133

REFERENCES .......................... 139

Figures

1. Steam-and-water cycle . . . . . . . . . . . . . 5

2. Organic-fluid two-phase turbine . . . . . . . . . . 6

3. Organic-fluid two-phase cycle ................ 8

4. Comparison of Rankine and two-phase cycles . . . . . . . . 10

5. Comparison of supercritical and two-phase cycles . . . . . . 11

6. Steam topping cycle with organic-fluid bottoming cycle.... 13

7. Wet-to-dry cycle .................... 14

8. Two-phase, two-component engine .............. 16

9. Two-phase, two-component cycle .............. 17

10. Two-phase nozzle ..................... 20

11. Experimental two phase nozzle ................ . 21

12. Water-and-nitrogen jet at $80 \mathrm{~m} / \mathrm{s}$.............. 23

13. Comparison of theoretical and experimental drop diameters and velocity coefficients for the LLL steam-and-water nozzle • 28

14. Comparison of theoretical and experimental exit velocities . . 29

15. Wet-to-dry expansion of toluene from $289^{\circ} \mathrm{C}$ to $70^{\circ} \mathrm{C}$. . .

16. Effect of drop diameter on liquid impingement . . . . . . . 41 
17. Rotor 1 blade shape . . . . . . . . . . . . . 42

18. Liquid exit flow at bigh liquid/gas mixture ratio . . . . . 43

19. Axial view of exit flow at $R=45$............ . . 45

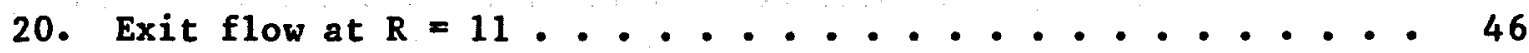

21. Exit flow at $R=4$.................. 48

22. Two-phase turbine experiment ................ 52

23. Single-stage turbine ................ 53

24. Comparison of theoretical and experimental torques of water-and-nitrogen turbine ............. 55

25. Comparison of theoretical and experimental efficiencies of water-and-nitrogen turbine .............. 57

26. Comparison of theoretical and experimental torques of LLL steam-and-water turbine . . . . . . . . . . . .

27. Comparison of theoretical and experimental efficiencies of LLL steam-and-water turbine .............. 63

28. Staging method ........................ 66

29. Rotor 2 blade shape ................. 67

30. Exit flow from Rotor 2 . . . . . . . . . . . . 69

31. Axial view of exit flow from Rotor 2 . . . . . . . . . 70

32. Comparison of exit flow from flat and curved blades . . . . 71

33. Comparison of theoretical and experimental blade torques of Rotor 2 . . . . . . . . . . . . . . . 72

34. Two-stage turbine ................... 73

35. Effect of nozzle position on second-stage zero-speed torque at 2200-rpm first-stage speed .......... . 75

36. Comparison of theoretical and experimental second-stage torques of two-stage turbine at 2200-rpm first-stage speed : . 76

37. Comparison of theoretical and experimental efficiencies of two-stage turbine at 2200-rpm first-stage speed . . . . . 77

38. Exit flow from a single blade . . . . . . . . . . . 80

39. Exit jet and delayed drainage flow from Rotor $2 \ldots \ldots 2$

40. Exit flow from bladed arm . . . . . . . . . . 83

41. Rotor 2 exit scoop for flow measurement . . . . . . . . 84

42. Separator turbine . . . . . . . . . . . . 86 
43. Comparison of efficiencies of impulse turbine and separator turbine . . . . . . . . . . . . . .

44. Theoretical efficiencies of 5-MW steam-and-water and Refrigerant-113 turbines . . . . . . . . . . 95

A-1. Two-phase turbine geometry . . . . . . . . . . . 100 A-2. Definitions of velocity vectors . . . . . . . . . 102 A-3. Impingement geometry . . . . . . . . . . . . 104 A-4. Impact behavior . . . . . . . . . . . . . . . 106 A-5. Impact and friction on a blade section . . . . . . . . 108 A-6. Blade lengths . . . . . . . . . . . . . . . 113 B-1. Separator turbine................... 134

Tables

1. Comparison of theoretical and experimental nozzle performance using water and nitrogen . . . . . . . . . 30

2. Comparison of theoretical and experimental nozzle performance using Refrigerant 22 . . . . . . . . . 33

3. Theoretical performance of LLL turbine nozzle . . . . . . 35

4. Comparison of theoretical and experimental turbine performance using water and nitrogen ........... 58

5. Comparison of theoretical and experimental turbine performance using Refrigerant 22 .......... . . 59

6. Comparison of theoretical and experimental performance of LLL steam-and-water turbine . . . . . . . . . . 64

7. Comparison of theoretical and experimental two-stage turbine performance ................. 78

8. Theoretical performance of 5-MW steam-and-water turbine.... 90

9. Theoretical performance of 5-MW Refrigerant-113 turbine . . . 93 A-1. Rotor model nomenclature ............. 125 


\section{INTRODUCTION}

Power conversion using two-phase liquid-gas mixtures has been investigated for use in pumping (Ref. 1), liquid-metal magnetohydrodynamics (Ref. 2), and turbine engines (Ref. 3). This report describes current research on two-phase turbines at JPL.

Two-phase turbines provide a way to operate in the wet region of water-andsteam mixtures or of organic fluids. In addition, two-phase, two-component mixtures such as steam and oil or steam and molten salts can, in principle, be used as working fluids in unusual cycles. Possible applications of two-phase turbines are in geothermal power, waste-beat recovery, refrigerant expansion, solar conversion, transportation turbine engines, and engine bottoming cycles. Potential advantages over conventional vapor cycles in these applications are more effective use of the energy in such hot liquids as geothermal fluids, better matching to sensible-heat sources, lower shaft speeds, and the flexibility of operating without the restriction of dry-vapor expansion.

This report will present theory and test results for two-phase turbines and give examples of applications. 


\section{BACKGROUND}

Earlier, I reported two-phase flow research on jet pumps (Ref. 1) and 1 iquid-metal magnetohydrodynamics (Ref. 2). Those two projects were based on the ability of a two-phase flow to provide pumping without using moving mechanical parts. By expanding a two-phase mixture in a nozzle and then removing the gas phase, a large rise in the dynamic pressure of the fluid can be achieved. The separation of gas from liquid increases the density term $p$ in the dynamic pressure $\frac{1}{2} \rho V^{2}$, enabling the separated liquid to flow through a diffuser to reach a pressure much bigher than the inlet pressure of the two-phase nozzle.

Instead of a pressure rise, power can be taken out of the liquid. This effect is the basis of liquid-metal magnetobydrodynamics, or liquid-meta 1 MHD. A liquid metal is circulated in a closed loop, and power is extracted from the liquid metal with a magnetic field. Liquid-metal MHD has been studied at the Jet Propulsion Laboratory (JPL), the Argonne National Laboratory, and elsewhere. Because of the efficiency limitations of two-phase nozzles, separators, diffusers, and generators, liquid-metal MHD cycles have been limited to about half the efficiency of turbine cycles, and applications appear limited to extreme temperature conditions where turbines cannot be used.

During the JPL liquid-metal MHD project in 1973, I suggested, not seriously, that the MHD generator could be replaced by a two-phase 1iquidmetal turbine to raise the efficiency of the liquid-metal MHD cycle. Lance Hays, an engineer on the project, recognized in this suggestion the germ of a serious possibility and pointed out that a two-phase turbine, coupled with a pump to return the liquid to the nozzle, could use two-phase mixtures other than liquid metals, such mixtures as steam and hydraulic oil, to provide a new type of turbine engine with low shaft speed and other possible advantages.

At the same time, A.L. Austin and his geothermal group at Lawrence Livermore Laboratory (LLL) proposed a two-phase turbine for geothermal power (Ref. 4). The two-phase fluid from geothermal wells (both the water and the steam) would be passed through the turbine. The LLL group pursued this idea experimentally in research on two-phase impulse turbines (Ref. 5). They 
hoped that the water drop sizes would be small enough for the steam and water to behave as a homogeneous fluid and give these turbines efficiencies comparable to those of vapor turbines.

Based on calculations of drop sizes and drop trajectories, I concluded that the liquid drops in two-phase turbines would be too large to follow the gas phase, and that the 1 iquid would impinge on the blades and form a thin liquid film. The friction drag of this film would be so high that the efficiency of single-stage impulse turbines would be limited to little more than 50 percent.

To achieve higher efficiency, Hays and I thought it would be necessary to use a "separator turbine" in which the liquid would be separated from the vapor in a rotary separator and then passed through a liquid turbine. This concept was subsequently pursued by Hays' company, Biphase Energy Systems, in seeking to develop commercial applications (Refs. 6 and 7).

In early turbine experiments at JPL during 1978, I studied the flow of water-and-nitrogen mixtures in rotary separators and concluded that the impact and other losses in rotary separators would limit turbine efficiency as severely as the liquid friction in bladed turbines. At the same time, LLL furnished JPL a surplus steam turbine for bladed turbine tests. The second row of blades was cut away to make a single-stage rotor. In water-and-nitrogen tests, this rotor gave as high an efficiency as seemed attainable with a separator turbine. In addition, I found it possible to further improve the efficiency by using two stages, with high speed in the first stage and a lower speed in the second stage. This two-phase turbine is the type discussed in this report.

It is also possible to achieve efficient two-phase expansion using positive-displacement expanders. Helical-screw (Lysholm) expanders have been tested by LLL (Ref. 8) using a two-phase steam-and-water flow, and by Hydrothermal Power Company in cooperation with JPL (Ref. 9). Efficiencies as high as 60 percent have been achieved in geothermal field tests at $500-\mathrm{kW}$ output power (Ref. 9). 


\section{APPLICATIONS}

A. Saturated Water Turbines

One of the simplest applications of two-phase turbines is the open-cycle expansion of saturated water or low-quality steam ("quality" is the steam fraction by mass). An example is the expansion of fluid from a geothermal we11.

Figure 1 shows steam-and-water expansion on a temperature-entropy (T-S) diagram. The expansion starts on or near the saturated liquid line and proceeds downward to the steam condenser pressure. This is the process proposed as the "total-flow" concept by LLL (Refs. 4 and 5).

An alternative approach for geothermal use is to replace with two-phase turbines the throttling steps used to provide steam in the conventional geothermal cycle. The output from the two-phase turbines adds to the output of the steam turbines. Hays and Cerini (Refs. 6 and 7) have developed such geothermal expanders, combining flash vaporization, separation, and power output in a single unit.

B. Organic-Fluid Turbines

One of the most promising applications of two-phase turbines is in closed-cycle engines using organic working fluids. The advantages over Rankine vapor cycles are better matching to the cooling curve of sensible-heat sources and elimination of the boiler. Possible applications are geothermal closed-cycle (binary) power plants, engine exhaust heat recovery, industrial waste-heat recovery, and bottoming cycles for steam and gas turbine plants.

Figure 2 shows the equipment arrangement in an organic-fluid two-phase turbine engine. The fluid to be cooled (the "source fluid"), such as geothermal hot water or engine exhaust, flows through the heat exchanger from $A$ to $B$ and is cooled by counterflow heat transfer to the organic working fluid. The working fluid is heated to saturation temperature. The saturated 


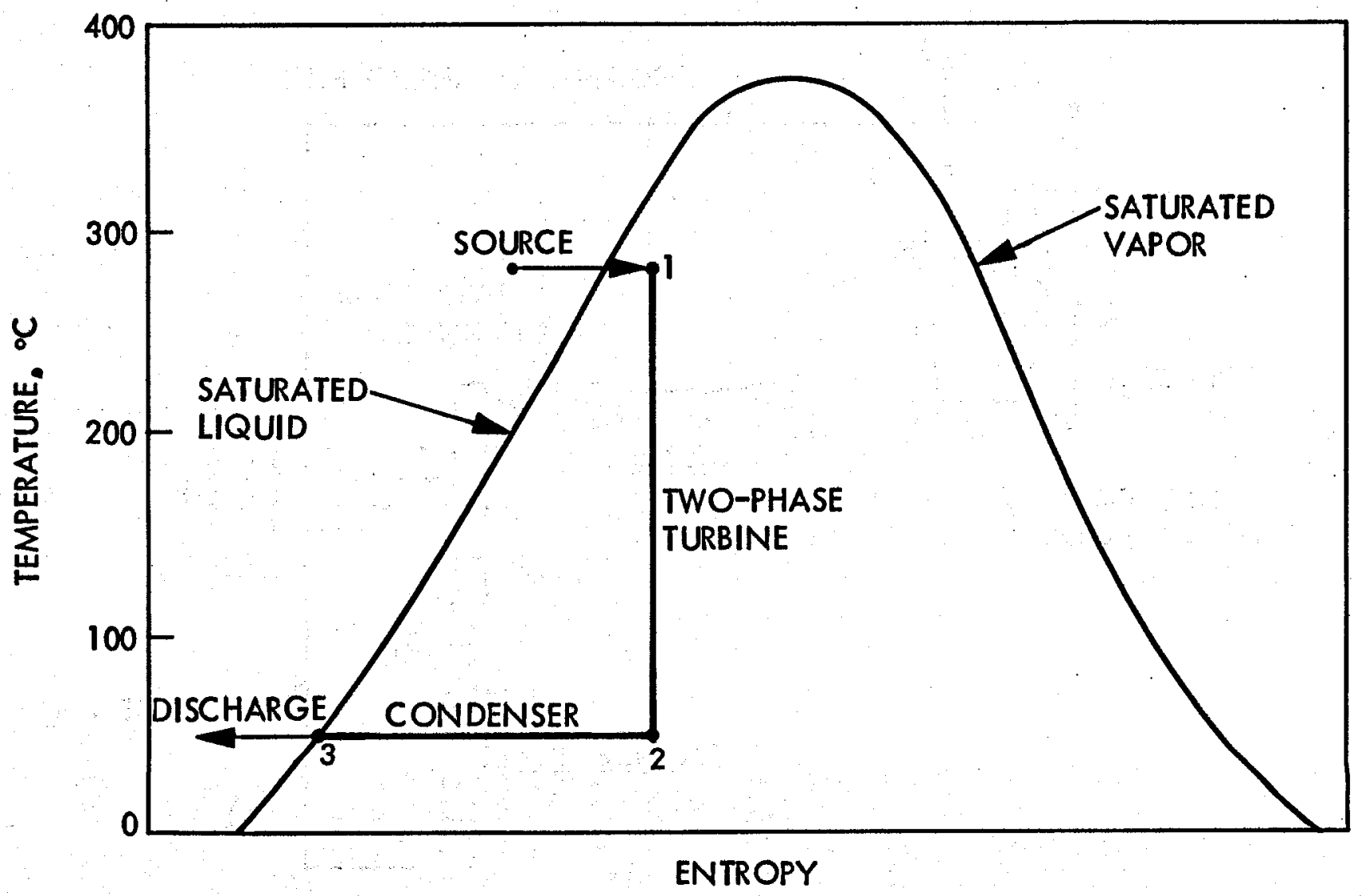

Fig. 1. Steam-and-water cycle 


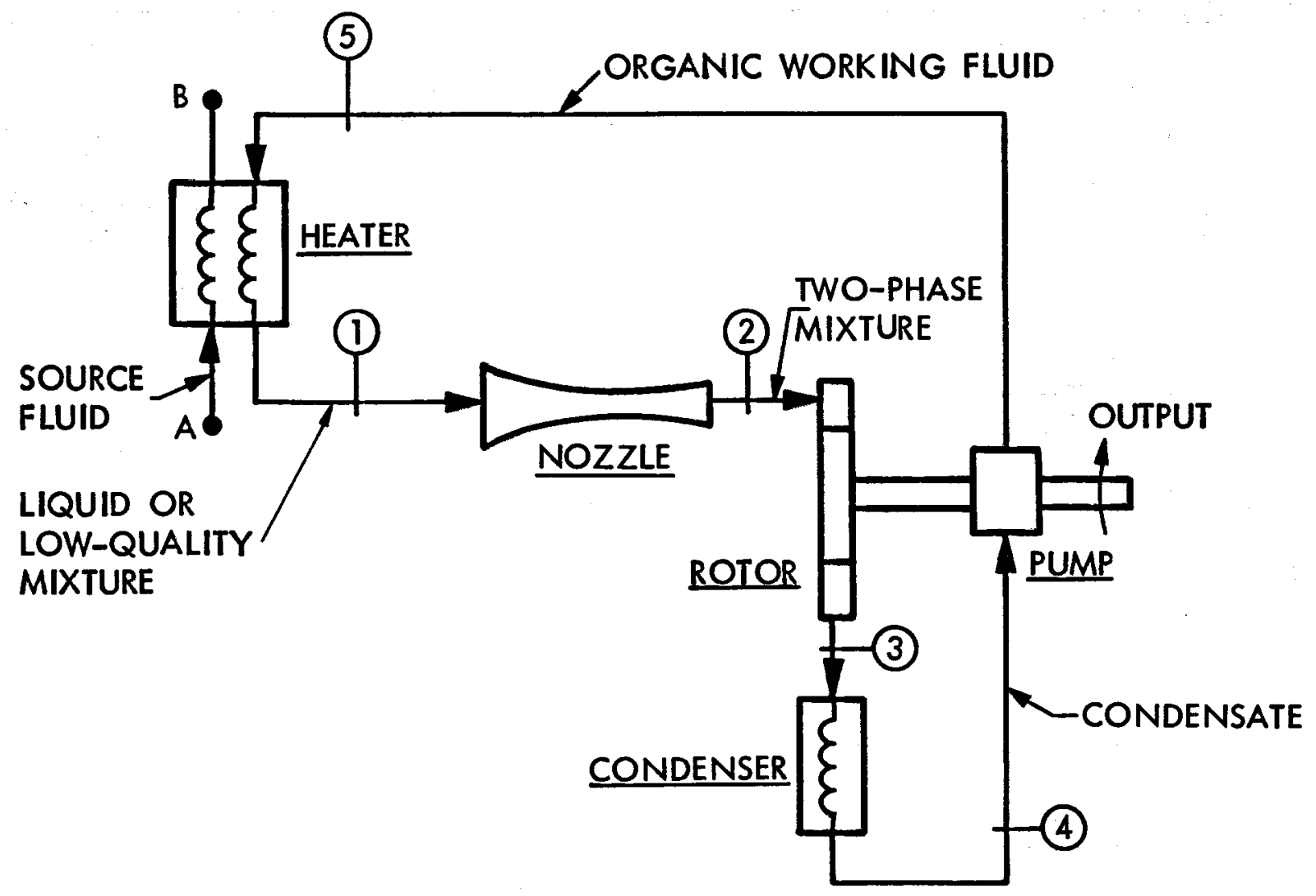

Fig. 2. Organic-fluid two-phase turbine 
liquid, with possibly a small amount of vapor, flows to a two-phase nozzle. The liquid expands, partially vaporizes, and accelerates in the nozzle. The two-phase mixture drives the turbine rotor. The vapor is condensed, and the condensate is pumped back to the heater by a pump on the turbine shaft.

The cycle is shown on a T-S diagram in Fig. 3. The state points are numbered to correspond with Fig. 2. The two-phase nozzle expansion takes the fluid from a saturated liquid at $150^{\circ} \mathrm{C}$ (point 1) to a two-phase flow of 0.6 quality at $40^{\circ} \mathrm{C}$ (point 2). The flow is decelerated in the rotor, condensed to point 4, and pumped back to nozzle inlet pressure at point 5 . The liquid is then reheated by the source fluid to point 1.

The feature of this cycle that makes it ideal for recovery of energy from a sensible-heat source is the straight-line beating of the working fluid from point 5 to point 1 over the full temperature range of the cycle. The heating curve of the working fluid matches the cooling curve of the source fluid. The temperature difference between the source fluid and the working fluid can be kept small at all points in the heat exchanger. By contrast, the heating curve of a Rankine cycle, in which the working fluid must be boiled to dry vapor, is a poor match to the source-fluid cooling curve. Large differences are necessary between the source-fluid temperature and working-fluid temperature over portions of the heat exchanger, and it may not be possible to cool the source fluid all the way to ambient temperature; both effects reduce the available work.

The appropriate efficiency for comparison of waste-heat cycles is the "utilization efficiency," defined as the ratio of power output to heat available. The heat available is the heat that could be extracted by cooling the source fluid all the way to the low-temperature limit set by ambient temperature or other external limitations. If $T_{C}$ is this low-temperature cooling limit, then the available heat is

$$
Q_{A}=\dot{m}_{P}\left(T_{A}-T_{C}\right)
$$




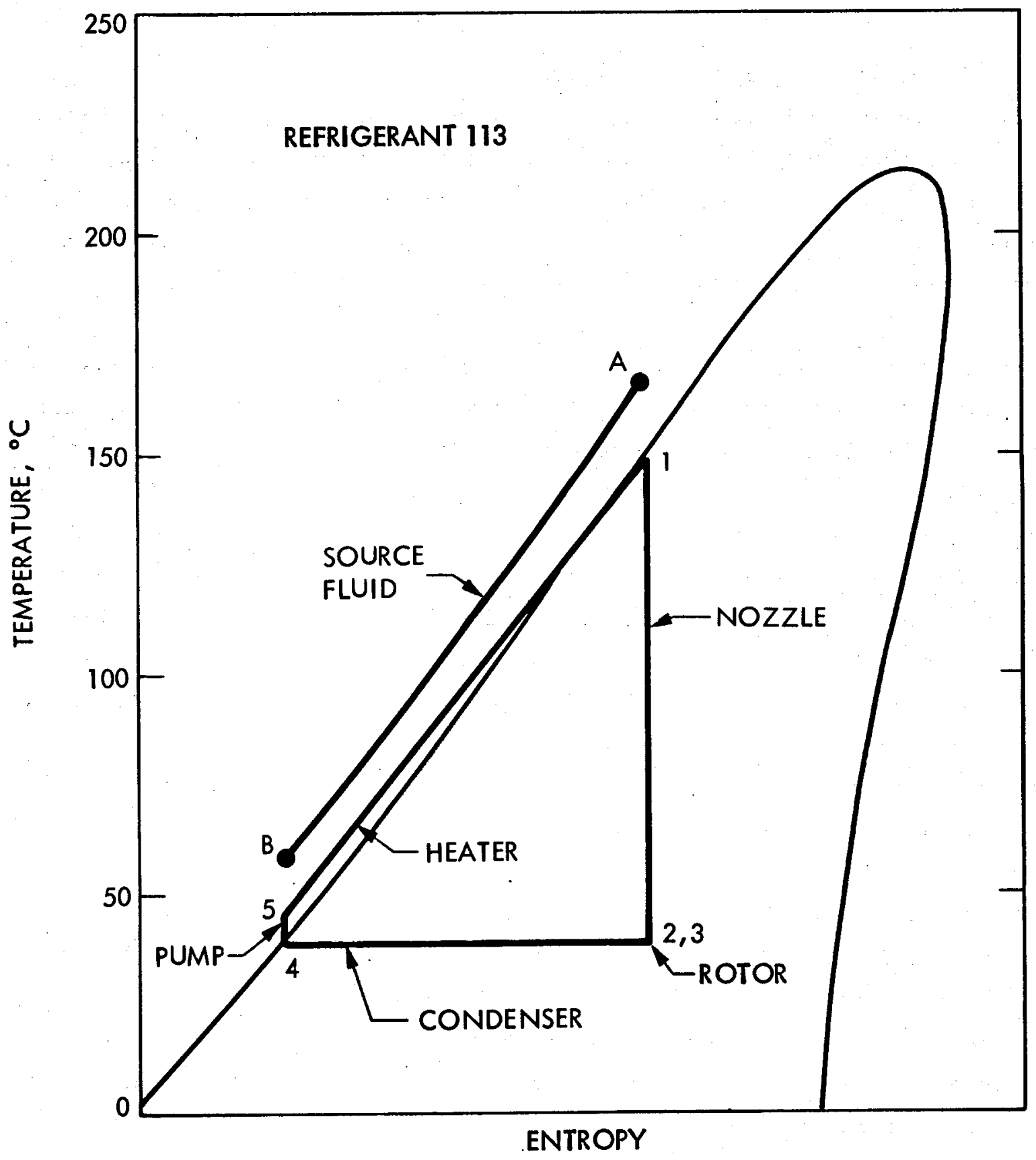

Fig. 3. Organic-fluid two-phase cycle

8 
and the utilization efficiency is

$$
\eta_{u}=\frac{P}{\dot{m} c_{p}\left(T_{A}-T_{C}\right)}
$$

where $P$ is the power output, and $\dot{m}$ is the flow rate, $c_{p}$ the specific heat, and $T_{A}$ the initial temperature of the source fluid.

If, due to cycle limitations, the gas is cooled only part way to the cooling limit and leaves at a temperature $T_{B}$ higher than $T_{C}$, then the heat input to the cycle is nic $\left(T_{A}-T_{B}\right)$ and the cycle efficiency, as conventionally defined, is

$$
\eta=\frac{P}{\dot{m}_{P}\left(T_{A}-T_{B}\right)}
$$

From Eqs. (2) and (3), it can be seen that the utilization efficiency is the cycle efficiency multiplied by the ratio of actual to available sourcefluid temperature drop.

$$
n_{u}=n \frac{T_{A}-T_{B}}{T_{A}-T_{C}}
$$

In Fig. 4, the utilization efficiencies of two-phase and Rankine cycles a re compared for the case in which the cooling limit is the same as the condensing, or rejection, temperature $T_{R}=38^{\circ} \mathrm{C}$, and the turbine and pump efficiencies are 100 percent. The two-phase cycle is 50 percent more efficient than the Rankine cycle for source fluid temperatures of 150 to $200^{\circ} \mathrm{C}$. The utilization efficiency of the two-phase cycle is close to the limiting efficiency $W_{A} / Q_{A}$ corresponding to the available work $W_{A}$ given by integration of the Carnot efficiency between $T_{A}$ and $T_{R}:$

In an effort to better match the working fluid heating curve to the source fluid cooling curve, some geothermal studies have proposed supercritical Rankine cycles. Figure $5(a)$ shows such a cycle using isobutane as 


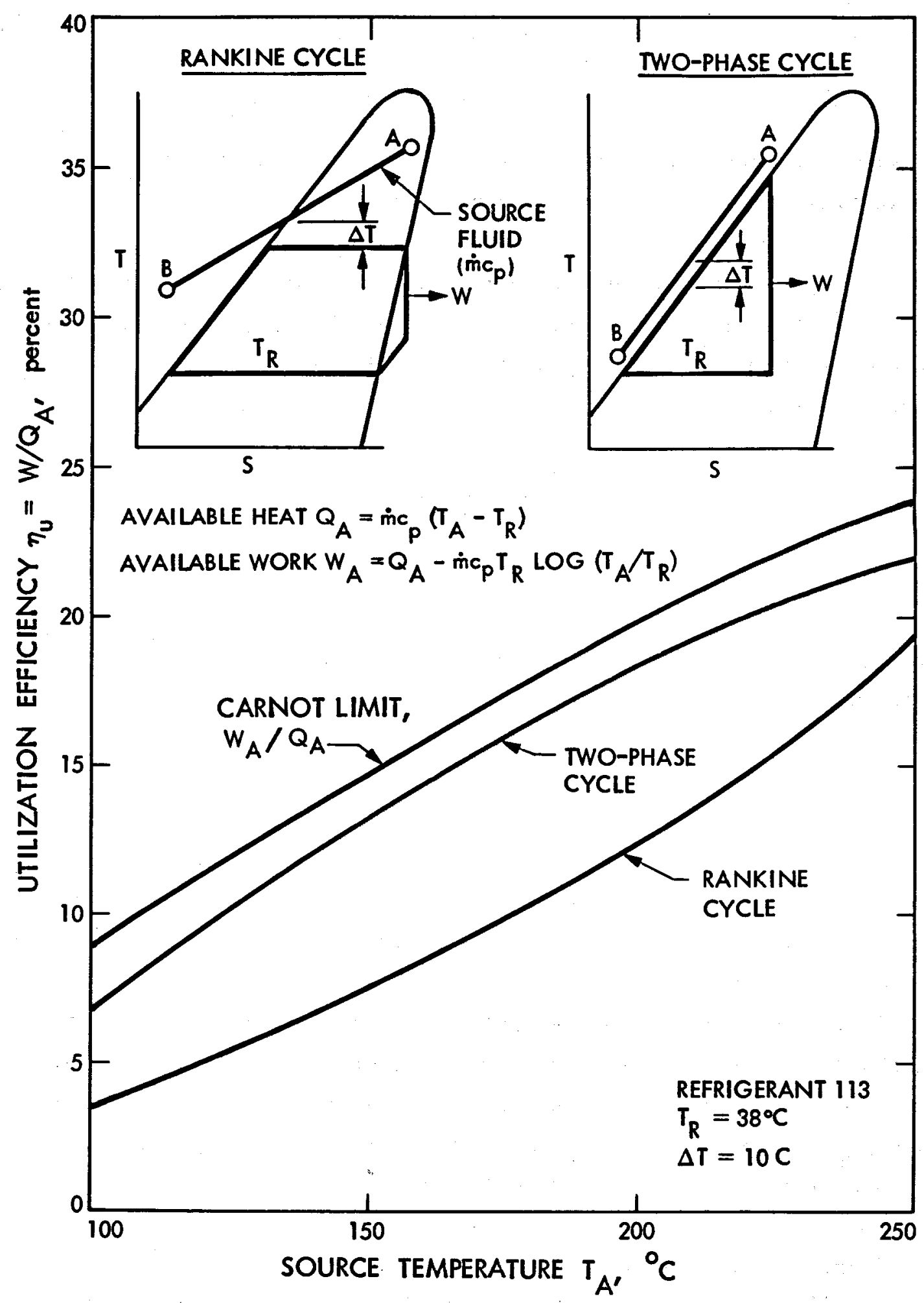

Fig. 4. Comparison of Rankine and two-phase cycles 

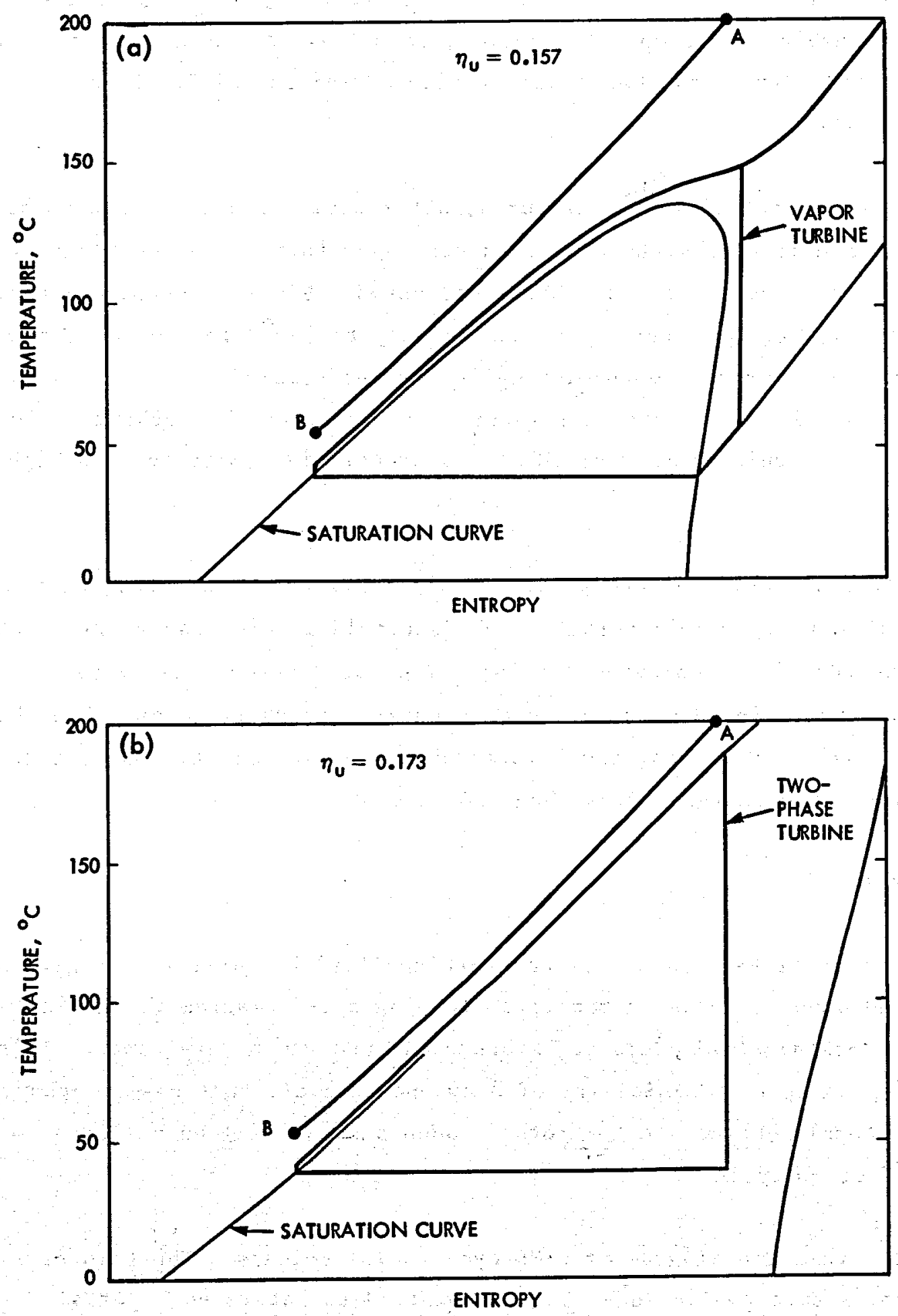

Fig. 5. Comparison of supercritical and two-phase cycles: (a) supercritical cycle (isobutane); (b) two-phase cycle (Refrigerant 113) 
the working fluid. The utilization efficiency, with $T_{C}=T_{R}=38{ }^{\circ} \mathrm{C}$ and 100-percent turbine and pump efficiencies, is 0.157. A two-phase cycle using Refrigerant 113, Fig. 5(b), has a utilization efficiency of 0.173 , a 10-percent gain.

At higher source-fluid temperatures, water could be used as the working fluid. The main problem with water in a two-phase turbine is the large steam volume and high velocity at low exhaust pressures. Figure 6 shows how water could be used at high pressure by expanding only to $150^{\circ} \mathrm{C}$ in the two-phase cycle and using an organic bottoming cycle for the remainder of the temperature drop. In this way a good temperature match between the working fluid and the source fluid could be maintained at a source-fluid temperature as high as $350^{\circ} \mathrm{C}$.

Another application of two-phase organic turbines is in refrigeration. Instead of throttling a refrigerant to produce cold liquid, the refrigerant could be expanded in a two-phase turbine. The work conventionally lost in the irreversible throttling process would be recovered as shaft power. The shaft power could assist in driving the compressor. The electricity consumption for refrigeration would be reduced by about 10 percent.

\section{Wet-to-Dry Cycle}

If the initial temperature of the working fluid is sufficiently high and the saturated vapor line has a positive slope on a T-S diagram (a "drying" fluid), the working fluid could be expanded all the way to dry vapor. This phenomenon opens up the possibility of a two-phase cycle that has two-phase flow in the nozzle but not in the rotor. Such a cycle will be called a "wet-to-dry" or WD cycle.

Figure 7 is a T-S diagram of a WD cycle using toluene. The toluene is expanded from saturated liquid at $290^{\circ} \mathrm{C}$ (point 1) to saturated vapor at $66^{\circ} \mathrm{C}$ (point 2). The vapor drives an impulse rotor and leaves the rotor 8 lightly superheated at point 3. The vapor is condensed to point 4 and pumped back to the nozzle inlet pressure at point 5. There is again an ideal match to the cooling curve of the source fluid, but two-phase rotor flow is not 


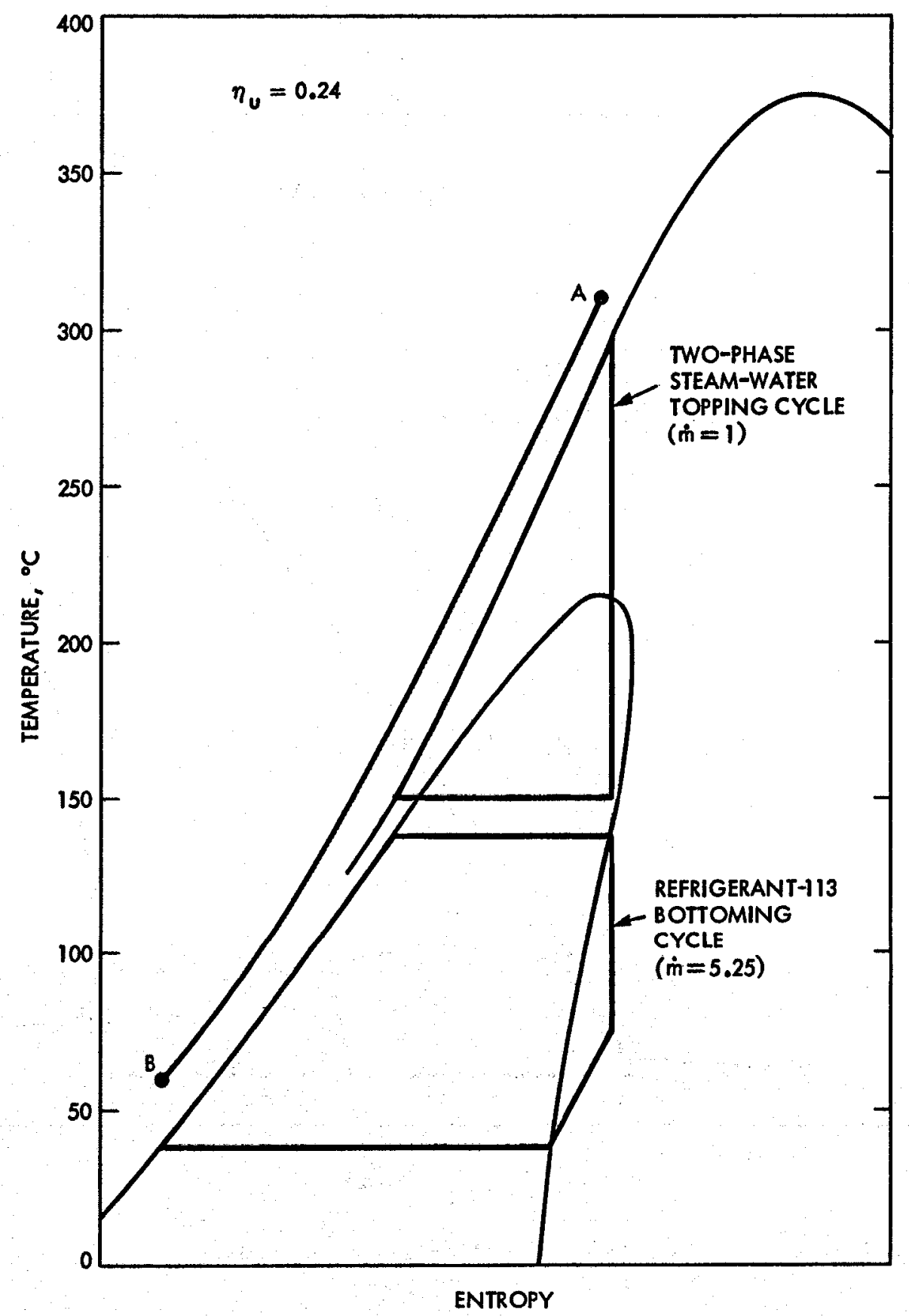

Fig. 6. Steam topping cycle with organic-fluid bottoming cycle 


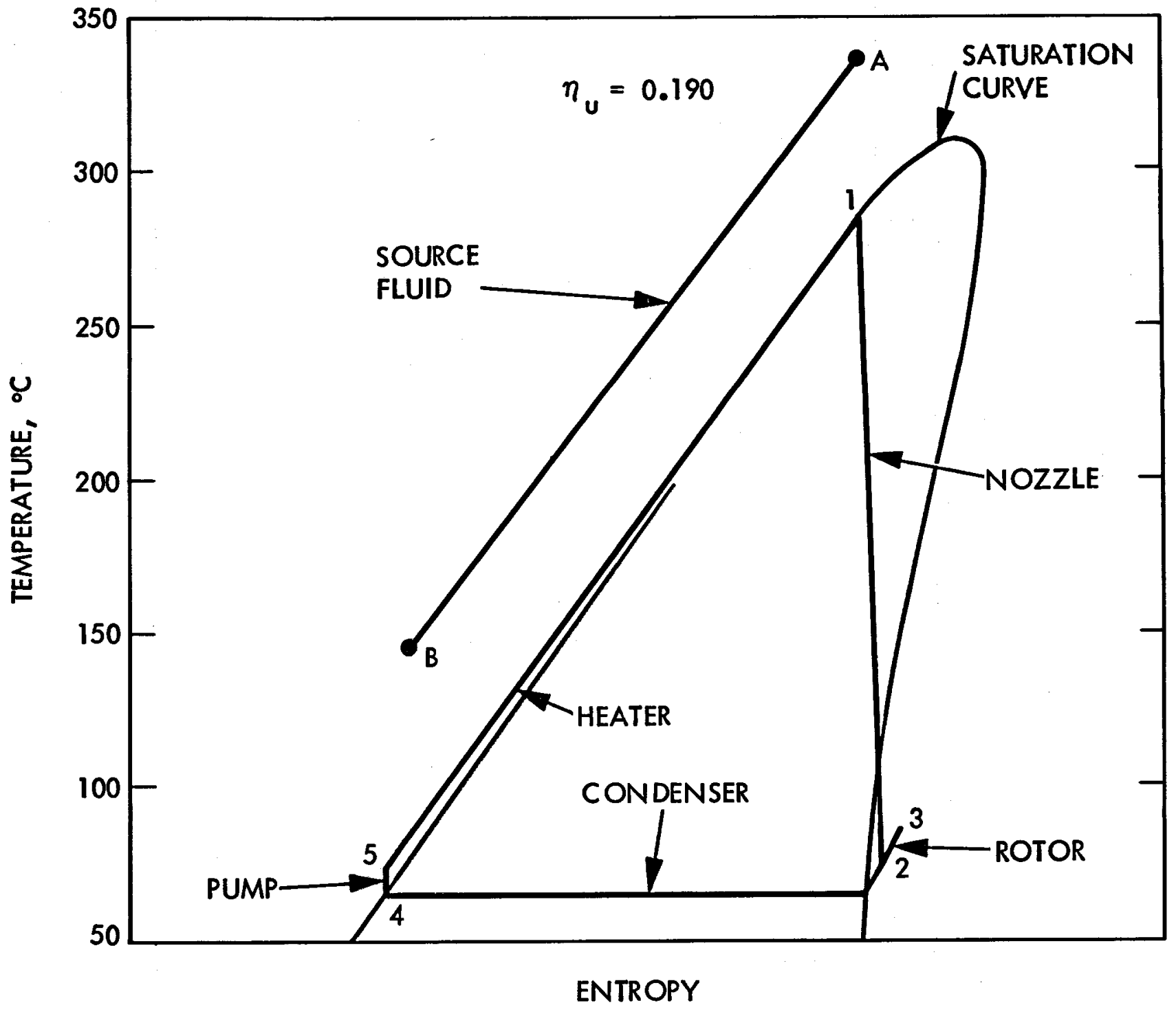

Fig. 7. Wet-to-dry cycle 
required. The utilization efficiency for the cycle of Fig. 7 is 0.19 whereas The utilization efficiency of the best toluene Rankine cycle using the same source fluid, and having the same turbine efficiency, would be only 0.14 .

\section{Two-Component Cycle}

Two-phase mixtures in which the vapor and 1iquid are different chemical compounds are called "two-component" mixtures. An example is steam mixed with an organic 1iquid or a molten salt. Sucb mixtures behave quite differently from the one-component mixtures discussed to this point.

Figure 8 shows the equipment arrangement for a two-phase, two-component engine, and Fig. 9 is a T-S diagram for the component that forms the vapor phase, in this case steam. The 1 iquid phase is a molten salt such as lithium carbonate or sodium hydroxide (it is not known if these liquids would actually be compatible with steam). The ratio of 1 iquid to vapor is 30 , by mass.

The steam and liquid mixture expands from the nozzle inlet, point 1 , to the steam condenser pressure at point 2. Because of the large ratio of liquid to steam, the mixture expands almost isothermally and the nozzle exit velocity is much lower than it would be for steam alone. The two-phase mixture drives the turbine rotor. The steam is separated from the liquid, cooled to saturation temperature in a regenerative heat exchanger (point 4) condensed to point 5, pumped back to the nozzle inlet pressure at point 6 , and heated to point 7 in the regenerative heat exchanger. The liquid leaving the turbine is pumped to the heater by a pump on the turbine shaft. The heated liquid is mixed with the condensate (water) in the mixer, and the water is vaporized by direct-contact heat transfer.

Possible applications of this cycle are in turbine engines for solar power or transportation. The advantage of the two-phase, two-component cycle for these applications is the ability to achieve a low shaft speed in a small turbine engine. A steam turbine of 150-kW shaft power, for example, using the temperatures given in Fig. 9, would have a speed of about $60,000 \mathrm{rpm}$. The two-phase turbine would operate at only about 10,000 $\mathrm{rpm}$. There is also an ficiency advantage. At the Fig. 9 temperatures, a steam Rankine cycle would 


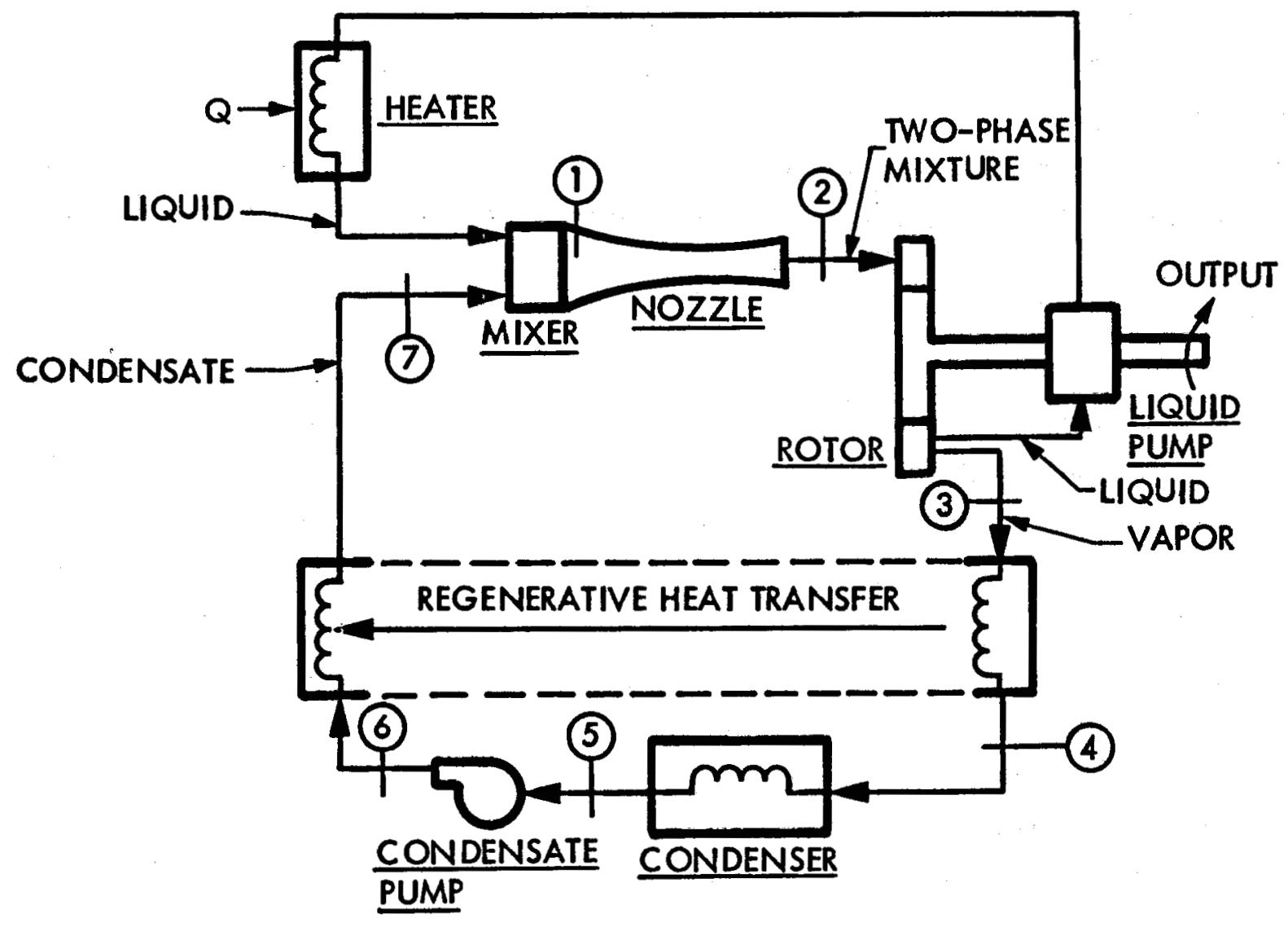

Fig. 8. Two-phase, two-component engine 


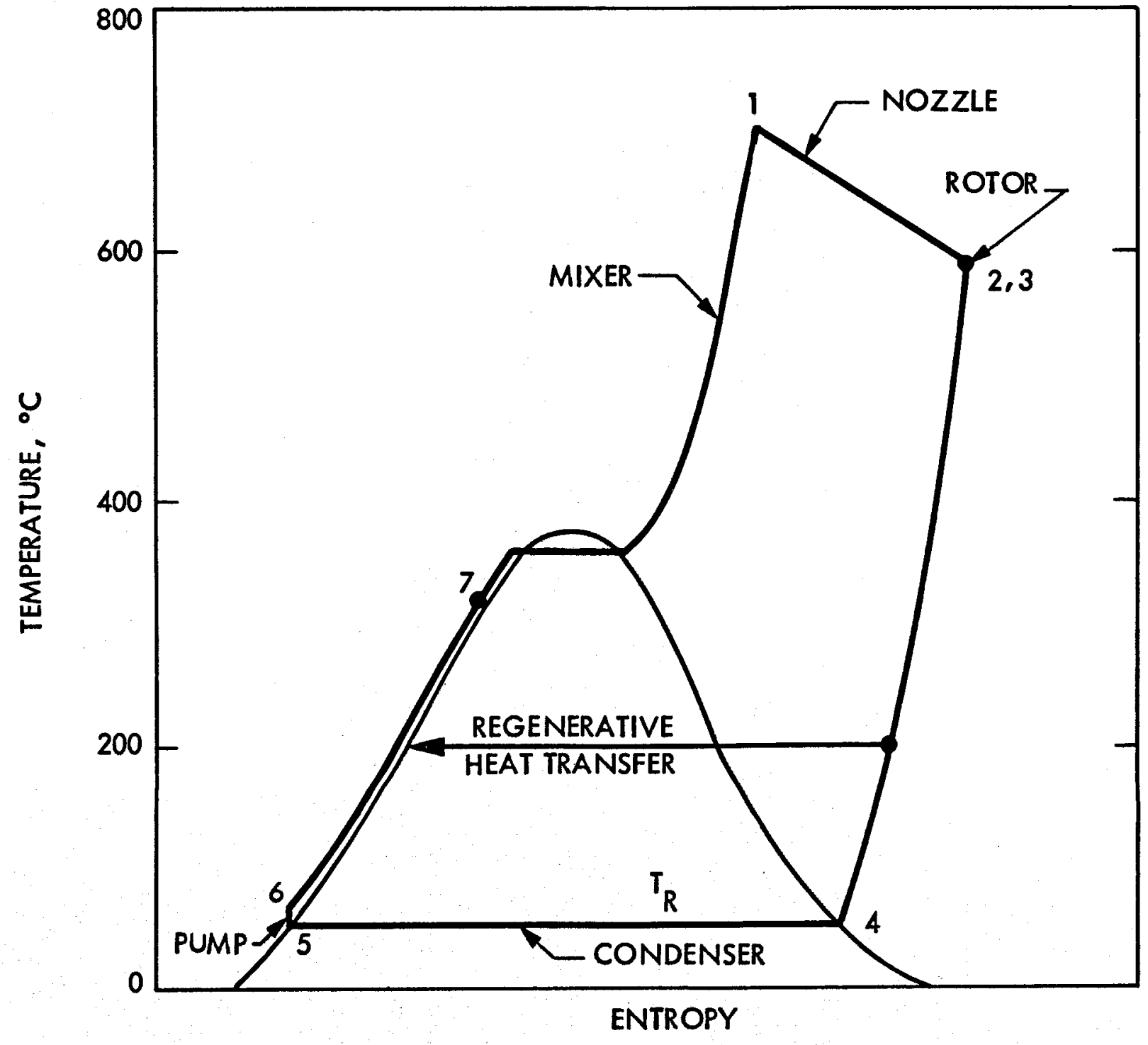

Fig. 9. Two-phase, two-component cycle 
have an efficiency of about 0.28 , whereas the two-phase cycle would have an efficiency of about 0.37 (for the same turbine efficiency), because the steam is continuously reheated in the two-phase nozzle. In addition, the two-phase cycle allows control of turbine speed because the mixture ratio can be varied to change the nozzle exit velocity, a capability unavailable in steam turbines. 


\section{A. Construction}

The nozzle converts the heat energy of the two-phase mixture to the kinetic energy of a jet. The gas is accelerated by pressure, and the liquid is partly accelerated by pressure, but mainly by drag. The gas moves faster than the liquid to produce the drag. The velocity difference, or "slip", also causes breakup of the 1 iquid into small drops.

The nozzle design used in the turbine tests is shown in Figs. 10 and 11. The liquid enters the inlet fitting, flows around a baffle, and enters a hexagonal array of 61 tubes of $6.35-\mathrm{mm}$ outside diameter and $4.57-\mathrm{mm}$ inside diameter. The tubes are aimed toward the nozzle throat. The tubes are clamped together at their exits by a tube cage and are held $1.4 \mathrm{~mm}$ apart at the inlets by a tube sheet. The liquid enters the nozzle through the tubes at a velocity of about $4 \mathrm{~m} / \mathrm{s}$.

The gas enters the mixer housing, flows through openings in the tube cage, enters the spaces between the liquid-injection tubes, and flows into the nozzle through the cusp-shaped gaps between the tube exits. The gas enters at about $30 \mathrm{~m} / \mathrm{s}$.

The multiple injection tubes and gas orifices provide a uniform distribution of flow rate and mixture ratio across the nozzle inlet. Where the inlet flow is saturated liquid, the multiple jets also provide an initial separation of the liquid streams so that vapor forms uniformly across the nozzle; a small amount of vapor is fed to the gas inlet to give a starting quality of 1 to 2 percent.

The nozzle has a converging-diverging shape. The inlet section has a 10-deg wall angle and the exit section a $2.5-\mathrm{deg}$ angle. The throat section has a very gradual area change with distance to minimize slip. 


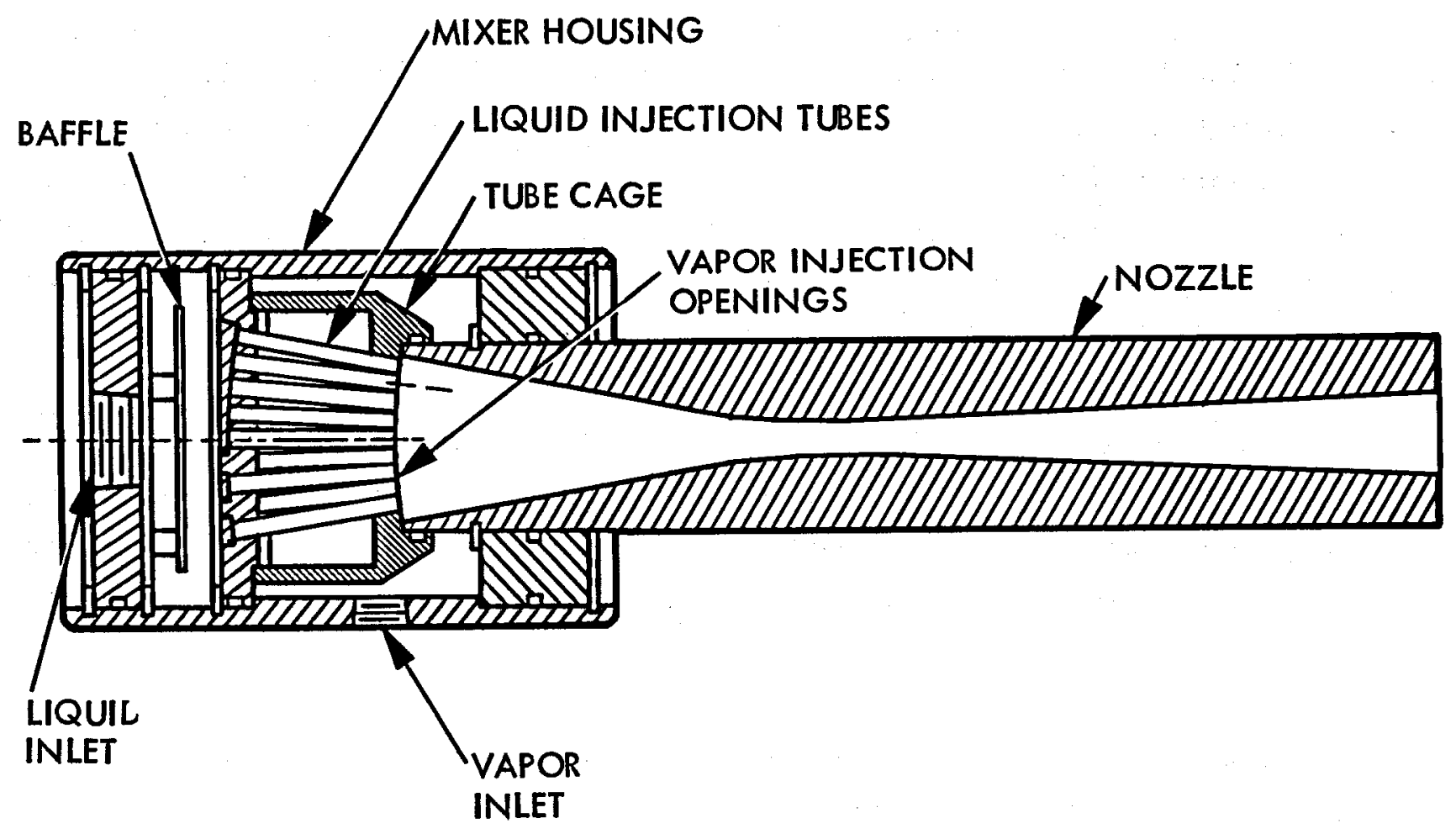

Fig. 10. Two-phase nozzle 


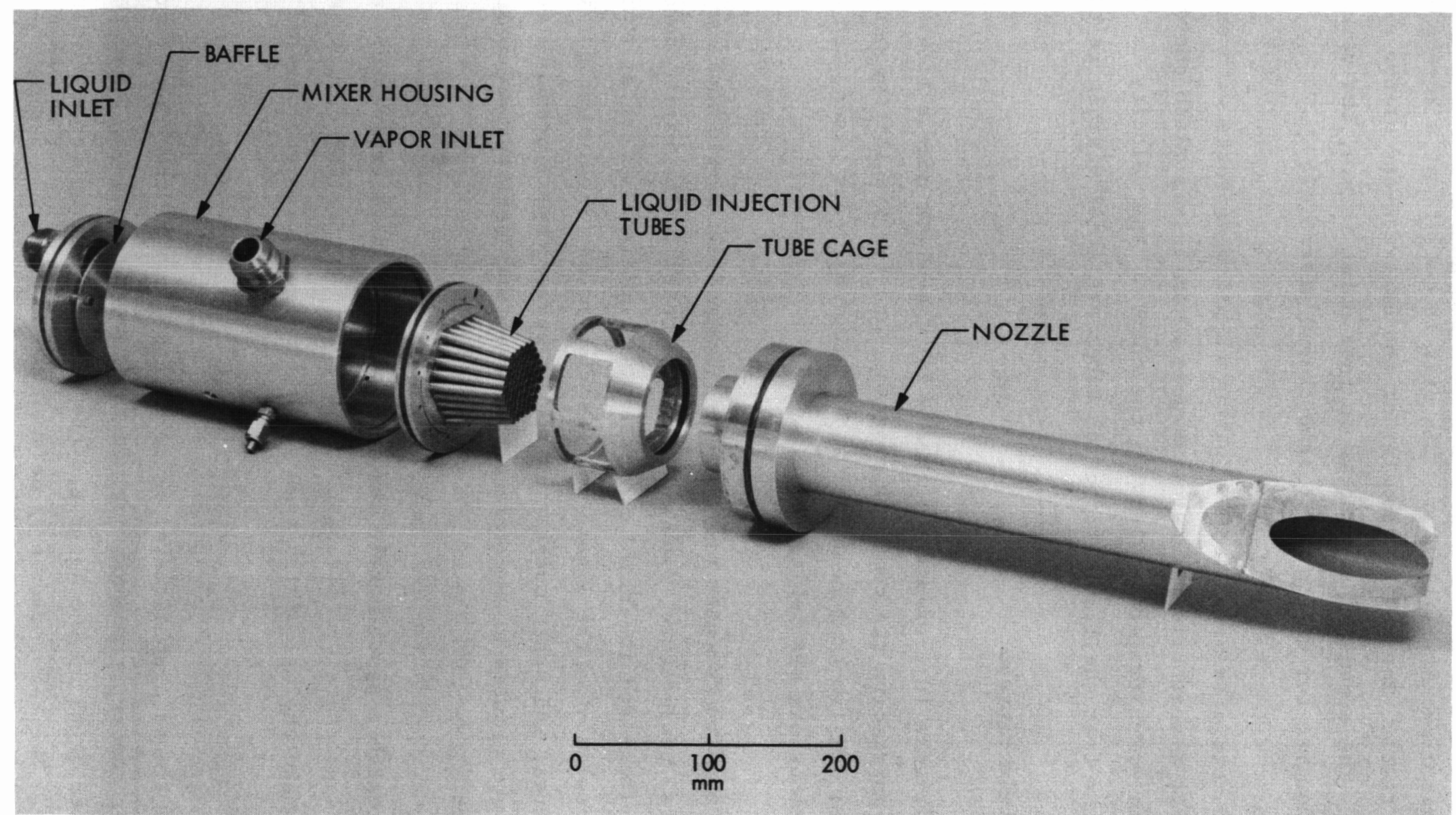

Fig. 11. Experimental two-phase nozzle 
The nozzle is designed for operation with Refrigerant 22 expanding from saturated liquid conditions at $20^{\circ} \mathrm{C}$ and $0.9 \mathrm{MPa}$ to atmospheric pressure. The throat diameter is $13.1 \mathrm{~mm}$. The exit is cut off at a 20-deg angle for turbine tests. The nozzle diameter at the upstream end of the exit ellipse is $27.6 \mathrm{~mm}$. The expansion area ratio to that point is 4.4 , the value calculated to be required for expansion to atmospheric pressure.

The nozzle is also used for water-and-nitrogen tests with expansion from

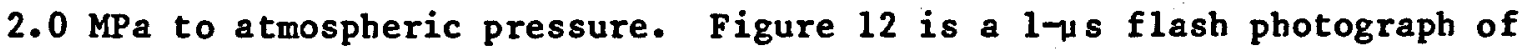
the water-and-nitrogen jet leaving the nozzle. The velocity is $80 \mathrm{~m} / \mathrm{s}$. Faint striations from the liquid injection tubes are still visible in the jet.

\section{B. Nozzle Program}

Reference 10 presents the theory for two-phase nozzle flow. The theory is incorporated in two computer programs, one for single-component flow and the other for two-component flow. The programs, test cases, and operating instructions are available from JPL.

To use the computer program, the nozzle inlet conditions are specified (pressure, temperature, flow rate, and velocity). The variation of pressure with distance and the fluid properties are entered in tabular form. The program calculates the liquid and gas flow rates, liquid and gas velocities, nozzle area, and other quantities at successive, small pressure steps. The results are printed at the exit pressure and any desired intermediate pressures.

To match a given nozzle shape, rather than a given pressure profile, the specified pressure profile can be modified in two or three successive computer runs to make the calculated area variation agree with the desired nozzle contour.

The liquid drop diameter is calculated from a Weber number criterion. The Weber number is proportional to the ratio between the pressure force tending to break up the drops and the surface tension force holding the drops together. The Weber number is defined as 


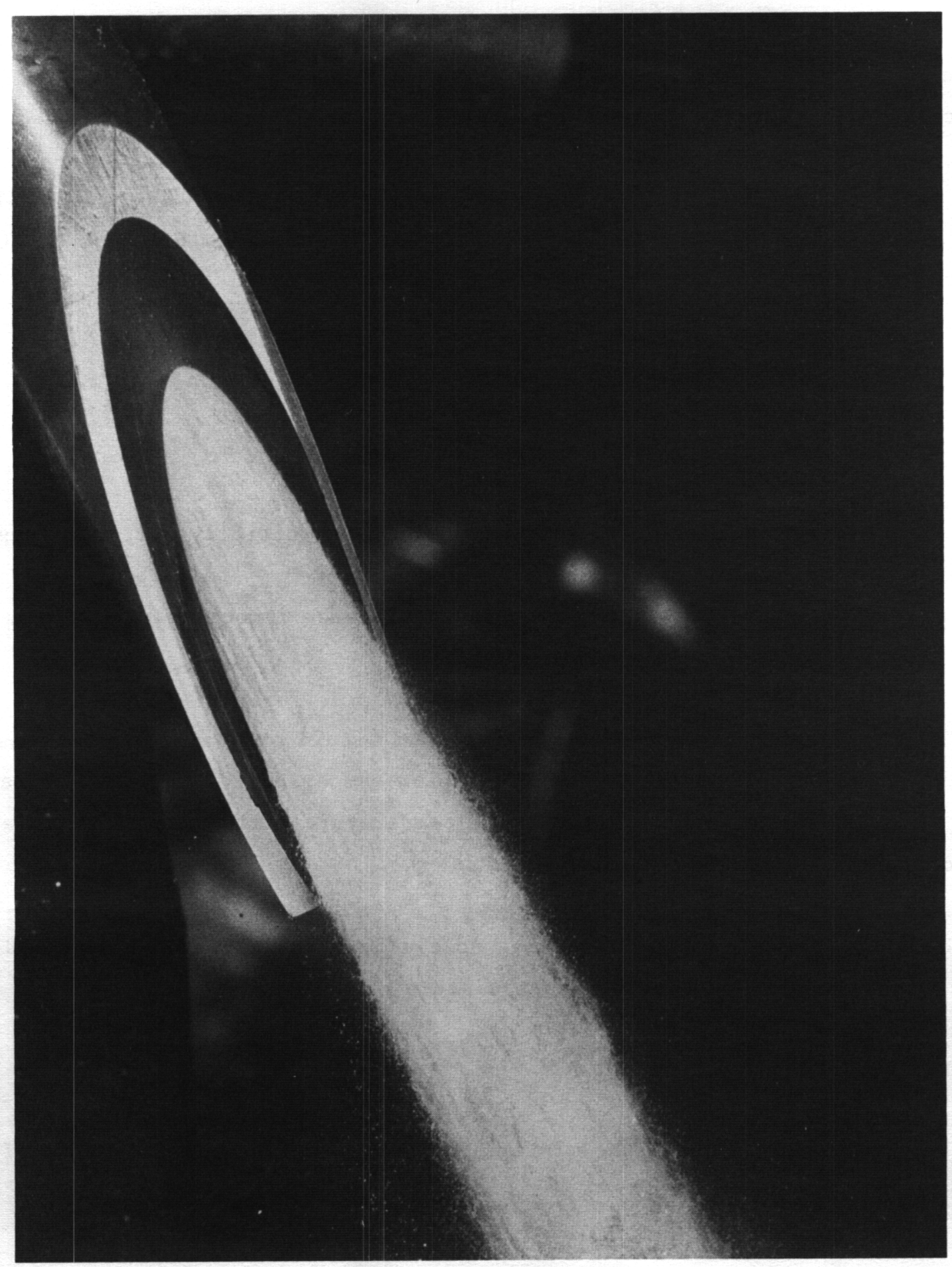

Fig. 12. Water-and-nitrogen jet at $80 \mathrm{~m} / \mathrm{s}$ 


$$
W e=\frac{\rho_{g}\left(v_{g}-v_{\ell}\right)^{2} D}{2 \sigma}
$$

where $o_{g}$ is the gas density, $v_{g}$ is the gas velocity, $v_{\ell}$ is the liquid velocity, $D$ is the drop diameter, and $\sigma$ is the surface tension.

Based on the drop breakup data reviewed in Ref. 10, the maximum stable drop diameter is the diameter for which the Weber number is 6. From Eq. (5), the corresponding maximum drop diameter is

$$
D_{\max }=\frac{12 \sigma}{\rho_{g}\left(v_{g}-v_{\ell}\right)^{2}}
$$

In the nozzle program, the drop diameter $D$ is initially set to a large value, and the diameter is reduced to $D_{\max }$ whenever $D_{\max }$ falls below $D$. Typically, breakup takes place over a short distance immediately upstream of the throat.

In the one-component nozzle program, the liquid and vapor are both assumed to have a temperature equal to the saturation temperature at the local pressure. In the two-component program, the temperature difference is calculated from drop heat transfer relations.

Wall friction is calculated using nozzle friction relations for singlephase flow evaluated at the two-phase mixture density.

\section{Performance Definitions}

In a two-phase nozzle, the mixture ratio $R$ is defined as the ratio of liquid mass flow rate $\dot{m}_{l}$ to gas flow range $\dot{\mathrm{m}}_{\mathrm{g}}$.

$$
R=\frac{\dot{\mathrm{m}}_{\ell}}{\dot{\mathrm{m}}_{\mathrm{g}}}
$$


The quality $x$ is the ratio of gas flow rate to total flow rate

$$
x=\frac{\dot{m}_{g}}{\dot{m}_{t}}=\frac{1}{1+R}
$$

where $\dot{\mathrm{m}}_{t}$ is the total flow rate $\dot{\mathrm{m}}_{\ell}+\dot{\mathrm{m}}_{8}$.

The maximum velocity thermodynamically possible for expansion from the inlet conditions to the exit pressure is the isentropic velocity $v_{i}$. The mass weighted mean velocity of the actual flow with differing liquid and gas velocities is

$$
\bar{v}=\frac{\dot{\mathrm{m}}_{\ell} \mathrm{v}_{\ell}+\dot{\mathrm{m}}_{\mathrm{g}} \mathrm{v}_{\mathrm{g}}}{\dot{\mathrm{m}}_{\mathrm{t}}}
$$

where $\mathrm{V}_{\ell}$ is the liquid velocity and $\mathrm{v}_{g}$ is the gas velocity. The mean velocity $\bar{V}$ is also equal to the jet momentum per unit mass.

In this report, $\bar{v}$ will be used for the mean velocity with wall friction included, and $\bar{v}_{0}$ will be used for the mean velocity without wall friction.

The thrust of a two phase nozzle, by the definition of $\bar{v}$, is

$$
F=\dot{\mathrm{m}}_{t} \bar{\nabla}
$$

Equation (10) is used to calculate the experimental value of the mean jet velocity $\bar{v}$; the thrust and flow rates are measured, and the thrust is divided by the total flow rate to give $\bar{\nabla}$.

* In Ref. $10, \bar{v}$ and $\bar{v}_{0}$ are denoted $\bar{v}_{\delta}$ and $\bar{v}$, respectively. 
The velocity coefficient of a nozzle is the ratio of mean velocity to isentropic velocity

$$
k_{v}=\frac{\bar{v}}{v_{i}}
$$

The kinetic power in the jet is

$$
P_{\text {jet }}=\frac{1}{2}\left(\dot{m}_{\ell} v_{\ell}^{2}+\dot{m}_{g} v_{g}^{2}\right)
$$

The isentropic jet power is

$$
P_{i}=\frac{1}{2} \dot{m}_{t} v_{i}^{2}
$$

The nozzle efficiency is

$$
n_{n}=\frac{P_{j e t}}{P_{i}}
$$

D. LLL Steam-and-Water Data

T. W. Alger at LLL measured velocities for steam-and-water nozzles, and the results are presented in Ref. 11. Nozzle 2 of Ref. 11 will be analyzed here. Nozzle 2 had a throat diameter of $6.4 \mathrm{~mm}$, an exit diameter of $31.8 \mathrm{~mm}$, a diverging length of $60.5 \mathrm{~mm}$, and a divergence half-angle of $12 \mathrm{deg}$. The convergence half-angle was $45 \mathrm{deg}$ and the throat had a sharp corner. In nozzle tests at an inlet pressure of $2.41 \mathrm{MPa}$, an inlet quality of 0.129 , and an exit pressure of $30 \mathrm{kPa}$, the measured velocity coefficient $\mathrm{K}_{\mathrm{v}}$ was between 0.90 and 0.95 (Fig. 10 of Ref. 11).

In Ref. 12 Alger presents measurements of drop diameters for steam-andwater nozzles. He used a light-scattering technique. The nozzles bad thin rectangular cross sections with side-wall contours similar to the nozzles of Ref. 11 , but the inlet pressure was reduced to $1.0 \mathrm{MPa}$ and the exit pressure 
o $20 \mathrm{kPa}$ to provide greater jet transparency. The measured mass-median drop diameter (which is about the right diameter to use for nozzle performance calculations) was found to be about $2.4 \mu \mathrm{m}$ (Ref. 12, p. 107).

Using the measured pressure profile for Nozzle 2 from Fig. 7 of Ref. 11 as input, Fig. 13 compares the data from Refs. 11 and 12 with predictions of the JPL nozzle program. The nozzle program, using Eq. (6) to calculate the drop diameter, predicts that the drops will break up to a 5.5- $\mu \mathrm{m}$ diameter. The highest measured velocity coefficient of 0.95 corresponds to a drop diameter of $2.8 \mu \mathrm{m}$, in good agreement with the measured drop diameter of $2.4 \mu \mathrm{m}$ from Ref. 12. Thus the drop diameter predicted by the nozzle program is perhaps as much as a factor of 2 too large.

\section{E. Water-and-Nitrogen Data}

Figure 14 compares the theoretical and experimental exit velocities for water-and-nitrogen flow in the nozzle of Fig. 11. The theoretical mean veloity $\bar{V}$ is 4 percent below the measured velocities, again indicating overestimation of drop size in the program.

The comparison given in Table 1 is at the mixture ratio of 68 used in the turbine tests. The column headed "Fitted" shows the program results fitted to the measured data to give the best estimates of the quantities that could not be measured.

The actual throat area is 9 percent higher than the throat area calculated by the nozzle program; this means that the measured flow rate is 9 percent below theoretical for a given throat area. During expansion, the water has a slight reduction in flow rate to $3.603 \mathrm{~kg} / \mathrm{s}$ because of evaporation, and the flow rate of the gas phase increases correspondingly.

The theoretical velocity ratio of gas to liquid is 1.46 . It is reasonable to assume that the velocity ratio in the experimental nozzle is the same. The "fitted" velocities that have that ratio and agree with the measured mean velocity $\bar{v}$ of $94.3 \mathrm{~m} / \mathrm{s}$ are $V_{l}=93.7 \mathrm{~m} / \mathrm{s}$ and $v_{g}=137.0 \mathrm{~m} / \mathrm{s}$. Te fitted nozzle efficiency is 0.782 , which is 8 percent higher than that predicted by the nozzle program. 


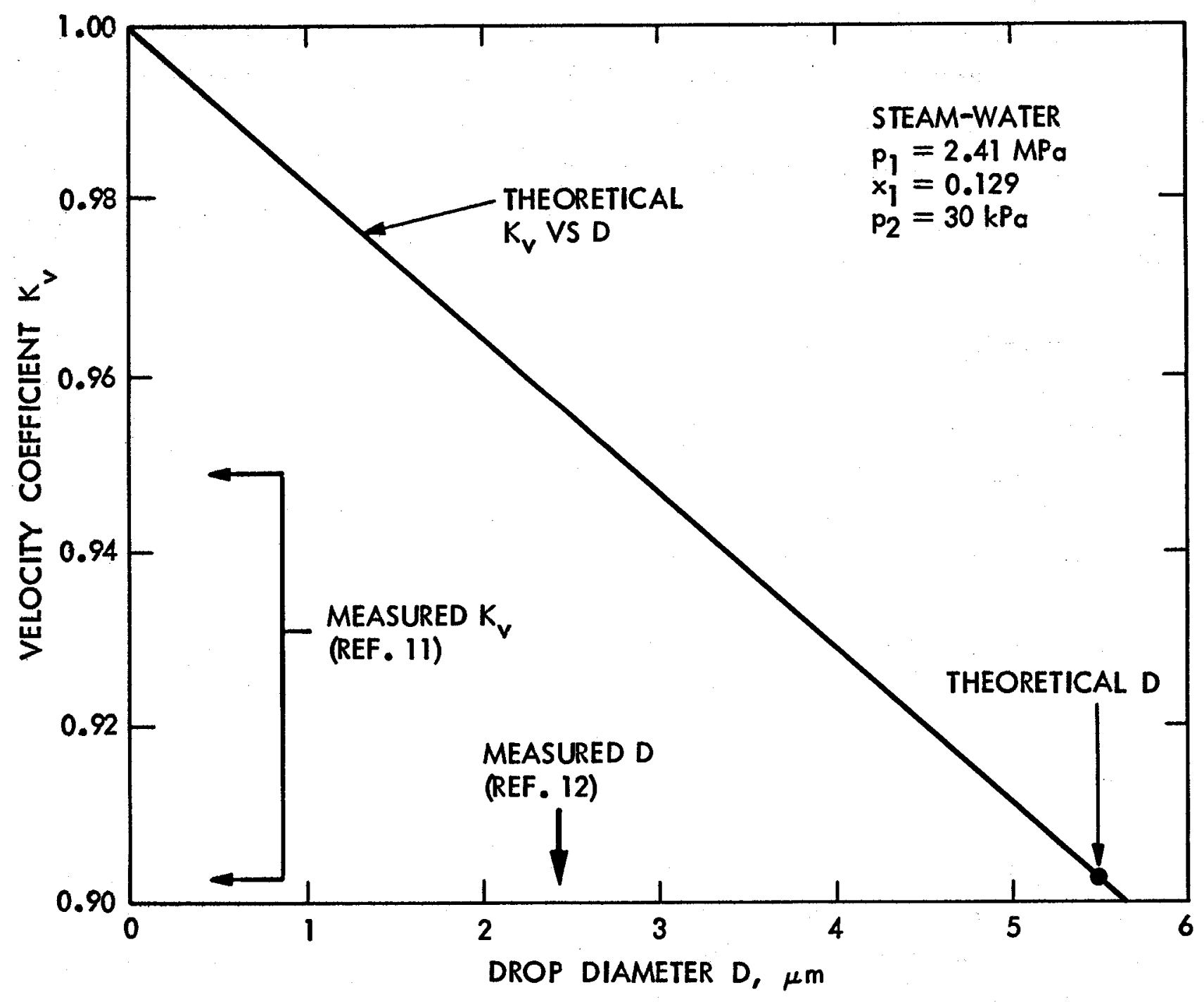

Fig. 13. Comparison of theoretical and experimental drop diameters and velocity coefficients for the LLL steam-and-water nozzle 


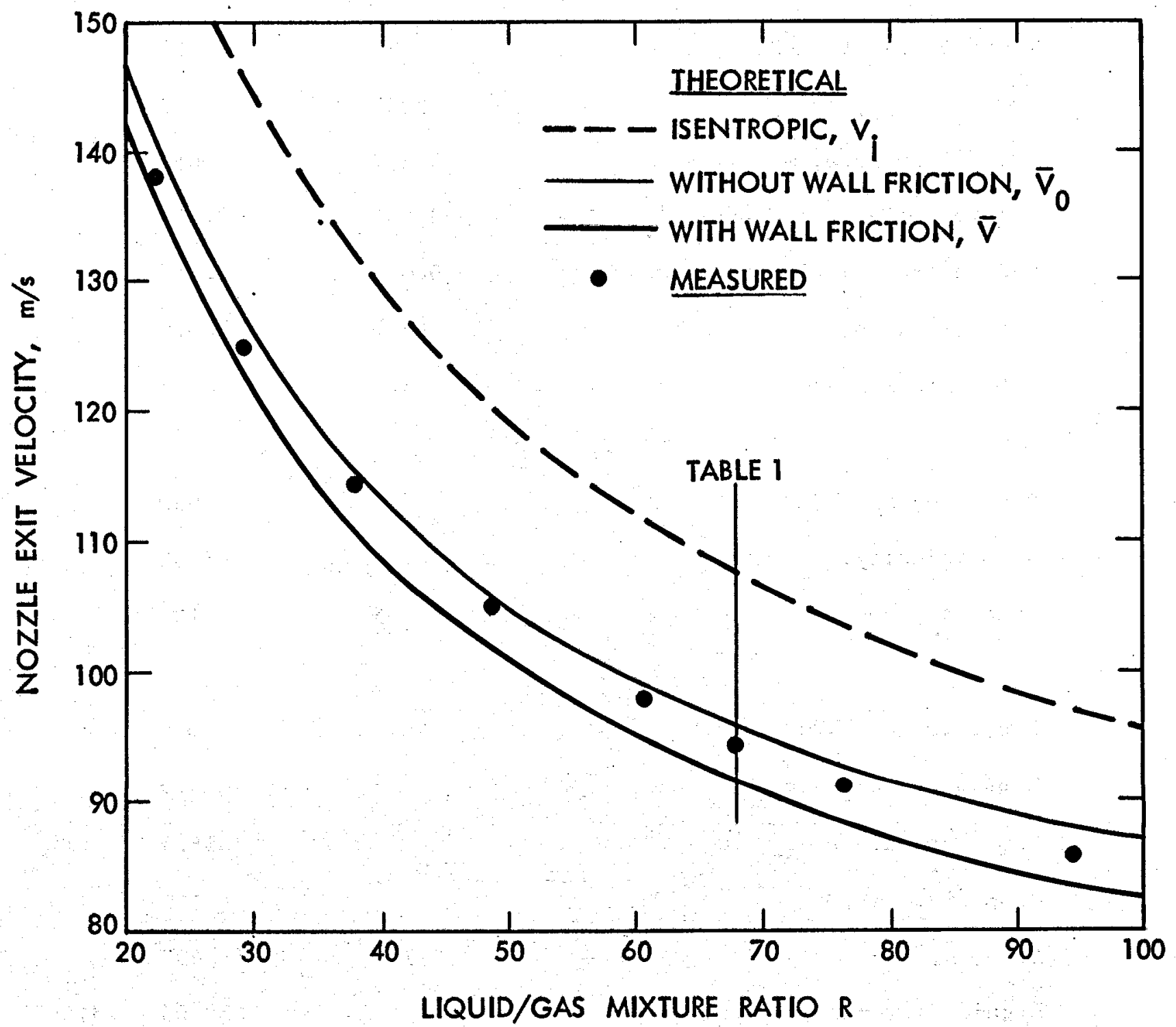

Fig. 14. Comparison of theoretical and experimental exit velocities 
Table 1. Comparison of theoretical and experimental nozzle performance using water and nitrogen

\section{Item}

\begin{tabular}{lll} 
& Value & \\
\hline Measured & $\begin{array}{l}\text { Nozzle } \\
\text { program }\end{array}$ & Fitted
\end{tabular}

Inlet

Temperature, $\mathrm{T}_{1},{ }^{\mathrm{O}} \mathrm{C}$

Pressure, $\mathrm{P}_{1}, \mathrm{kPa}$

2000

2000

Total flow rate, $\dot{\mathrm{m}}_{\mathrm{t}}, \mathrm{kg} / \mathrm{s}$

3.657

3.657

Liquid (water) flow rate, $\dot{\mathrm{m}}_{\ell}, \mathrm{kg} / \mathrm{s}$

3.604

3.604

Gas (nitrogen) flow rate, $\dot{\mathrm{m}}_{\mathrm{g}}, \mathrm{kg} / \mathrm{s}$

0.053

0.053

Mixture ratio, $\mathrm{R}$

68.0

68.0

Velocity, $v_{1}, \mathrm{~m} / \mathrm{s}$

3.6

3.6

Throat

Pressure, $P_{t}, k P a$

Mean velocity, $\bar{v}_{t}, \mathrm{~m} / \mathrm{s}$

57.8

Area, $A_{t}, \mathrm{~mm}^{2}$

Exit

Pressure, $P_{2}, \mathrm{kPa}$

98.6

98.6

Liquid temperature, $\mathrm{T}_{\ell} ;{ }^{\mathrm{O}} \mathrm{C}$

21.3

Gas temperature, $\mathrm{T}_{\mathrm{g}},{ }^{\circ} \mathrm{C}$

15.3

Drop diameter, $d_{2}, \mu m$

Area, $\mathrm{A}_{2}, \mathrm{~mm}^{2}$

597

403

Liquid flow rate, $\dot{\mathrm{m}}_{\ell}, \mathrm{kg} / \mathrm{s}$

$3.603 \quad 3.603$

Gas flow rate, $\dot{\mathrm{m}}_{\mathrm{g}}, \mathrm{kg} / \mathrm{s}$

$3.054 \quad 0.054$

Mixture ratio $R_{2}$

66.7 
Table 1 (contd)

\begin{tabular}{|c|c|c|c|}
\hline \multirow[b]{2}{*}{ Item } & \multicolumn{3}{|c|}{ Value } \\
\hline & Measured & $\begin{array}{l}\text { Nozzle } \\
\text { program }\end{array}$ & Fitted \\
\hline Mean free-stream velocity, $\overline{\mathrm{v}}_{0}, \mathrm{~m} / \mathrm{s}$ & & 95.1 & \\
\hline Mean velocity, $\bar{v}, \mathrm{~m} / \mathrm{s}$ & 94.3 & 90.5 & 94.3 \\
\hline Liquid velocity, $v_{\ell}, \mathrm{m} / \mathrm{s}$ & & 89.9 & 93.7 \\
\hline Gas velocity, $v_{g}, \mathrm{~m} / \mathrm{s}$ & & 131.5 & 137.0 \\
\hline Jet power, $P_{\text {jet }}, \mathrm{kW}$ & & 15.03 & 16.32 \\
\hline Isentropic velocity, $v_{i}, \mathrm{~m} / \mathrm{s}$ & & 106.8 & \\
\hline Isentropic power, $\mathbf{P}_{\mathbf{i}}, \mathbf{k W}$ & & 20.86 & \\
\hline Velocity coefficient, $\mathrm{K}_{\mathrm{v}}$ & 0.883 & 0.847 & 0.883 \\
\hline Efficiency, $n_{n}$ & & 0.721 & 0.782 \\
\hline Flow a rea ratio, $R_{a}$ & & 8.9 & \\
\hline
\end{tabular}


The quantity that chiefly influences turbine rotor efficiency is the ratio $R_{a}$ of gas flow area to liquid flow area; the larger the ratio the lower the rotor efficiency. The value of $R_{a}$ for this nozzle is 8.9, a smaller value than in practical turbines, but useful for researcb purposes in making 1 iquid effects predominate.

\section{F. Refrigerant-22 Data}

The nozzle of Fig. 11 was tested with saturated liquid Refrigerant 22. The results are presented in Table 2.

A small amount of superheated Refrigerant-22 vapor was fed into the gas inlet to give a starting quality of 2 percent. For the measured total flow rate, the nozzle program calculated a throat area 4 percent less than actual. The measured exit velocity is 2 percent higher than theoretical. The fitted nozzle efficiency shows a 14-percent improvement over the water-and-nitrogen nozzle efficiency of 0.78 . The efficiency is higher because the higher molecular weight of Refrigerant-22 vapor gives lower slip velocity, and the lower surface tension of Refrigerant-22 liquid gives smaller drop diameter.

\section{G. LLL Turbine Nozzle}

The nozzle used in the Lawrence Livermore Laboratory (LLL) turbine tests (Refs. 13 and 14) was analyzed by the nozzle program, and the results are presented in Table 3.

The theoretical nozzle efficiency is 0.865 . The theoretical velocity coefficient is 0.90 . The measured velocity coefficient (Table 16 of Ref. 13) was 0.94 when the nozzle was tested without the exit duct used in turbine tests and 0.91 with the exit duct. The velocity coefficient was only 0.83 based on thrust measurements during turbine tests. Because of the uncertainty in the nozzle performance, the theoretical performance values given in Table 3 will be the ones used in analyzing the turbine tests. 
Table 2. Comparison of theoretical and experimental nozzle performance using Refrigerant 22

\begin{tabular}{|c|c|c|c|}
\hline \multirow[b]{2}{*}{ Item } & \multicolumn{3}{|c|}{ Value } \\
\hline & Measured & $\begin{array}{l}\text { Nozzle } \\
\text { program }\end{array}$ & Fitted \\
\hline Inlet & & & \\
\hline Temperature, $\mathrm{T}_{1},{ }^{\circ} \mathrm{C}$ & 18.6 & 18.6 & \\
\hline Pressure, $\mathrm{P}_{1}, \mathrm{kPa}$ & 875 & 875 & \\
\hline Total flow rate, $\dot{\mathrm{m}}_{t}, \mathrm{~kg} / \mathrm{s}$ & 1.339 & 1.339 & \\
\hline Liquid flow rate, $\dot{\mathrm{m}}_{\ell}, \mathrm{kg} / \mathrm{s}$ & 1.312 & 1.312 & \\
\hline Gas flow rate, $\dot{\mathrm{m}}_{\mathrm{g}}, \mathrm{kg} / \mathrm{s}$ & 0.027 & 0.027 & \\
\hline Quality, $x_{1}$ & 0.02 & 0.02 & \\
\hline Velocity, $v_{1}, \mathrm{~m} / \mathrm{s}$ & 1.7 & 1.7 & \\
\hline Throat & & & \\
\hline Pressure, $\mathrm{P}_{\mathrm{t}}, \mathrm{kPa}$ & & 726 & \\
\hline Mean velocity, $\bar{v}_{t}, \mathrm{~m} / \mathrm{s}$ & & 22.6 & \\
\hline Area, $A_{t}, \mathrm{~mm}^{2}$ & 135 & 129 & \\
\hline Quality, $x_{t}$ & & 0.059 & \\
\hline Exit & & & \\
\hline Pressure, $P_{2}, k P a$ & 98.6 & 98.6 & \\
\hline Temperature, $\mathrm{T}_{2},{ }^{\mathrm{O}} \mathrm{C}$ & & -41 & \\
\hline Drop diameter, $d_{2}, \mu \mathrm{m}$ & & 33 & \\
\hline Area, $A_{2}, \mathrm{~mm}^{2}$ & 685 & 599 & \\
\hline Liquid flow rate, $\dot{\mathrm{m}}_{\ell}, \mathrm{kg} / \mathrm{s}$ & & 0.969 & 0.969 \\
\hline Gas flow rate, $\dot{\mathrm{m}}_{\mathrm{g}}, \mathrm{kg} / \mathrm{s}$ & & 0.370 & 0.370 \\
\hline Quality, $x_{2}$ & & 0.276 & \\
\hline Mixture ratio $R_{2}$ & & 2.6 & \\
\hline
\end{tabular}


Table 2 (contd)

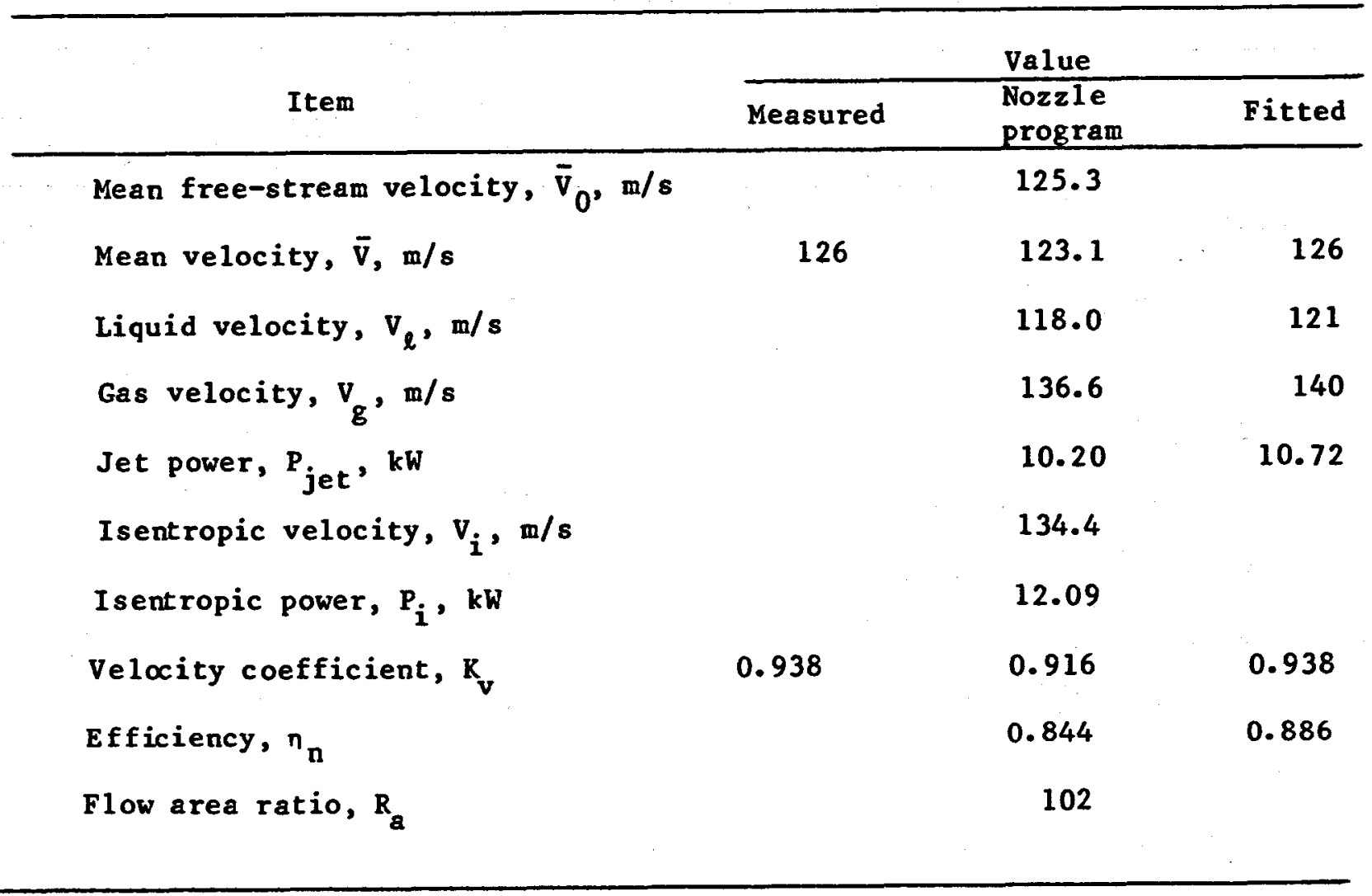


Table 3. Theoretical performance of LLL turbine nozxle

\section{Item}

Value

Inlet

Temperature, $\mathrm{T}_{1},{ }^{{ }} \mathrm{C}$

224.6

Pressure, $P_{1}, \mathrm{kPa}$

2528

Total flow rate, $\dot{\mathrm{m}}_{t}, \mathrm{~kg} / \mathrm{s}$

0.596

Liquid (water) flow rate, $\dot{\mathrm{m}}_{\ell}, \mathrm{kg} / \mathrm{s}$

0.512

Gas (steam) flow rate, $\dot{\mathrm{m}}_{\mathbf{g}}, \mathrm{kg} / \mathrm{s}$

0.084

Quality, $x_{1}$

0.141

Velocity, $v_{1}, \mathrm{~m} / \mathrm{s}$

Throat

Pressure, $P_{t}, \mathrm{kPa}$

Mean velocity, $\bar{v}_{t}, \mathrm{~m} / \mathrm{s}$

131.9

Area, $A_{t}, \mathrm{~mm}^{2}$

Quality, $x_{t}$

0.174

Exit

Pressure, $\mathrm{P}_{2}, \mathrm{kPa}$

Temperature, $\mathrm{T}_{2},{ }^{{ }} \mathrm{C}$

51.3

Drop diameter, $d_{2}, \mu m$ 22

Area, $A_{2}, \mathrm{~mm}^{2}$

Liquid flow rate, $\dot{\mathrm{m}}_{l}, \mathrm{~kg} / \mathrm{s}$

0.397

Gas flow rate, $\dot{m}_{g}, \mathrm{~kg} / \mathrm{s}$

0.199

Quality, $x_{2}$

0.334

Mean free-stream velocity, $\bar{\nabla}_{0}, \mathrm{~m} / \mathrm{s}$

633.6

Mean velocity, $\bar{\nabla}, \mathrm{m} / \mathrm{s}$

627.0

Liquid velocity, $v_{\ell}, \mathrm{m} / \mathrm{s}$

508.7 
Table 3 (contd)

\begin{tabular}{lc}
\hline Item & Value \\
\hline Gas velocity, $\mathrm{V}_{\mathrm{g}}, \mathrm{m} / \mathrm{s}$ & 863.0 \\
Jet power, $\mathrm{P}_{\mathrm{jet}}, \mathrm{kW}$ & 125.5 \\
Isentropic velocity, $\mathrm{V}_{\mathrm{i}}, \mathrm{m} / \mathrm{s}$ & 697.7 \\
Isentropic power, $\mathrm{P}_{\mathrm{i}}, \mathrm{kW}$ & 145.1 \\
Velocity coefficient, $\mathrm{K}_{\mathrm{v}}$ & 0.899 \\
Efficiency, $\mathrm{n}_{\mathrm{n}}$ & 0.865 \\
Flow area ratio, $\mathrm{R}_{\mathrm{a}}$ & 3300 \\
\hline
\end{tabular}


The drop diameter of $22 \mu \mathrm{m}$ calculated for the LLL turbine nozzle is veral times larger than that for the small nozzles of Refs. 11 and 12, because the turbine nozzle is longer and the pressure gradient is smaller, resulting in less shear to break up the drops.

H. Wet-to-Dry Nozzle

A toluene wet-to-dry (WD) nozzle was analyzed to determine the theoretical effect of expanding to dry vapor. The calculated efficiency is very high. For toluene expanding from $289^{\circ} \mathrm{C}$ and 0.01 quality to $70^{\circ} \mathrm{C}$, the exit quality is 1.0 and the efficiency is 0.98 .

Figure 15 shows how the nozzle diameter, quality, and phase velocities vary from inlet to exit for a toluene WD nozzle of $1.0-\mathrm{kg} / \mathrm{s}$ flow rate. The specified pressure profile is shown in the upper curve. The large nozzle length of $0.76 \mathrm{~m}$ is chosen to give a $2.5-\mathrm{deg}$ divergence half-angle. The throat diameter is $9.8 \mathrm{~mm}$, the exit diameter is $53 \mathrm{~mm}$, and the expansion area ratio is 29 . The area ratio is large because the quality at the throat is only 0.24 and most of the vapor remains to be formed. The vapor exit velocity (representing the entire mass flow at the exit) is $503 \mathrm{~m} / \mathrm{s}$. The isentropic velocity is $508 \mathrm{~m} / \mathrm{s}$. 

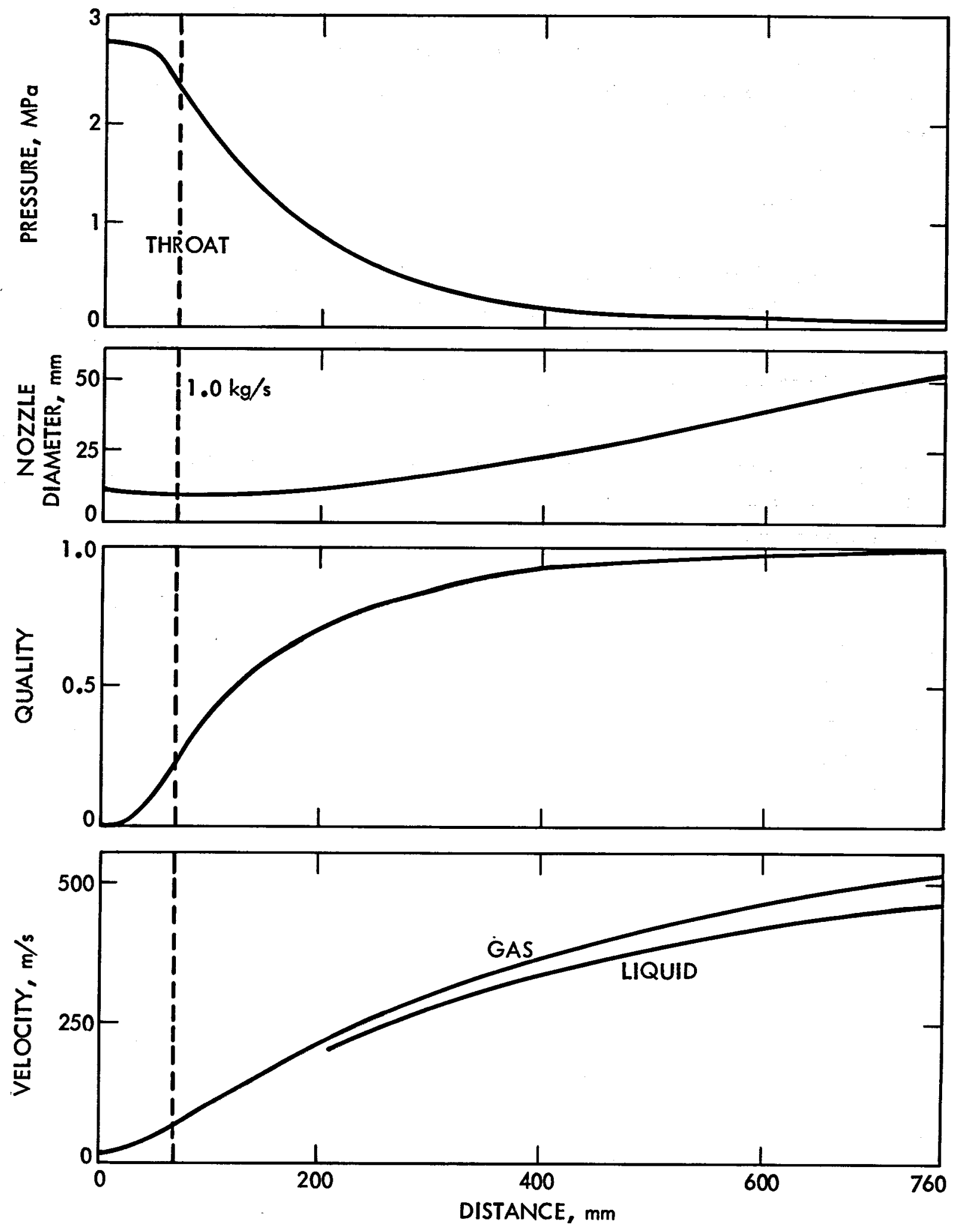

Fig. 15. Wet-to-dry expansion of toluene from $289^{\circ} \mathrm{C}$ to $70^{\circ} \mathrm{C}$ 
SECTION $\mathrm{V}$

ROTORS

\section{A. Erosion}

One of the uncertainties in two-phase turbines is blade erosion. Even if performance problems are overcome, will satisfactory lifetime be possible? There should be no problem at the low velocities of organic working fluids, but there may be a problem with steam-and-water mixtures. Blade erosion measurements in steam turbines have been correlated by the following relation (Ref. 15):

$$
\frac{\text { mass loss per unit area }}{\text { mass of liquid impinging per unit area }}=\mathrm{K}(\mathrm{v}-\mathrm{v})_{c}^{2.6}
$$

where $V$ is the speed of the impinging liquid drops and $v_{c}$ is a threshold velocity below which little or no erosion occurs.

The threshold velocity given in Ref. 15 for 12-percent chrome steel is $120 \mathrm{~m} / \mathrm{s}$. The turbine blades in a two-stage, two-phase turbine travel at about two-thirds the speed of the jet. The jet velocity can, therefore, be $360 \mathrm{~m} / \mathrm{s}$ without erosion, by this criterion. However, the velocity for steam-and-water mixtures is higher than this at many conditions of interest; the liquid velocity for the LLl turbine, for example (Table 3), is $509 \mathrm{~m} / \mathrm{s}$. Therefore, rapid erosion is a possibility in steam-and-water two-phase turbines.

For organic working fluids, the velocity is much lower. Refrigerant 113 expanding from $150^{\circ} \mathrm{C}$ to $46^{\circ} \mathrm{C}$ and 0.64 quality in a waste-heat cycle, for example, reaches only $158 \mathrm{~m} / \mathrm{s}$.

Erosion was also of concern in the liquid-metal MHD project (Ref. 2). Erosion tests were made with a water-and-nitrogen jet at $137 \mathrm{~m} / \mathrm{s}$. A blunt-tipped a luminum cone placed in the jet eroded back $1.8 \mathrm{~mm}$ in 1100 hours, but 304 
stainless steel eroded at only a tenth of that rate. These results indicate that erosion rates of reasonably hard alloys at relative speeds below about $120 \mathrm{~m} / \mathrm{s}$ should not be a problem.

A WD-cycle turbine would, in principle, escape erosion entirely because only dry vapor enters the rotor.

\section{B. Liquid Path}

The key fact about the flow leaving the nozzle and entering the rotor in a two-phase turbine is that the drops are large, the gas density is low, and the drops travel in a straight line like bullets until they hit something.

Figure 16 shows the results of trajectory calculations for water drops in a water-and-nitrogen jet at atmospheric pressure. The mixture travels through a 90-degree bend. Small drops follow the gas with only a small outward drift, and only the drops starting near the outer wall impinge. Large drops travel straight into the wall. The fraction of entering liquid that impinges on the outer wall is plotted against drop diameter for various channel curvatures and flow velocities. Even for the largest channel radius (50 mm) and smallest velocity $(75 \mathrm{~m} / \mathrm{s})$ there is complete impingement of drops larger than $13 \mu \mathrm{m}$ in diameter; a $13-\mu \mathrm{m}$ drop entering at the inner wall would just strike the outer wall at the end of the turn. Even $2.5-\mu \mathrm{m}$ drops would suffer 50-percent impingement (those drops entering the outer half of the channel) at $150-$ to $250-\mathrm{m} / \mathrm{s}$ velocity and a $25-\mathrm{mm}$ channel radius. Thus, drop diameters can be only 1 to $2 \mu \mathrm{m}$ for small impingement fractions at practical conditions. Such diameters are below the range produced by two-phase nozzles.

Liquid flow behavior was studied photographically in the turbine rotor obtained from LLL, which will be referred to as Rotor 1. The blade shape is shown in Fig. 17. Figure 18 is a $1-\mu \mathrm{s}$ flash photograph of the flow leaving the rotor in water-and-nitrogen tests. The total flow rate is $3.6 \mathrm{~kg} / \mathrm{s}$, the mixture ratio of water to nitrogen is 45 , the jet velocity (mean velocity $\bar{v}$ ) is $80 \mathrm{~m} / \mathrm{s}$, the rotor speed is $1540 \mathrm{rpm}$ (the speed for maximum efficiency), the blade speed is $42 \mathrm{~m} / \mathrm{s}$ (downward in the photograph), and the shaft output power is $8.1 \mathrm{~kW}$. The drop diameter calculated by the nozzle program is $150 \mathrm{\mu m}$. 


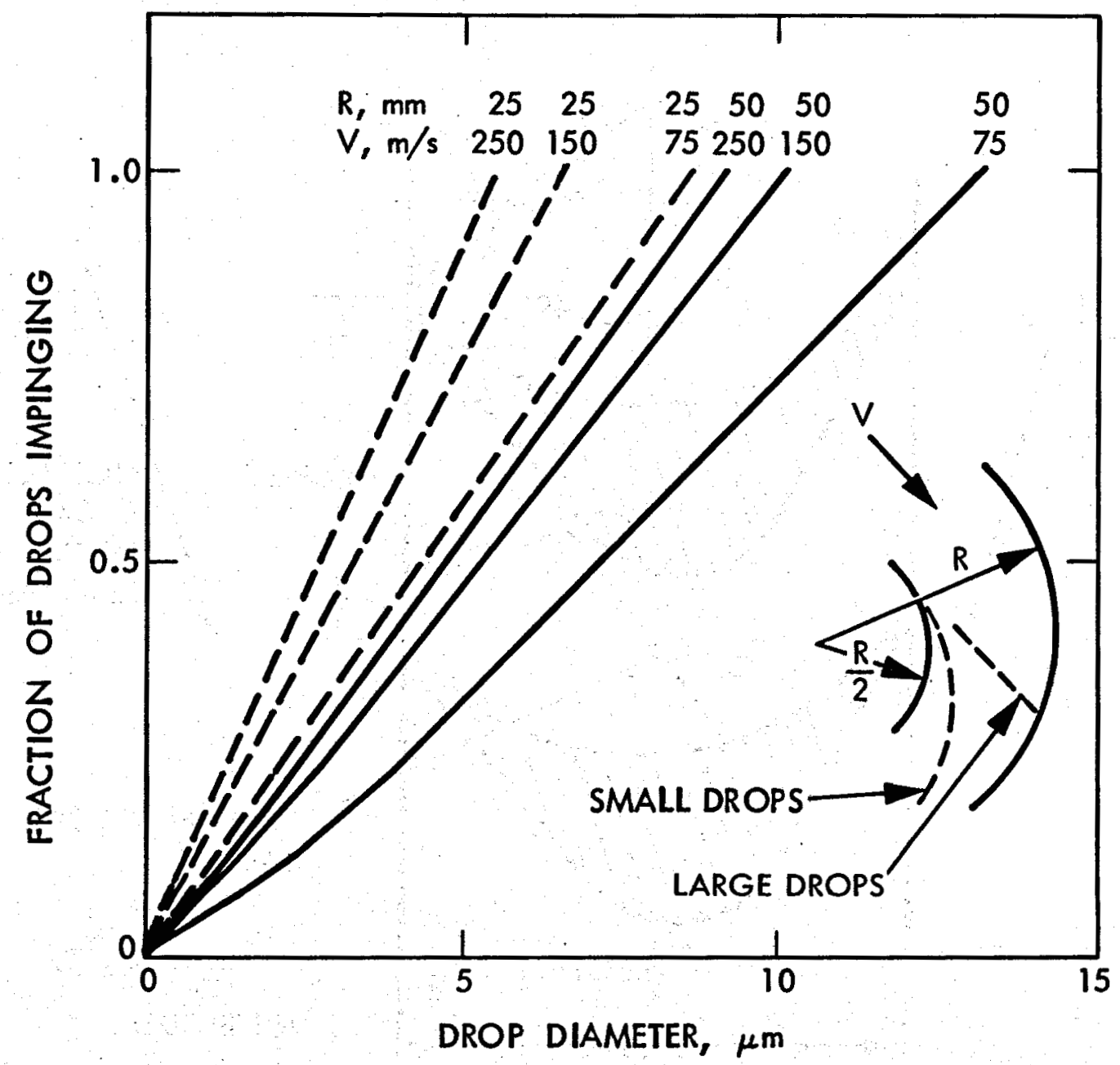

Fig. 16. Effect of drop diameter on liquid impingement 


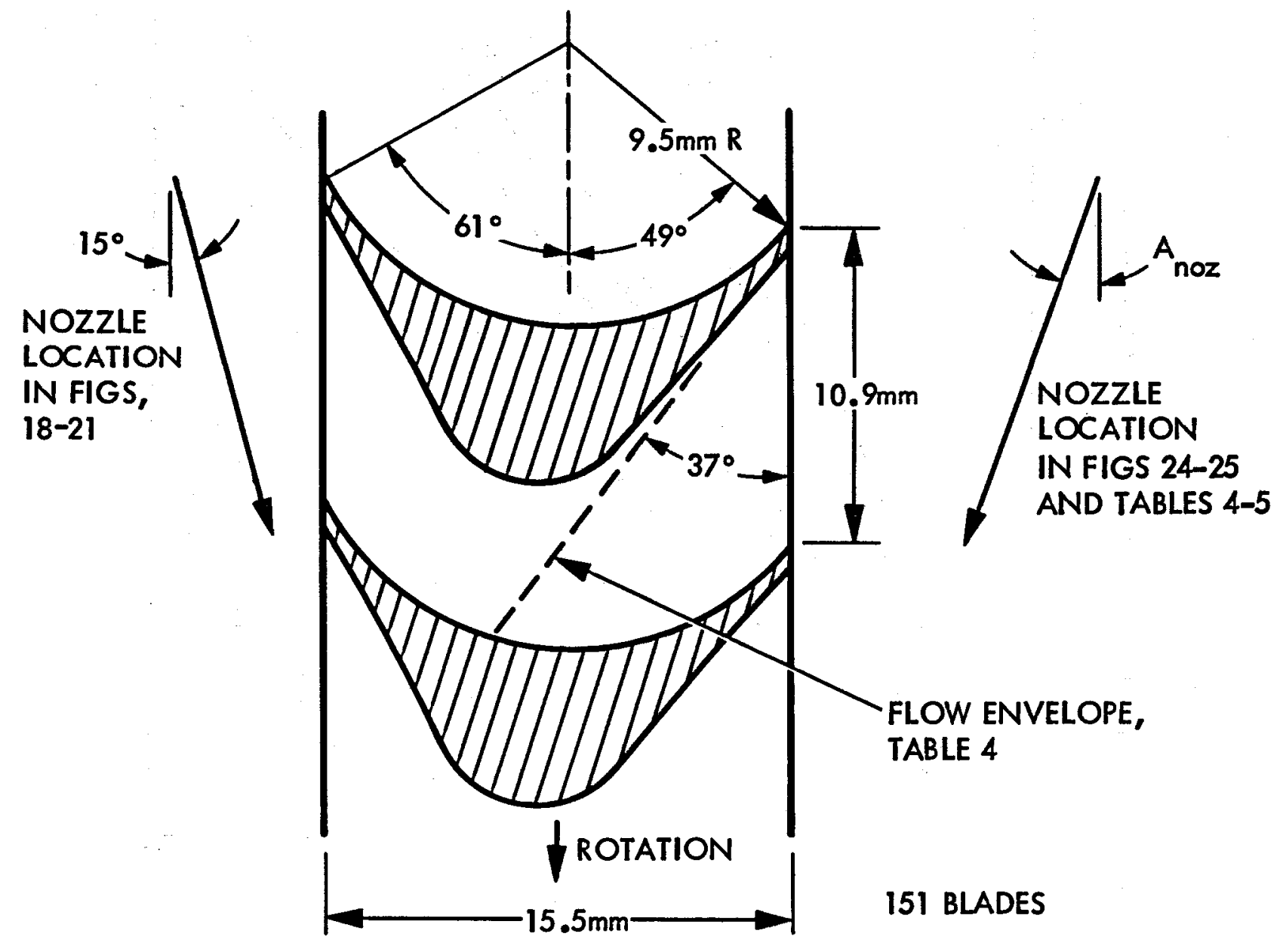

Fig. 17. Rotor 1 blade shape 


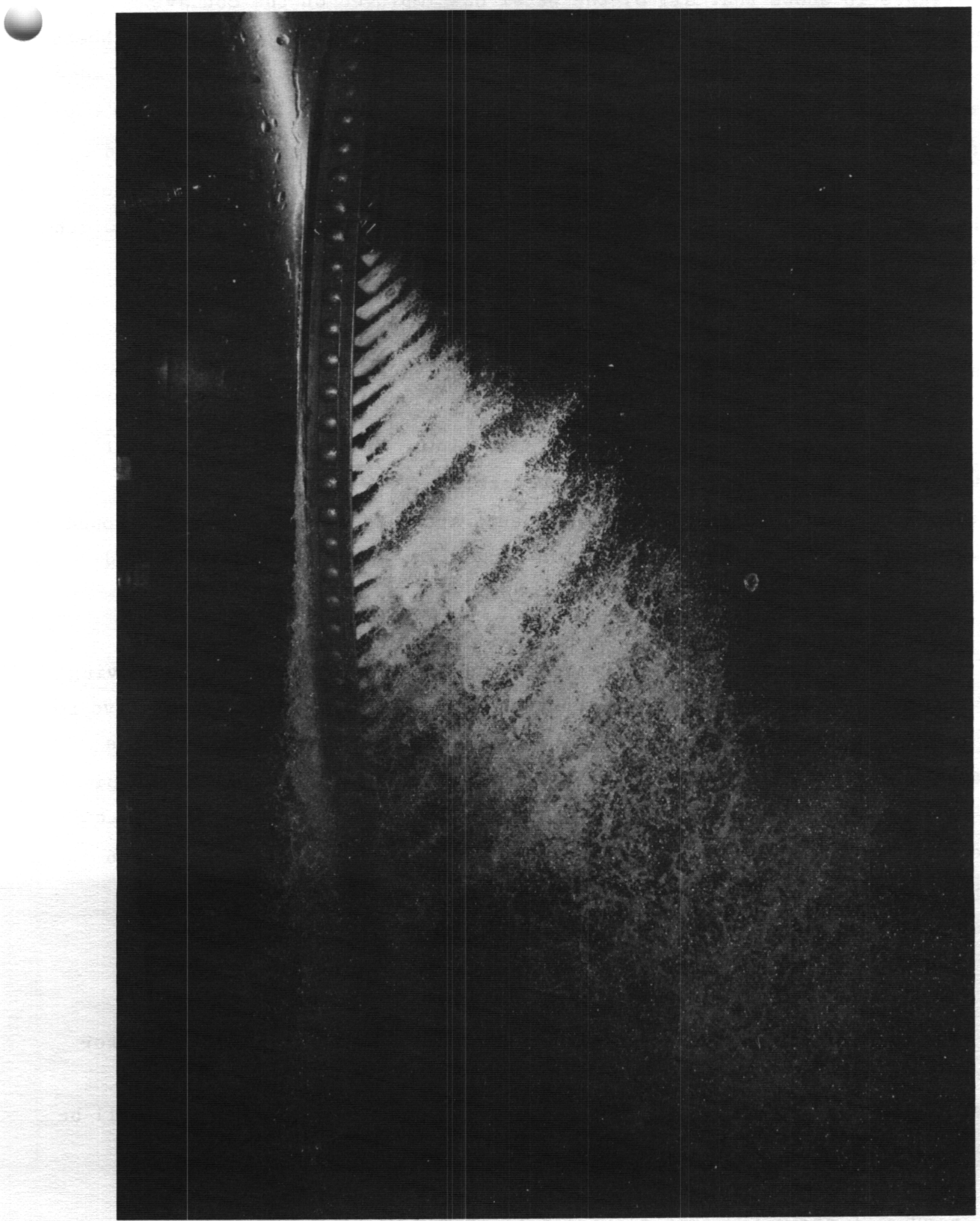

Fig. 18. Liquid exit flow at high 1 iquid/gas mixture ratio $(R=45)$ 
Figure 18 shows that all of the water has impinged on the concave (upward-facing) sides of the blades and formed thin liquid sheets. The sheets are only about $0.5 \mathrm{~mm}$ thick, 5 percent of the blade spacing. The leading edge of each sheet emerges from a blade when the blade has traveled about half way down across the nozzle exit; at that position the first liquid intercepted by the blade has had time to cross the blade. Similarly, the trailing edge of each liquid sheet leaves when the blade has traveled about a balf nozzle width beyond the end of the nozzle.

To the eye, the flow has the same appearance as the jet leaving a nozzle. The rotor has merely slowed and deflected the nozzle jet.

Figure 19 is an axial view of the same flow. The first sheet of exit flow appears opposite the middle of the nozzle exit. About three leading edges can be seen before the emerging sheets are hidden behind the foreground flow. The liquid leaves in a direction tangent to the rotor but deflected slightly outward from the original direction of nozzle flow.

The vector velocities, both relative and absolute, of the liquid leaving the rotor can be measured from the photographs. The exit velocity relative to the rotor is in the plane of the liquid sheets, and is at the speed of the advancing leading edges. The absolute exit velocity is in the direction of the envelope of the sheets at the velocity of advance of the sheets in that direction. The relative exit velocity measured from Fig. 18 is $27 \mathrm{~m} / \mathrm{s}$ ( 66 percent of the relative inlet velocity) at $43 \mathrm{deg}$ above horizontal (the water does not follow the blade contour to the full 49-deg exit angle). The absolute exit velocity is $27 \mathrm{~m} / \mathrm{s}$ at $46 \mathrm{deg}$ below horizontal.

Two undesirable flow effects can be seen in Fig. 18. Some of the water leaves the rotor on the nozzle side, and the trailing edges of the liquid sheets do not detach cleanly. These effects, which reduce efficiency, will be discussed in a later section.

Figure 20 shows the exit flow at a lower liquid flow rate and higher velocity. The liquid flow rate is $1.9 \mathrm{~kg} / \mathrm{s}$, the mixture ratio is 11 , the jet velocity is $141 \mathrm{~m} / \mathrm{s}$, the rotor speed is $2770 \mathrm{rpm}$, the blade speed is $76 \mathrm{~m} / \mathrm{s}$, 


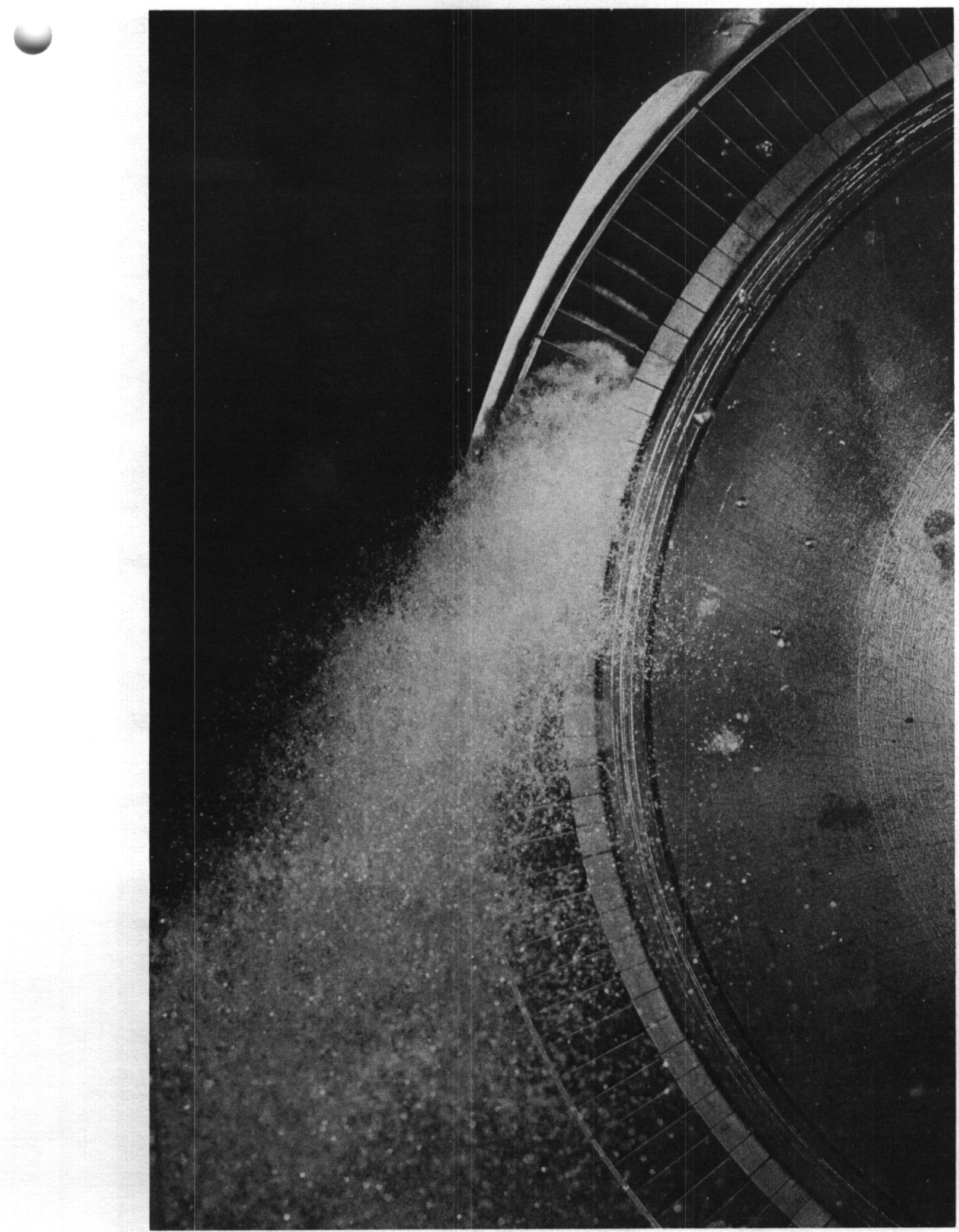

Fig. 19. Axial view of exit flow at $R=45$ 


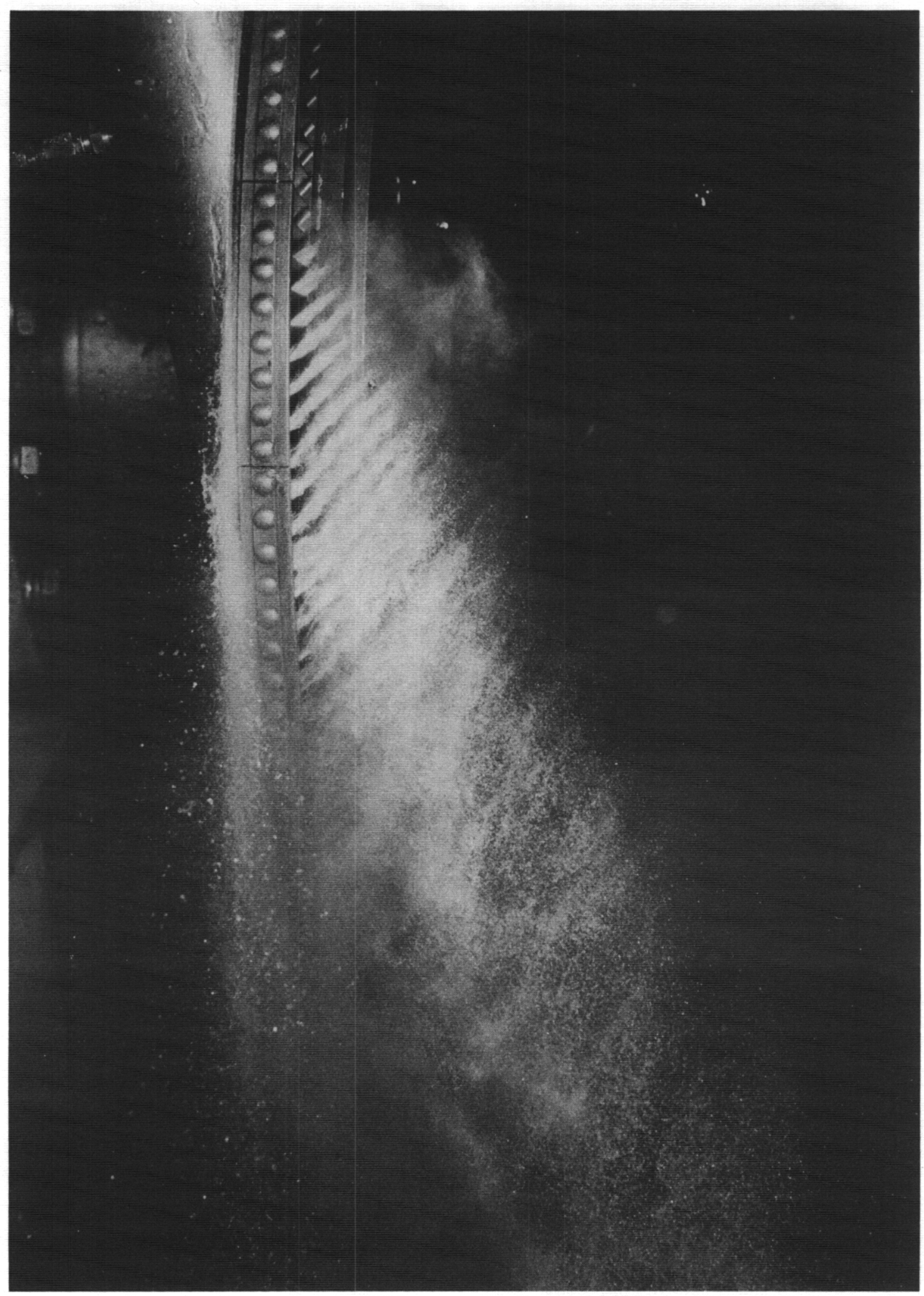

Fig. 20. Exit flow at $R=11$ 
and the shaft power is $13.8 \mathrm{~kW}$. The drop diameter from the nozzle program is $75 \mu \mathrm{m}$. Figure 20 shows again that the water leaves as thin sheets, but some mist is also visible above the sheets. Evidently, some of the drops from the nozzle are small enough to remain entrained in the nitrogen flow. The mist leaves the rotor in a more nearly horizontal direction than the 1 iquid, showing that the nitrogen and entrained small drops suffer less velocity loss in the rotor than the 1 iquid, and are ejected at a higher speed. The water velocity loss is greater than that in Fig. 18, as evidenced by the steeper downward angle of the exit flow. The relative exit velocity of the water sheets, as measured from the photograph, is $36 \mathrm{~m} / \mathrm{s}$ ( 51 percent of the relative inlet velocity), and the absolute exit velocity is $56 \mathrm{~m} / \mathrm{s}$ at $63 \mathrm{deg}$ below horizontal.

Figure 21 shows the exit flow at a still lower mixture ratio. The liquid flow rate is $0.54 \mathrm{~kg} / \mathrm{s}$, the mixture ratio is 4 , the jet velocity is $152 \mathrm{~m} / \mathrm{s}$, the rotor speed is $3260 \mathrm{rpm}$, the blade speed is $89 \mathrm{~m} / \mathrm{s}$, and the shaft power is $5.7 \mathrm{~kW}$. The drop diameter from the nozzle program is $64 \mathrm{\mu m}$. More mist is visible than in the previous photograph. The relative exit velocity of the water sheets is $40 \mathrm{~m} / \mathrm{s}$ ( 57 percent of the relative inlet velocity), and the absolute exit velocity is $66 \mathrm{~m} / \mathrm{s}$ at $66 \mathrm{deg}$ below horizontal.

\section{Rotor Program}

The picture that emerges from drop trajectory calculations and flow photographs is that the bulk of the liquid entering a two-phase turbine travels straight into the blades while the gas travels through as though the liquid were not present. Therefore, to calculate the performance of a twophase turbine rotor, it should be sufficient to model the liquid flow as straight-in impingement, unaffected by the gas, followed by film flow along the blade surface. The gas flow can be modeled as conventional gas turbine flow, unaffected by the liquid.

Such a model is derived in Appendix A. The liquid flow is modeled in detail, but the gas is merely assumed to exert a known fraction $n_{g}$ of the ideal gas-phase torque at any given speed. The ideal gas-phase force on the blades at zero turbine speed is $2 \dot{\mathrm{m}}_{\mathrm{g}} \mathrm{V}_{\mathrm{g}}$, because the gas flow is ideally 


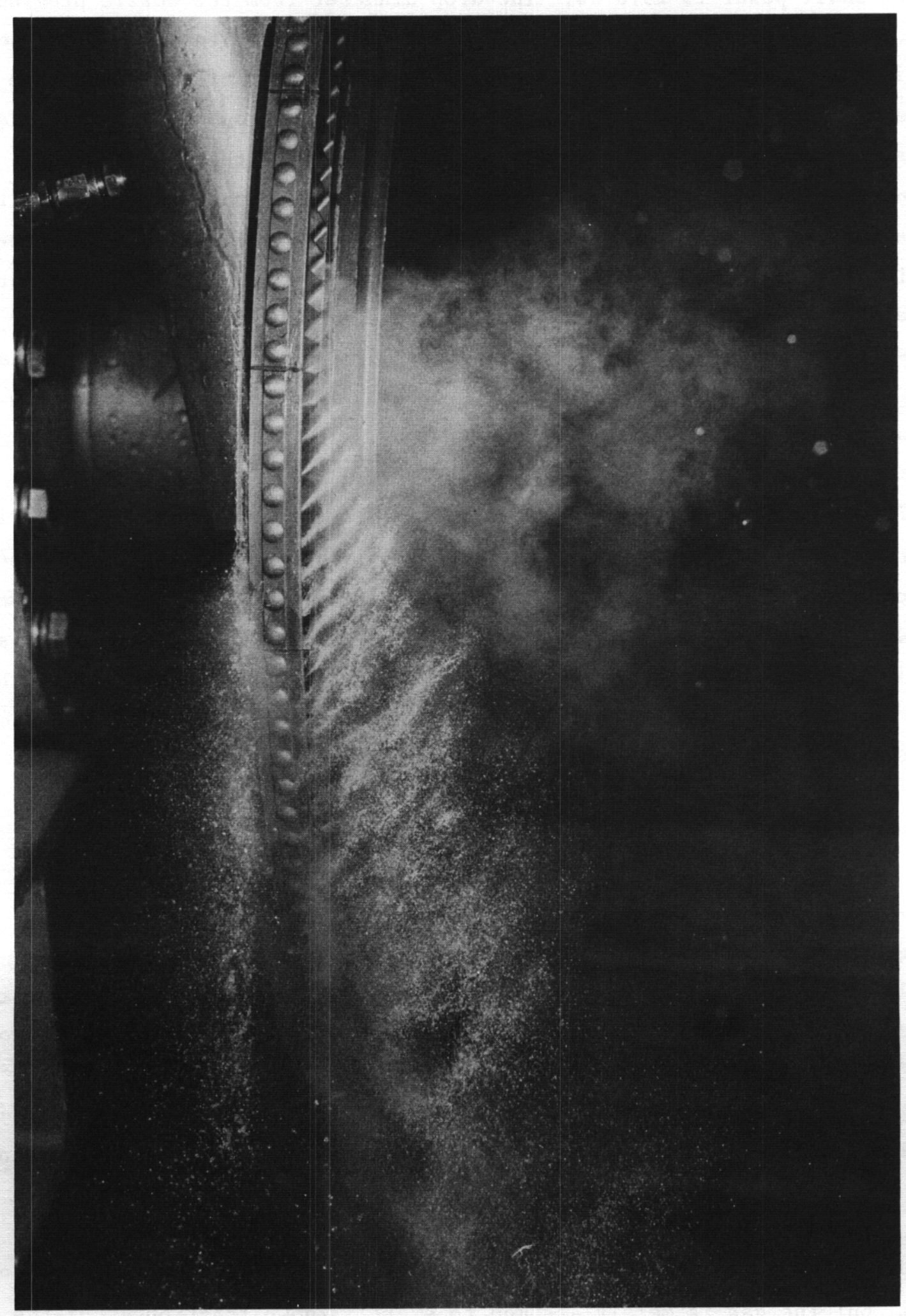

Fig. 21. Exit flow at $R=4$ 
reversed without velocity loss. The force ideally decreases with speed in proportion to $\left(1-v_{b} / v_{g}\right)$, where $v_{b}$ is the blade speed. Thus, the gas-phase force is

$$
F_{g}=2 n_{g} \dot{m}_{g} v_{g}\left(1-v_{b} / v_{g}\right)
$$

The gas-phase efficiency $F_{g} V_{b} /\left(\frac{1}{2} \dot{m} g v_{g}^{2}\right)$ has a peak value of $n_{g}$ at a blade speed of half the gas speed. Thus, the specified gas torque factor $n_{g}$ is also the peak gas-phase efficiency.

The rotor flow model of Appendix $A$ is incorporated in a computer program that was used for the theoretical calculations presented in this report. The inputs to the program are the nozzle exit dimensions; nozzle angle relative to the rotor; rotor speed; 1 iquid and gas flow rates; 1 iquid and gas velocities; blade shape; rotor diameter; liquid density and viscosity; gas torque fraction (peak gas-phase efficiency) $\eta_{g}$; and (for windage torque calculation) gas density and viscosity.

Several different torques, powers, and efficiencies are calculated. First, the program calculates the total force $F_{b}$ exerted on the blades by the two-phase flow. Multiplying this force by the rotor radius $R_{b}$ to the center of the blades gives the "blade torque" $L_{b}$. Multiplying this torque by the angular speed $w$ gives the "blade power" $\mathrm{P}_{\mathrm{b}}$.

$$
P_{b}=L_{b} \omega
$$

The windage, or disc friction, torque $L_{w}$ is calculated from the Mann and Marston correlations (Ref. 16). Subtracting windage torque from the blade torque gives the theoretical "rotor torque" $L_{r}$.

$$
L_{r}=L_{b}-L_{w}
$$

The product of rotor torque and rotor angular speed is the "rotor power" $\mathbf{r}$

$$
P_{r}=I_{\mathbf{r}} \omega
$$


The ratio of the blade power to the jet power is the "blade efficiency" $n_{\mathrm{b}} \cdot$

$$
n_{b}=\frac{P_{b}}{P_{j e t}}
$$

where $P_{\text {jet }}$ is the jet power given by Eq. (12). This is the most useful efficiency for the comparison of experiment with theory.

The ratio of rotor power to jet power is the "rotor efficiency" "r.

$$
n_{r}=\frac{P_{r}}{P_{j e t}}
$$

The ratio of blade power $P_{b}$ to isentropic powe $P_{i}$ will be called the "nozzle-blade efficiency" "nb

$$
n_{n b}=\frac{P_{b}}{P_{i}}=n_{n} n_{b}
$$

where $\eta_{n}$ is the nozzle efficiency defined in Eq. (14). The nozzle-blade efficiency is the efficiency that would be attained with a large number of nozzles so that windage loss is negligible relative to output power.

The ratio of rotor power to isentropic power is the "turbine efficiency" $n^{*}$

$$
n_{t}=\frac{P_{r}}{P_{i}}
$$

The turbine efficiency is also equal to the product of nozzle efficiency and rotor efficiency.

$$
n_{t}=n_{n} n_{r}
$$


The turbine efficiency is the only efficiency that counts in practical applications. The other efficiencies are useful for analysis purposes.

\section{Rotor Test Apparatus}

Figures 22 and 23 show the apparatus used in the two-phase turbine experiments. The test rotor is driven by a $60-\mathrm{kW}$ electric motor through a variable-speed belt drive and a gear box. The gear box is an automobile transmission driven from the drive-shaft side. Rotor speeds can be adjusted from $700 \mathrm{rpm}$ to $6000 \mathrm{rpm}$, but the highest used in flow tests was $3500 \mathrm{rpm}$. The rotor shaft can also be locked for zero-speed tests. The gear box is connected to the rotor through a rotating strain-gage torque transducer.

The nozzle used in the turbine tests is the one shown in Fig. 11. Various throat diameters, exit diameters, and cut-off angles have been used. In some of the tests, as shown in Figs. 22 and 23, the nozzle was pivoted on bearings and restrained by a load cell for nozzle thrust measurement.

The nozzle is fed through flexible hoses. In Fig. 22, the nozzle is connected for Refrigerant 22 tests. Liquid Refrigerant 22 is fed from a nitrogen-pressurized tank through a hand-operated valve to the liquid inlet of the nozzle. Vapor is fed from a beated-Refrigerant 22 cylinder (not shown).

For water-and-nitrogen tests, the liquid line is connected to water pumps, and the hand valve is used for controlling the water flow rate. In those tests, the nitrogen line is connected to the gas inlet of the nozzle, and the nitrogen flow rate is controlled by a pressure regulator.

A water sump is located under the deck plates beneath the turbine. During turbine tests, the deck plates are removed and the flow leaving the rotor discharges into the sump. In the Refrigerant-22 tests, the liquid vaporizes on contact with the water and is exhausted from the building by blowers. 


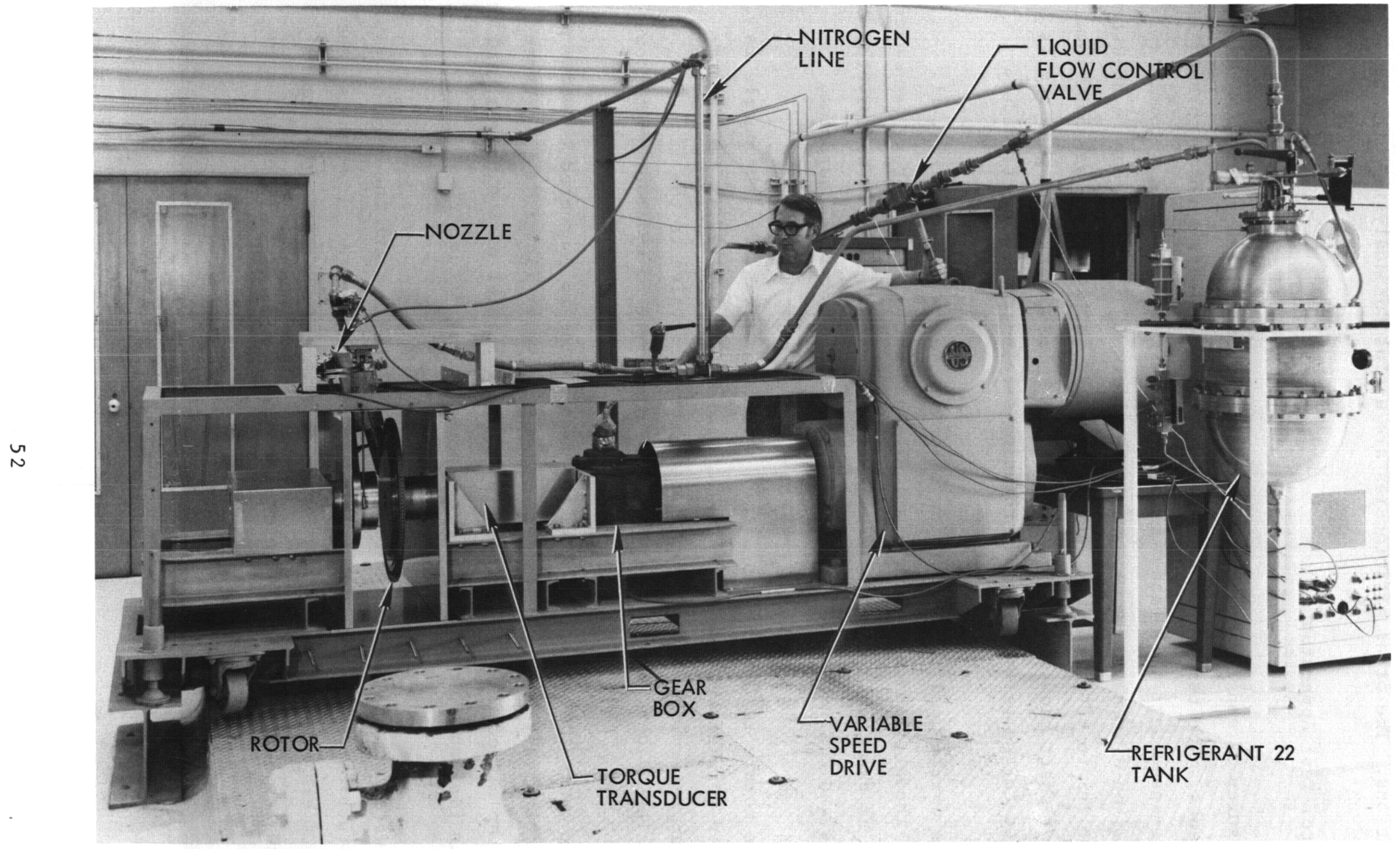

Fig. 22. Two-phase turbine experiment 


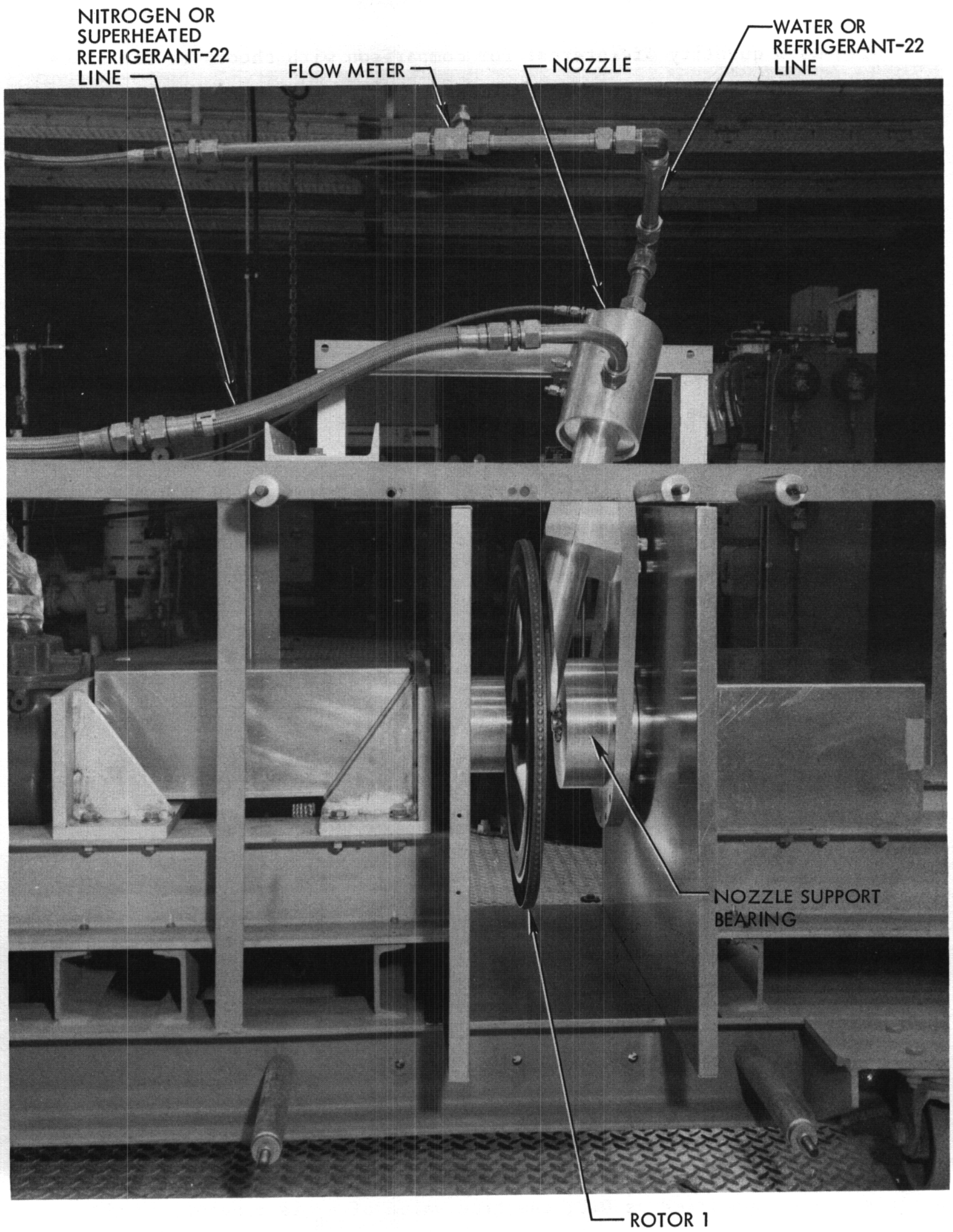

Fig. 23. Single-stage turbine 
The main quantity of interest for comparison with theory is the blade torque $L_{b}$. Blade torque is measured by setting the rotor speed at a desired value, with nozzle flow off, and recording the torque required to drive the rotor. Then the nozzle flow is turned on, the variable-speed drive is adjusted slightly to reduce the speed to the no-flow value, and the torque is recorded again. The torque without flow is the windage torque $L_{w}$. The torque with flow, which is a torque exerted by the rotor on the drive system (causing the electric motor to act as a generator and feed power back into the power line) is the rotor torque $L_{r}$. The sum of the two torques (measured in practice as the change in the recorder pen deflection between flow off and flow on) is the blade torque $\mathrm{L}_{b}$.

Blade power is calculated from Eq. (17), $P_{b}=I_{b} w$, and the blade efficiency is calculated from Eq. (20), $\eta_{b}=P_{b} / P_{j e t}$. The value used for the jet power $P_{j e t}$ is the "fitted" value obtained from the measured nozzle thrust, the calculated exit mixture ratio, and the calculated exit velocity ratio from the nozzle program, as illustrated in Table 1.

\section{F. Water-and-Nitrogen Turbine Data}

Rotor 1 was tested with water and nitrogen at the nozzle conditions given in Table 1. The nozzle was mounted at an angle $A_{\text {noz }}$ of 20 deg on the right side of the rotor as drawn in Fig. 17.

Figure 24 presents the measured blade torque $L_{b}$ as a function of rotor speed. The torque varies from $125 \mathrm{~N}-\mathrm{m}$ at zero speed to $40 \mathrm{~N}-\mathrm{m}$ at $2250 \mathrm{rpm}$, and the torque follows a straight line. The speed at which the torque extrapolates to zero is $3300 \mathrm{rpm}$, corresponding to a blade speed of $91 \mathrm{~m} / \mathrm{s}$, which is close to the nozzle exit velocity.

Figure 24 also presents the theoretical torque calculated by the rotor program (Appendix A). The gas torque factor $n_{g}$ (equal to the peak gas-phase efficiency) is specified as 0.8 ; the true value of $\eta_{g}$ is probably in the range 0.6 to 0.9 , but the nitrogen flow rate is so small compared with the water flow rate in these tests that the uncertainty in $n_{g}$ bas negligible effect on the theoretical torque. 


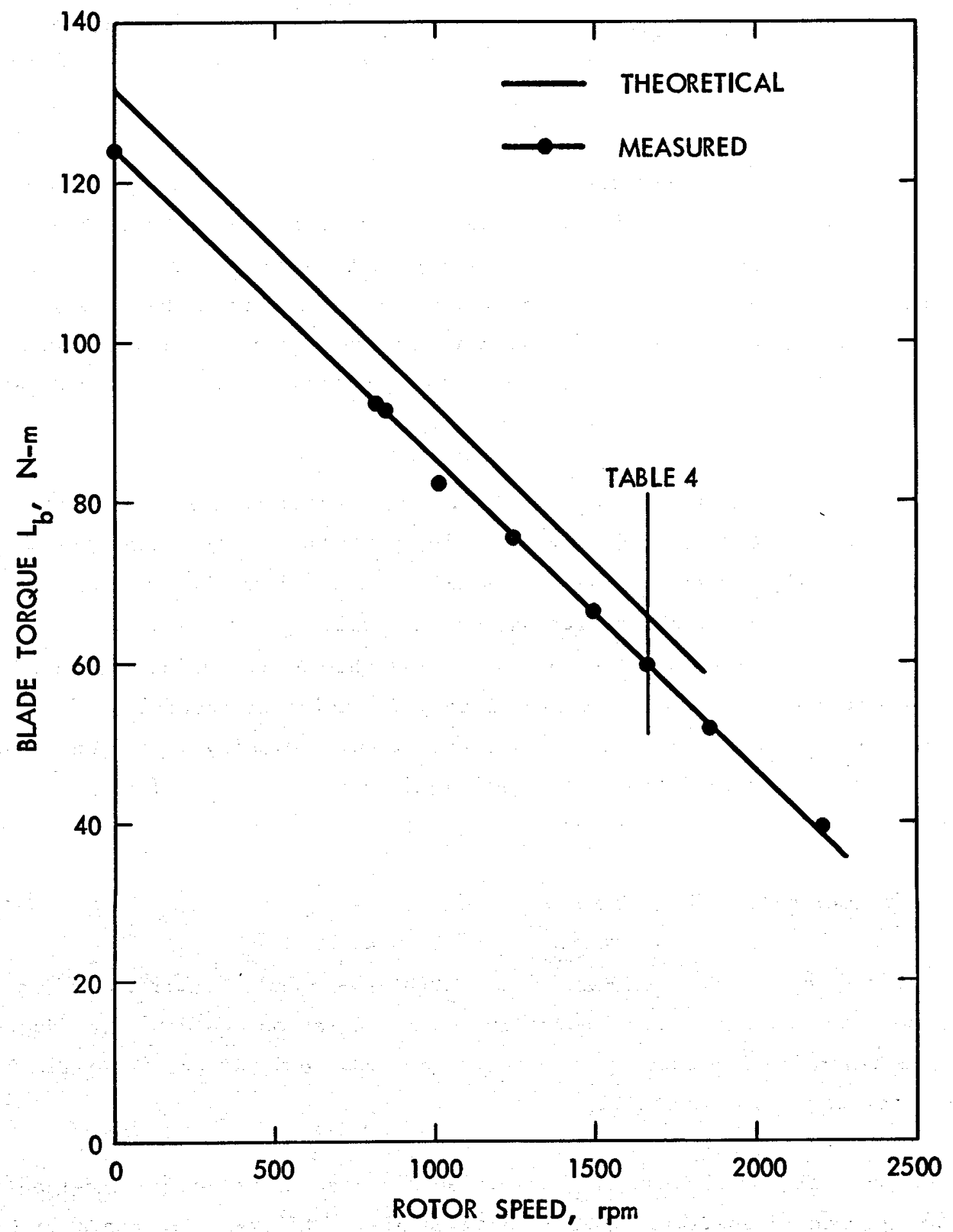

Fig. 24. Comparison of theoretical and experimental torques of water-and-nitrogen turbine 
The theoretical blade torque varies from $132 \mathrm{~N}-\mathrm{m}$ at zero speed to $59 \mathrm{~N}-\mathrm{m}$ at $1850 \mathrm{rpm}$. Beyond this speed, the rotor program calculates that the flow impinges on the backs of the blades. This effect is not modeled in the theory, and therefore the theoretical calculations are only carried to 1850 rpm.

Figure 25 compares the theoretical and experimental blade efficiencies $n_{b}$. The peak experimental efficiency is 0.631 at $1650 \mathrm{rpm}$. The peak theoretical efficiency is 0.709 . The agreement between theoretical and experimental efficiencies is sufficiently close to show that the theory accounts for the major losses, but that there are additional losses amounting to about 10 percent. The possible additional losses are discussed in a later section.

Table 4 compares the theoretical and experimental performance at the peak-efficiency speed of $1650 \mathrm{rpm}$. The windage torque is six times greater than theoretical, but the theoretical windage torque from the Mann and Marston correlations is for a tightly-fitting housing, which gives lower windage torque than that for an unenclosed rotor. The theoretical values of relative inlet velocity $V_{1}$ and relative exit velocity $v_{3}$ (using the notation of Appendix A) show that there is a substantial liquid velocity loss even at the favorable operating conditions (low gas/liquid area ratio $R_{a}$ ) of this turbine.

\section{G. Refrigerant-22 Turbine Data}

Rotor 1 was tested with Refrigerant 22 at the nozzle conditions of Table 2. Because only a few runs of about 10 seconds duration could be made due to cost and tank-size limitations, the tests were made only at the theoretical peak-efficiency speed of $1880 \mathrm{rpm}$.

The results for the run with the steadiest conditions and most reliable data are presented in Table 5. The measured blade efficiency is essentially the same as in the water-and-nitrogen tests. However, this efficiency is only 2 percent less than the theoretical blade efficiency using an assumed gas torque 


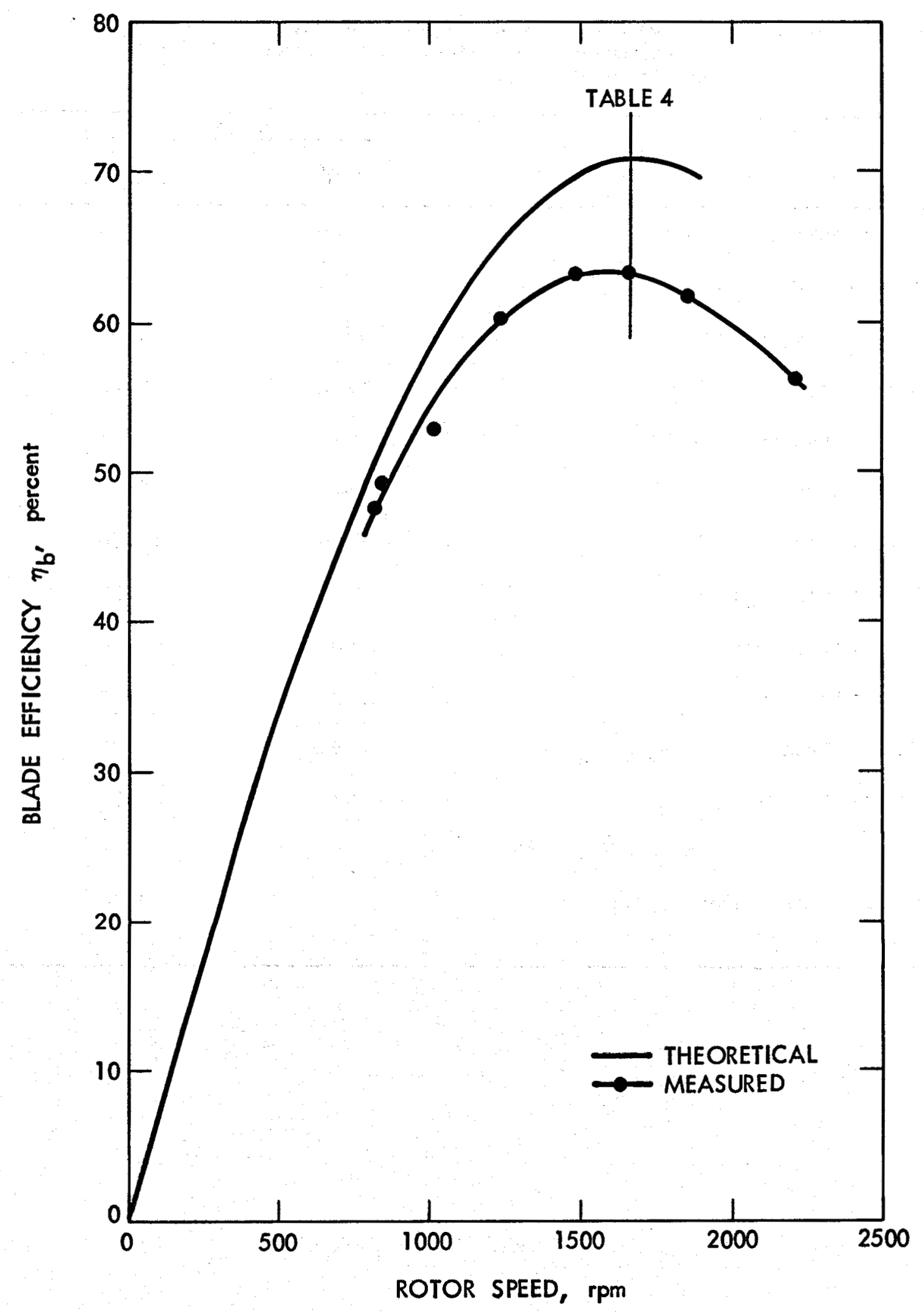

Fig. 25. Comparison of theoretical and experimental efficiencies of water-and-nitrogen turbine 
Table 4. Comparison of theoretical and experimental turbine performance using water and nitrogen (Table 1 nozzle conditions)

\begin{tabular}{|c|c|c|}
\hline \multirow[b]{2}{*}{ Item } & \multicolumn{2}{|c|}{ Value } \\
\hline & Measured & $\begin{array}{c}\text { Rotor } \\
\text { program }\end{array}$ \\
\hline Nozzle angle, $A_{n}$, deg & 20 & 20 \\
\hline Rotor radius, $R_{b}, \mathrm{~mm}$ & 263 & 263 \\
\hline Rotor speed, N, rpm & 1652 & 1652 \\
\hline Rotor torque, $L_{r}, N-m$ & 57.2 & 66.5 \\
\hline Windage torque, $\mathbf{L}_{w}, N-m$ & 2.3 & 0.4 \\
\hline Blade torque, $\mathrm{L}_{b}, \mathrm{~N}-\mathrm{m}$ & 59.5 & 66.9 \\
\hline Rotor power, $\mathrm{P}_{\mathbf{r}}, \mathrm{kW}$ & 9.90 & 11.50 \\
\hline Blade power, $P_{b}, k W$ & 10.29 & 11.57 \\
\hline Rotor efficiency, ${ }^{n} \mathbf{r}$ & 0.607 & 0.704 \\
\hline B lade efficiency, $\eta_{b}$ & 0.631 & 0.709 \\
\hline Nozzle-blade efficiency, $n_{n b}$ & 0.494 & 0.555 \\
\hline Turbine efficiency, $n_{t}$ & 0.475 & 0.551 \\
\hline Relative inlet velocity, $v_{1}, \mathrm{~m} / \mathrm{s}$ & & 53.3 \\
\hline Relative exit velocity, $v_{3}, \mathrm{~m} / \mathrm{s}$ & & 29.6 \\
\hline
\end{tabular}


Table 5. Comparison of theoretical and experimental turbine performance using Refrigerant 22 (Table 2 nozzle conditions)

\begin{tabular}{|c|c|c|}
\hline \multirow[b]{2}{*}{ Item } & \multicolumn{2}{|c|}{ Value } \\
\hline & Measured & $\begin{array}{l}\text { Rotor } \\
\text { program }\end{array}$ \\
\hline Nozzle angle, $A_{n}$, deg & 15 & 15 \\
\hline Rotor radius, $R_{b}, \mathrm{~mm}$ & 261 & 261 \\
\hline Rotor speed, N, rpm & 1880 & 1880 \\
\hline Rotor torque, $\mathrm{L}_{\mathrm{r}}, \mathrm{N}-\mathrm{m}$ & 32.2 & 34.0 \\
\hline Windage torque, $\mathbf{L}_{w}, \mathrm{~N}-\mathrm{m}$ & 1.7 & 0.5 \\
\hline Blade torque, $L_{b}, N-m$ & 33.9 & 34.5 \\
\hline Rotor power, $\mathrm{P}_{\mathbf{r}}, \mathrm{kW}$ & 6.34 & 6.69 \\
\hline B lade power, $P_{b}, k W$ & 6.67 & 6.79 \\
\hline Rotor efficiency, ${ }^{n} r$ & 0.591 & 0.624 \\
\hline Blade efficiency, $n_{b}$ & 0.622 & 0.633 \\
\hline Nozzle-blade efficiency, $n_{n b}$ & 0.551 & 0.561 \\
\hline Turbine efficiency, $n_{t}$ & 0.524 & 0.553 \\
\hline Relative inlet velocity, $v_{1}, \mathrm{~m} / \mathrm{s}$ & & 72.6 \\
\hline Relative exit velocity, $v_{3}, \mathrm{~m} / \mathrm{s}$ & & 19.2 \\
\hline
\end{tabular}


factor (gas phase efficiency) $n_{g}$ of 0.8 . The uncertainty in the gas-phase efficiency introduces perhaps a 5-percent uncertainty in the theoretical torque because the liquid/gas mixture ratio is only 2.6 .

The measured turbine efficiency of 0.52 is the highest efficiency achieved with a two-phase turbine to date.

H. LLL Steam-and-Water Turbine Data

A two-phase turbine was tested by Lawrence Livermore Laboratory with a water-and-steam mixture at the nozzle conditions of Table 3 . The results are reported in Refs. 13 and 14.

The measured turbine efficiency $n_{t}$ of the LLL turbine is plotted in Fig. 30 of Ref. 13. Blade torque is recovered from those measurements as follows: The $n_{t}$ values are multiplied by the isentropic jet power $P_{i}=$ $145.1 \mathrm{~kW}$ (Table 3); the resulting rotor power values $P_{\mathbf{r}}$ are divided by the rotor speed $w$ at each data point to recover the rotor torque values $L_{r}$; the experimental windage torque $\mathrm{L}_{w}$ at each data point is then calculated from the measured moment coefficients given in Fig. 29 of Ref. 13; adding $L_{r}$ to $\mathrm{L}_{w}$ gives the measured blade torque $\mathrm{L}_{b}$; multiplying $\mathrm{L}_{b}$ by rotor speed $w$ gives the measured blade power $P_{b^{*}}$

The windage torque in the LLL tests was very large - 30 percent of the blade torque and six times the torque calculated from the Mann and Marston correlations for a closely fitting housing. Because it cannot be expected that the windage torque measured in motoring tests is exactly the same as the torque that should be added to rotor torque to obtain blade torque, there is an uncertainty of perbaps 5 to 10 percent in the recovered blade torque values for the LLL turbine.

The theoretical blade torque of the LLL turbine is calculated using a gas torque factor $\eta_{g}$ of 0.8 , which introduces an uncertainty of several percent since the steam flow is 33 percent of the total. An even larger uncertainty is introduced by using the theoretical nozzle velocities from Table 3 as inputs to the rotor program since reliable nozzle measurements were not available. 
Figure 26 compares the theoretical and experimental blade torques of the LLL turbine. The theoretical torque curve ends at $1700 \mathrm{rpm}$, which is the speed at which liquid theoretically starts striking the backs of the blades. The torque results are similar to those obtained with the JPL water-andnitrogen turbine, with the measured blade torques 10 to 20 percent below theoretical.

Figure 27 compares the theoretical and experimental blade efficiencies. The highest measured efficiency is 0.47 at $1815 \mathrm{rpm}, 10$ percent below theoretical. With a slightly lower blade angle to avoid impingement on the back, the rotor program predicts that the blade efficiency would reach 0.62 at 3200 rpm.

Table 6 compares the theoretical and experimental performance in more detail at the highest test speed for which the water theoretically cleared the backs of the blades, $1575 \mathrm{rpm}$. This was also the speed at which the measured turbine efficiency $n_{t}$ reached its maximum value of 0.233 ; because of the large windage torque, the efficiency decreased again at higher speeds.

A significant theoretical result shown in Table 6 is that the relative velocity of the liquid leaving the blades is only $17 \mathrm{~m} / \mathrm{s}, 5$ percent of the relative inlet velocity. This means that the torque could be calculated simply by assuming that the liquid stops on the blades and is thrown off at rotor speed. This approximation reduces the theoretical torque of the liquid by only 4 percent. The large velocity loss of the liquid is a consequence of the very high gas/liquid area ratio $R_{a}=3300$ (Table 3 ) which forces the liquid to spread over a large area in a very thin film. If the relative liquid velocity on the blade stayed at half the impinging velocity, the liquid film thickness would be only $22 \mu \mathrm{m}$.

\section{Staging Method}

Higher turbine efficiencies can be obtained by using two or more rotor stages. The approach is to reduce the velocity difference between the liquid and the blades and thereby reduce the energy dissipation due to friction. 


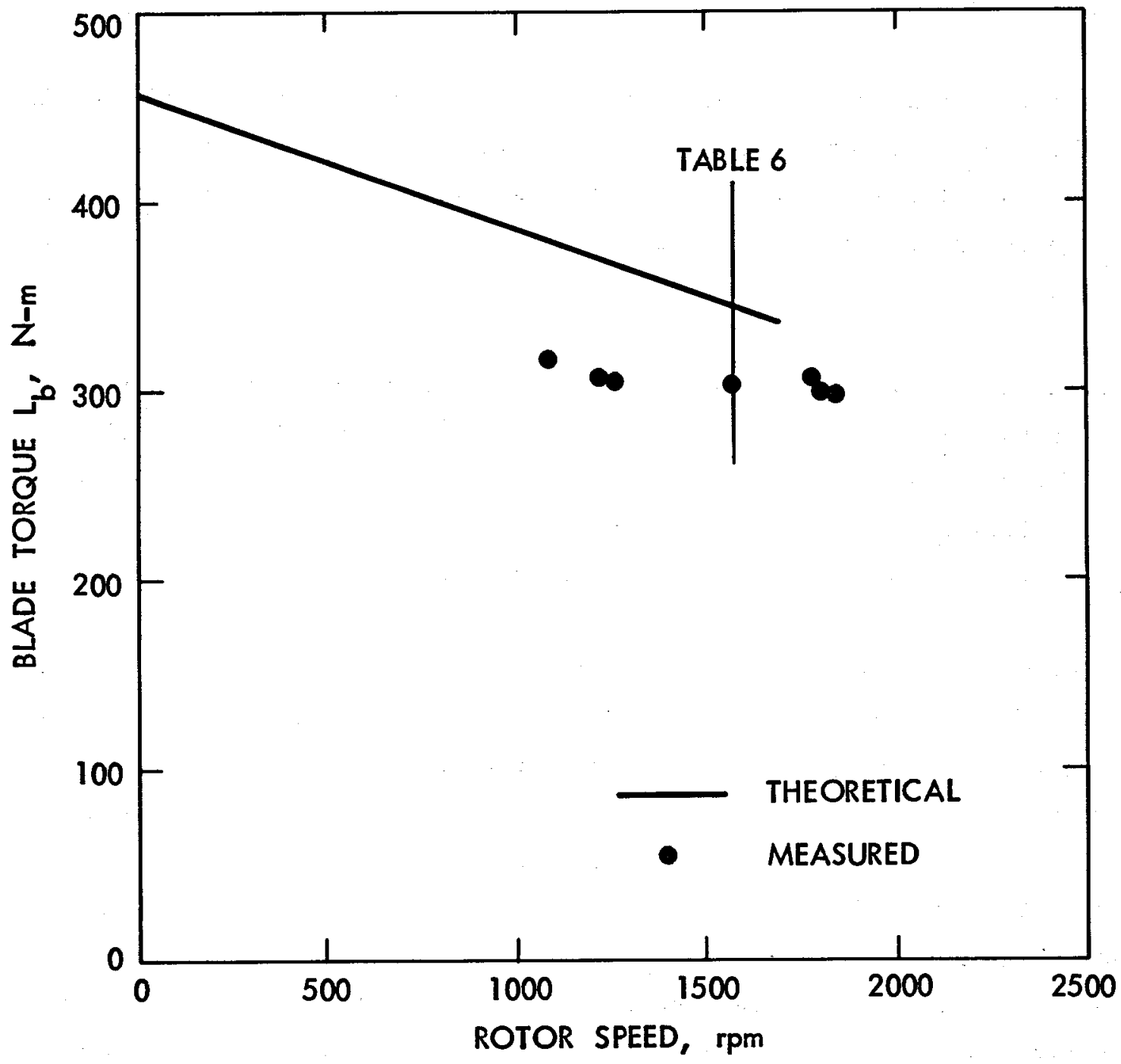

Fig. 26. Comparison of theoretical and experimental torques of LLL steam-and-water turbine 


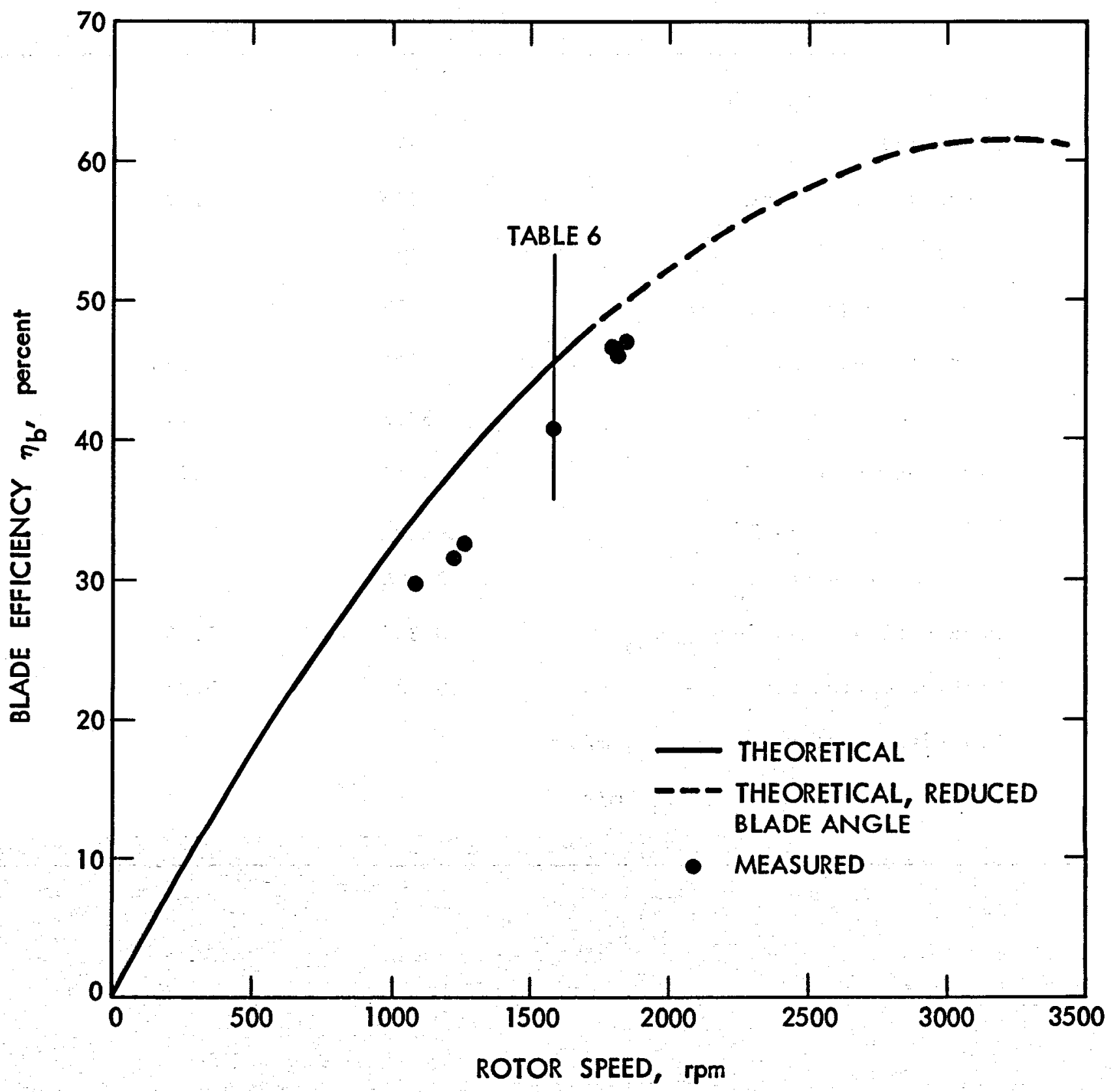

Fig. 27. Comparison of theoretical and experimental efficiencies of LLL steam-and-water turbine 
Table 6. Comparison of theoretical and experimental performance of LLL steam-and-water turbine (Table 3 nozzle conditions)

\begin{tabular}{|c|c|c|}
\hline \multirow[b]{2}{*}{ Item } & \multicolumn{2}{|c|}{ Value } \\
\hline & Measured & $\begin{array}{c}\text { Rotor } \\
\text { program }\end{array}$ \\
\hline Nozzle angle, $A_{n}$, deg & 20 & 20 \\
\hline Rotor radius, $R_{b}$, mm & 973 & 973 \\
\hline Rotor speed, $\mathrm{N}, \mathbf{r} \mathrm{pm}$ & 1575 & 1575 \\
\hline Rotor torque, $\mathrm{I}_{\mathbf{r}}, \mathrm{N}-\mathrm{m}$ & 205 & 329 \\
\hline Windage torque, $\mathrm{L}_{\mathrm{w}}, \mathrm{N}-\mathrm{m}$ & 99 & 17 \\
\hline Blade torque, $\mathrm{L}_{b}, \mathrm{~N}-\mathrm{m}$ & 304 & 346 \\
\hline Rotor power, $\mathrm{P}_{\mathrm{r}}, \mathrm{kW}$ & 33.8 & 54.3 \\
\hline Blade power, $P_{b}, k W$ & 50.1 & 57.1 \\
\hline Rotor efficiency, ${ }^{n} r$ & 0.269 & 0.433 \\
\hline Blade efficiency, $n_{b}$ & 0.399 & 0.455 \\
\hline Nozzle-blade efficiency, $n_{n b}$ & 0.345 & 0.394 \\
\hline Turbine efficiency, $n_{t}$ & 0.233 & 0.374 \\
\hline Relative inlet velocity, $v_{1}, \mathrm{~m} / \mathrm{s}$ & & 362 \\
\hline Relative exit velocity, $v_{3}, \mathrm{~m} / \mathrm{s}$ & & 17 \\
\hline
\end{tabular}


Figure 28 illustrates the principle. The upper diagram shows a singlestage turbine blade in which the friction loss is so large that the flow is brought to a complete halt relative to the blade. The flow rate is unity, the jet velocity is 3 , in arbitrary units, and the blade is traveling at the peakefficiency speed of 1.5 , in the same units. The flow is slowed from 3 to 1.5 , exerting a force of 1.5. The blade power, equal to force times velocity, is 2.25. The jet power is $3^{2} / 2$ or 4.5 . Thus, the blade efficiency is 0.5 .

In the lower diagram, two stages are arranged in series so that the flow leaving the first stage enters the second. The flow is still brought to a halt relative to the blades in each stage. The first stage has a blade speed of 2. The flow is slowed from 3 to 2 in the first stage, exerting a force of 1 and providing a power of 2 . The first-stage exit flow enters the second stage at the velocity of 2 and is slowed to 1 , exerting a force of 1 and providing a power of 1 . The total power of the two stages is 3 , giving an efficiency of 0.66 .

With $N$ stages, the efficiency is $N /(N+1)$. Thus, even with large friction and complete velocity loss in each stage, the efficiency can, in principle, approach unity with a large number of stages.

This same principle is used in drag-disc, or Tesla turbines, where the flow spirals inward between parallel discs, slowing due to the friction of the discs but always moving slightly faster than the disc speed. The efficiency can approach unity if the velocity difference between the fluid and the discs can be kept small throughout the inward spiral path.

\section{J. First-stage Rotor Data}

To investigate staging experimentally, a second rotor was built, designated "Rotor 2," for use as the first stage with Rotor 1 as the second stage. Figure 29 shows the blade shape of Rotor 2. The blade angle is much shallower than in Rotor 1 , because Rotor 2 runs at high speed, and the flow enters at a shallow angle. Before the final curved contour was machined into the blades, the rotor was tested with the flat blade shape indicated by the dashed line on the upper blade in Fig. 29. 
(a)

$$
\text { JET POWER }=\frac{1}{2} 3^{2}=4.5 \square \text { JET SPEED }=3
$$

$$
\begin{aligned}
& \text { RELATIVE SPEED OUT }=0 \\
& \text { ABSOLUTE SPEED OUT }=1.5 \\
& \text { PORCE }=3-1.5=1.5 \\
& \text { POWER }=(1.5)(1.5)=2.25 \\
& \text { EFFICIENCY }=\frac{2.25}{4.5}=\frac{1}{2}
\end{aligned}
$$

(b)

$$
\begin{aligned}
& \text { JET POWER }=\frac{1}{2} 3^{2}=4.5 \mid \text { JET SPEED }=3 \\
& \text { ABSOLUTE SPEED OUT }=2 \\
& \text { FIRST-STAGE FORCE }=3-2=1 \\
& \text { FIRST-STAGE POWER }=(1)(2)=2 \\
& \text { RELATIVE SPEED OUT }=0 \uparrow \text { RELATIVE SPEED IN }=1 \\
& \text { SECOND STAGE FORCE }=2-1=1 \\
& \text { SECOND-STAGE POWER }=(1)(1)=1 \\
& \text { TOTAL POWER }=2+1=3 \\
& \text { EFFICIENCY }=\frac{3}{4.5}=\frac{2}{3}
\end{aligned}
$$

Fig. 28. Staging method: (a) single-stage turbine; (b) two-stage turbine 


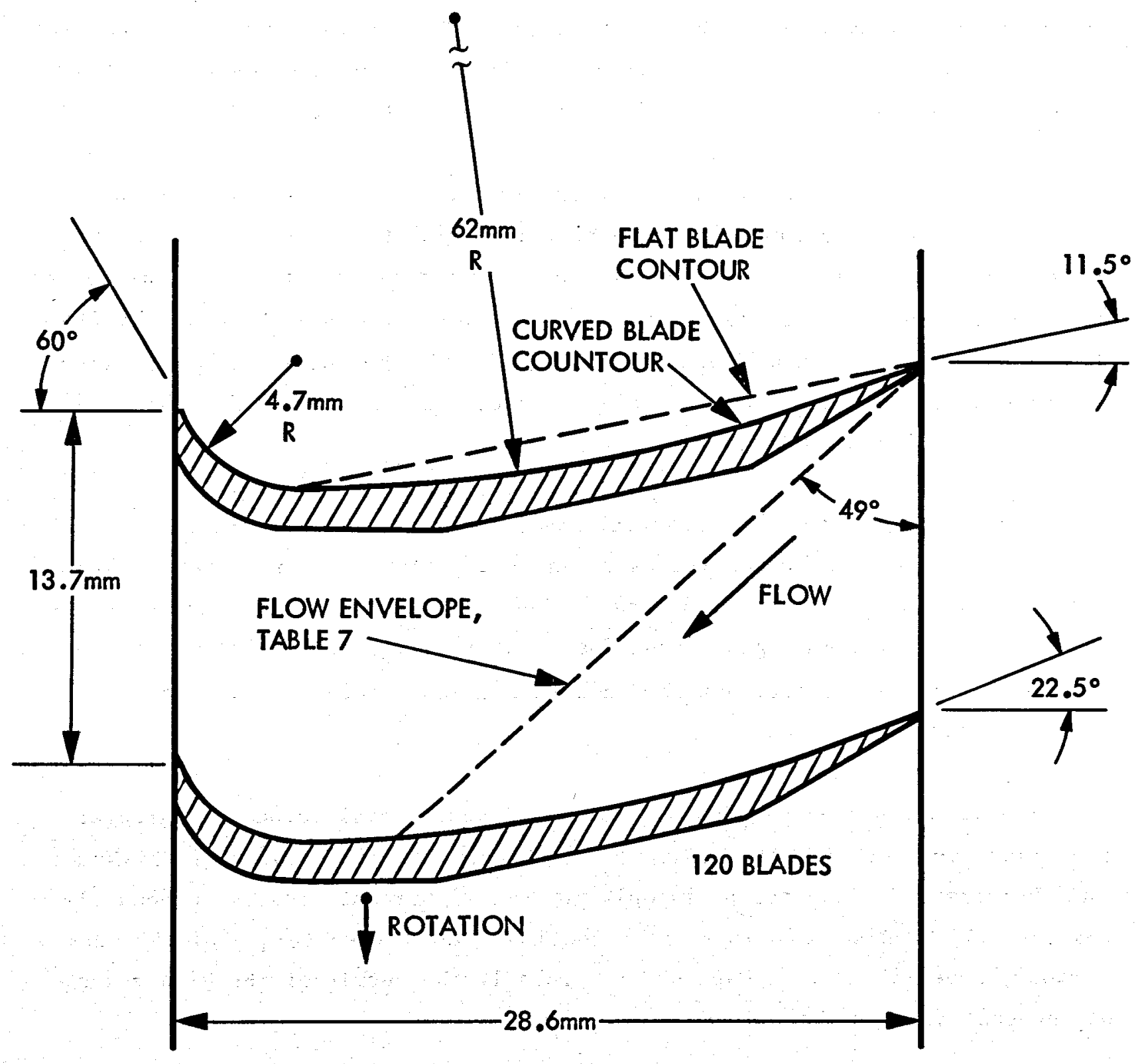

Fig. 29. Rotor 2 blade shape 
Figure 30 is a 1- $\mu \mathrm{s}$ flash photograph of the water-and-nitrogen flow leaving Rotor 2 at $2200 \mathrm{rpm}$. The rotor has the flat blade contour in this photograph. The liquid leaves as thin sheets, as with Rotor 1. The downward angle of the exit flow is large because of the high rotor speed. Figure 31 shows the same flow from the axial direction. The liquid can be seen reaching the blade exit on the near side after the blade has traveled about four blade spacings from the initial point of interception of the nozzle flow.

The improvement in the flow pattern after the flat blades were remachined to the curved contour can be seen in Fig. 32. With the flat blades, the flow leaves at angles ranging from $57 \mathrm{deg}$ above horizontal at the top of the jet to only $30 \mathrm{deg}$ above horizontal at the bottom. With the curved blades, the flow leaves at angles between 60 and $45 \mathrm{deg}$. Evidently the curved blades provide needed centrifugal force during impingement to keep the liquid from bouncing back from the blade surface.

A comparison between theoretical and experimental blade torques is made in Fig. 33 at the nozzle conditions of Table 1. Above $2300 \mathrm{rpm}$, the liquid starts impinging on the backs of the blades, and the theoretical curve ends at that point. The assumed gas torque factor $\eta_{g}$ is again 0.8 , which may be optimistic for this rotor, but the uncertainty has little effect because of the small gas flow.

The difference between theoretical and experimental torques is greater than that for Rotor 1. At $2200 \mathrm{rpm}$, the theoretical blade torque is $54 \mathrm{~N}-\mathrm{m}$ and the measured blade torque is only $40 \mathrm{~N}-\mathrm{m}, 25$ percent less. The possible reasons will be discussed in a later section. The bigher torque of the curved contour, especially at low speeds, is probably the result of the higher angle of the exit flow as shown in Fig. 32 .

K. Two-Stage Turbine Data

The two rotors were assembled as a two-stage turbine. As shown in Fig. 34, the first stage (Rotor 2 ) is connected to the variable-speed electric 


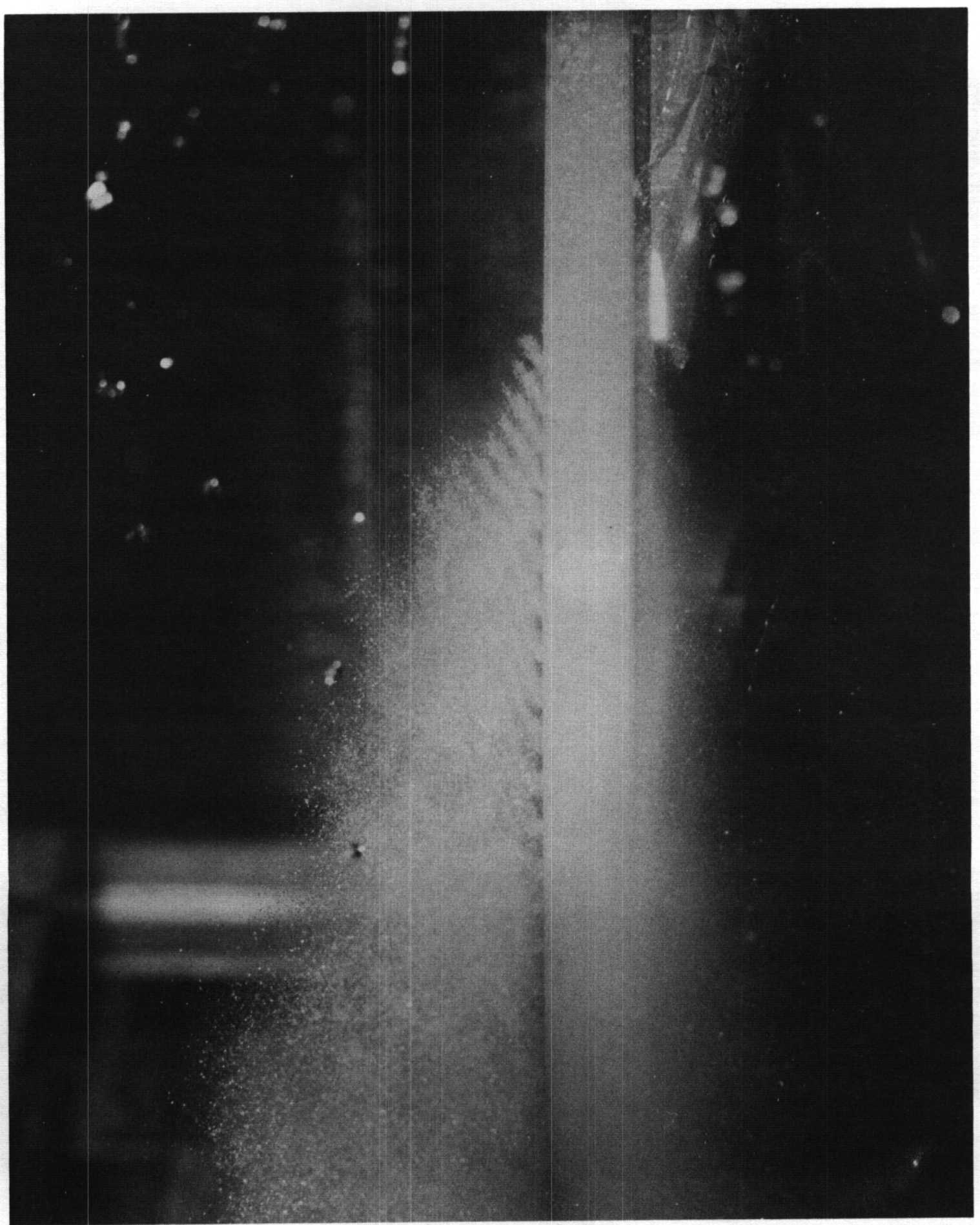

Fig. 30. Exit flow from Rotor 2 


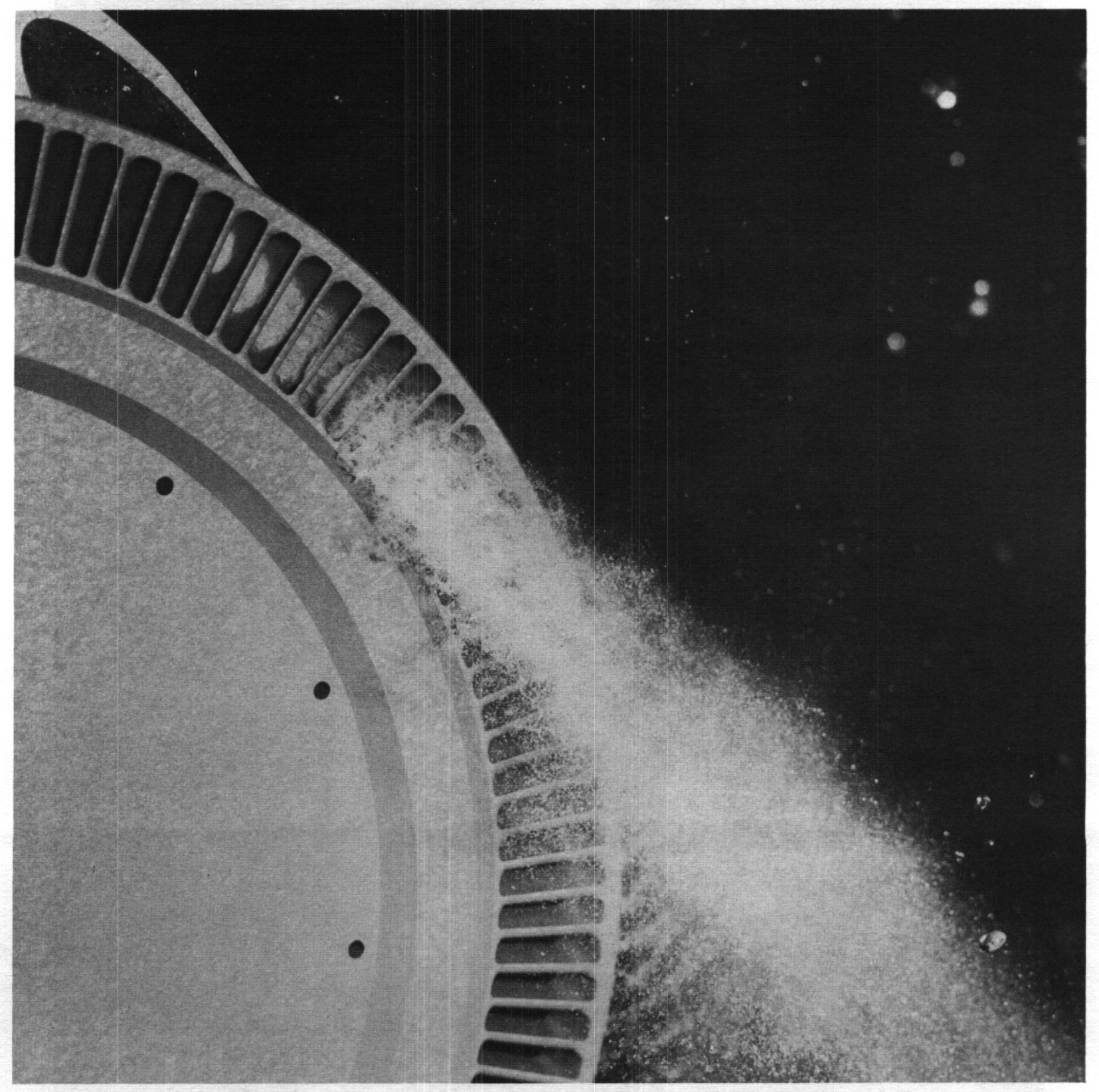

Fig. 31. Axial view of exit flow from Rotor 2 

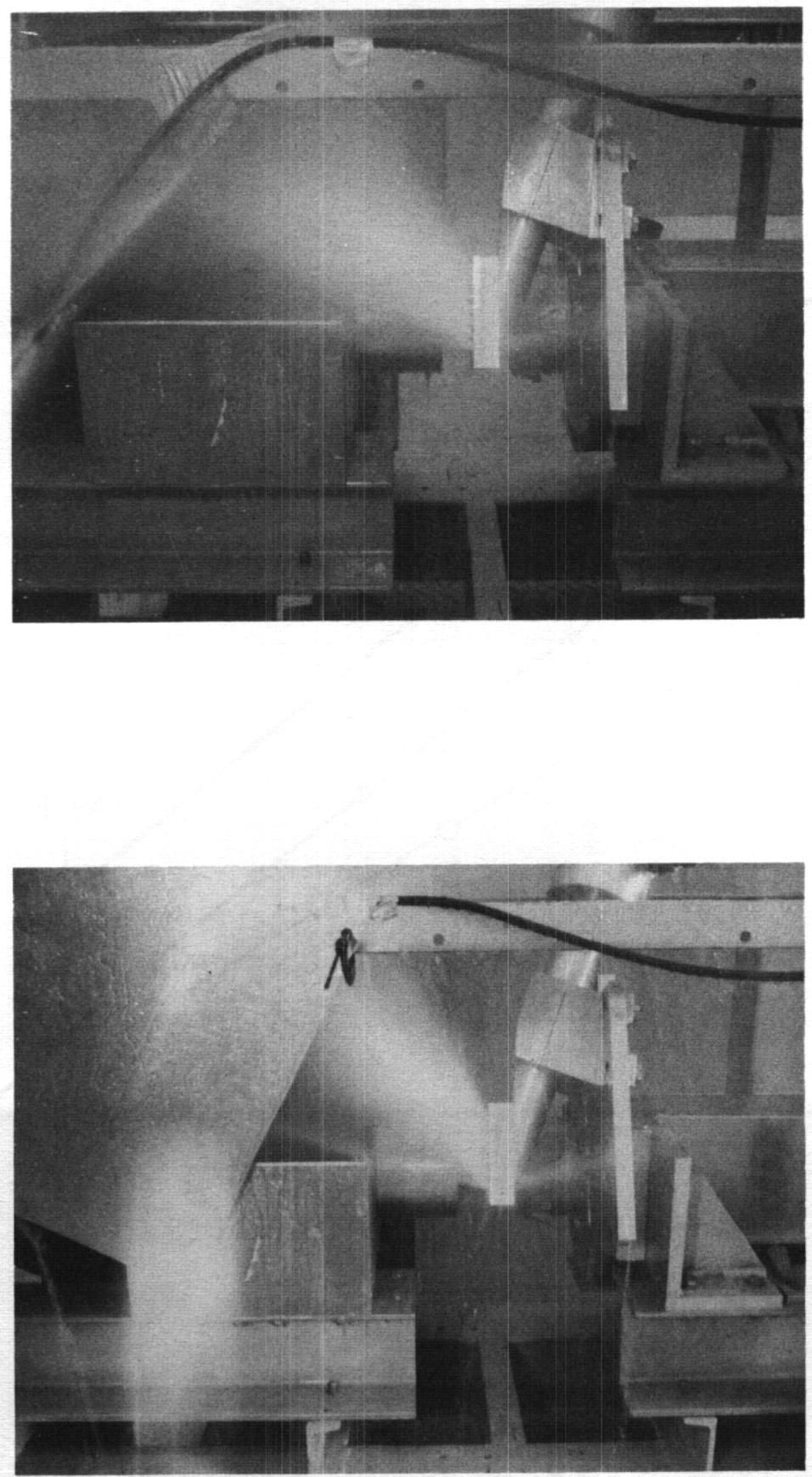

Fig. 32. Comparison of exit flow from flat and curved blades (zero blade speed): (a) flat contour; (b) curved contour 


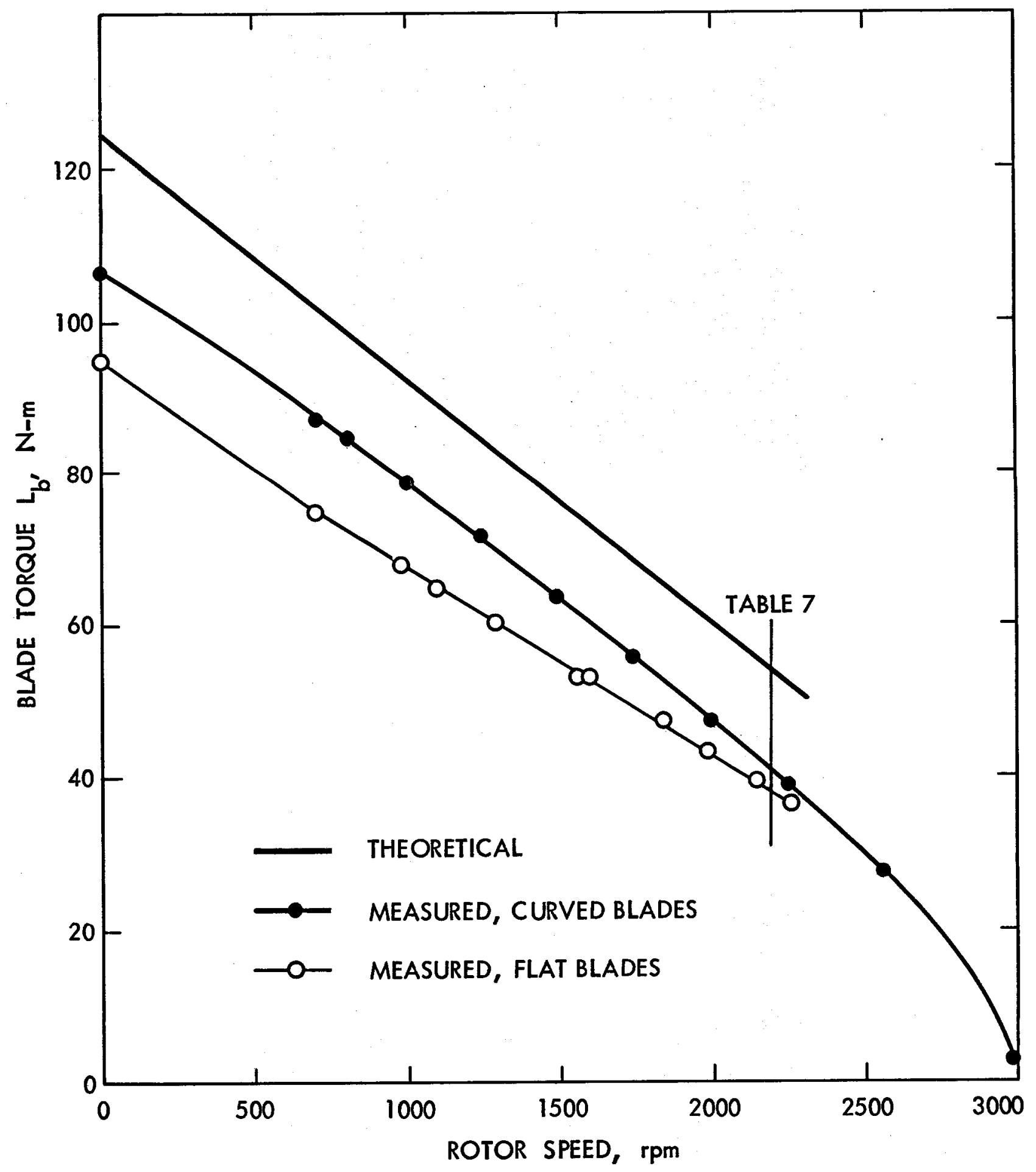

Fig. 33. Comparison of theoretical and experimental blade torques of Rotor 2 


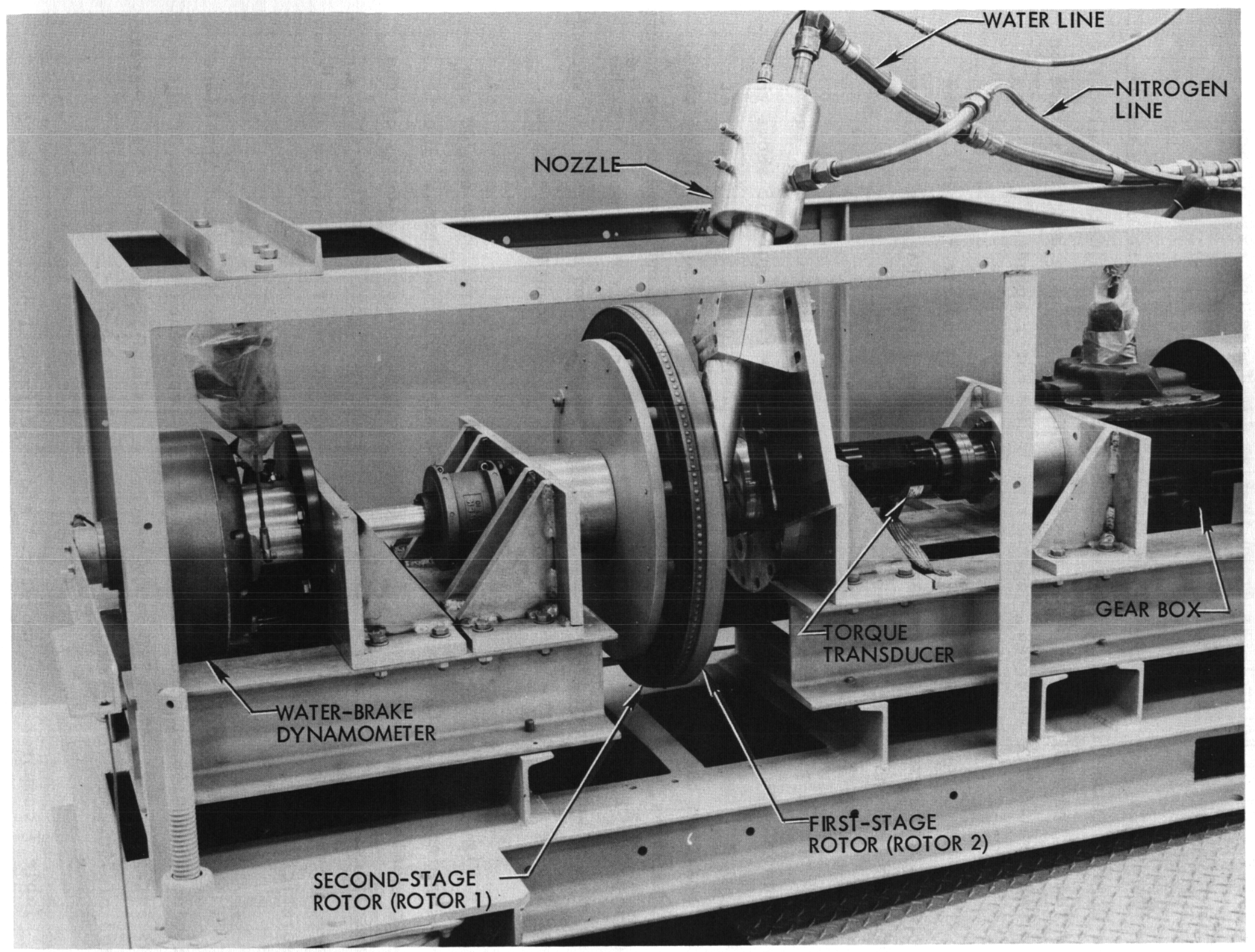

Fig. 34. Two-stage turbine 
drive. The second stage (Rotor 1 ) is connected to a water-brake dynamometer. The right side of Rotor 1, as drawn in Fig. 17, faces the exit of Rotor 2. There is a gap of $0.5 \mathrm{~mm}$ between the rotors.

To make a test run, the first-stage rotor is set at the desired speed. The flow is turned on and the dynamometer water flow is adjusted to give the desired second-stage speed. The torque of the first stage and the torque on the dynamometer are recorded, together with the rotor speeds.

Windage torque is measured separately with the nozzle flow off. The windage torque exerted on the second stage by the first stage is sufficient to rotate the second stage for these measurements.

The nozzle position can be adjusted radially and tangentially, and there is an optimum position for maximum total shaft power. Figure 35 shows the effect of moving the nozzle. The best radial position is $R_{b}=261 \mathrm{~mm}$, at which position the nozzle exit ellipse is tangent to the outer wall of the blade passages, as shown in the sketch. The maximum second-stage torque occurs with a nozzle displacement $8 \mathrm{~mm}$ to the right of center $(x=-8 \mathrm{~mm})$, but the first-stage torque is low. The highest-power combination of first- and secondstage torque is with the nozzle located $25 \mathrm{~mm}$ left of center $(x=25 \mathrm{~mm})$.

In Fig. 36, the theoretical second-stage torque curve ends at $700 \mathrm{rpm}$ where impingement on the backs of the second-stage blades begins. The theoretical torque is calculated using the theoretical exit velocity of the first-stage rotor. Because the measured torque is higher than theoretical, the absolute exit velocity from the first-stage rotor is evidently bigher than theoretical.

Figure 37 presents the efficiency of the two-stage turbine. The blade efficiency of 0.56 at zero second-stage speed represents the output of the first-stage rotor. The efficiency reaches a maximum of 0.70 at a second-stage speed of $750 \mathrm{rpm}$. The peak theoretical efficiency is 0.85 .

Table 7 compares the theoretical and experimental performance at a second-stage rotor speed of $678 \mathrm{rpm}$. The experimental windage torques are several times higher than theoretical but have the right sign (positive, or 


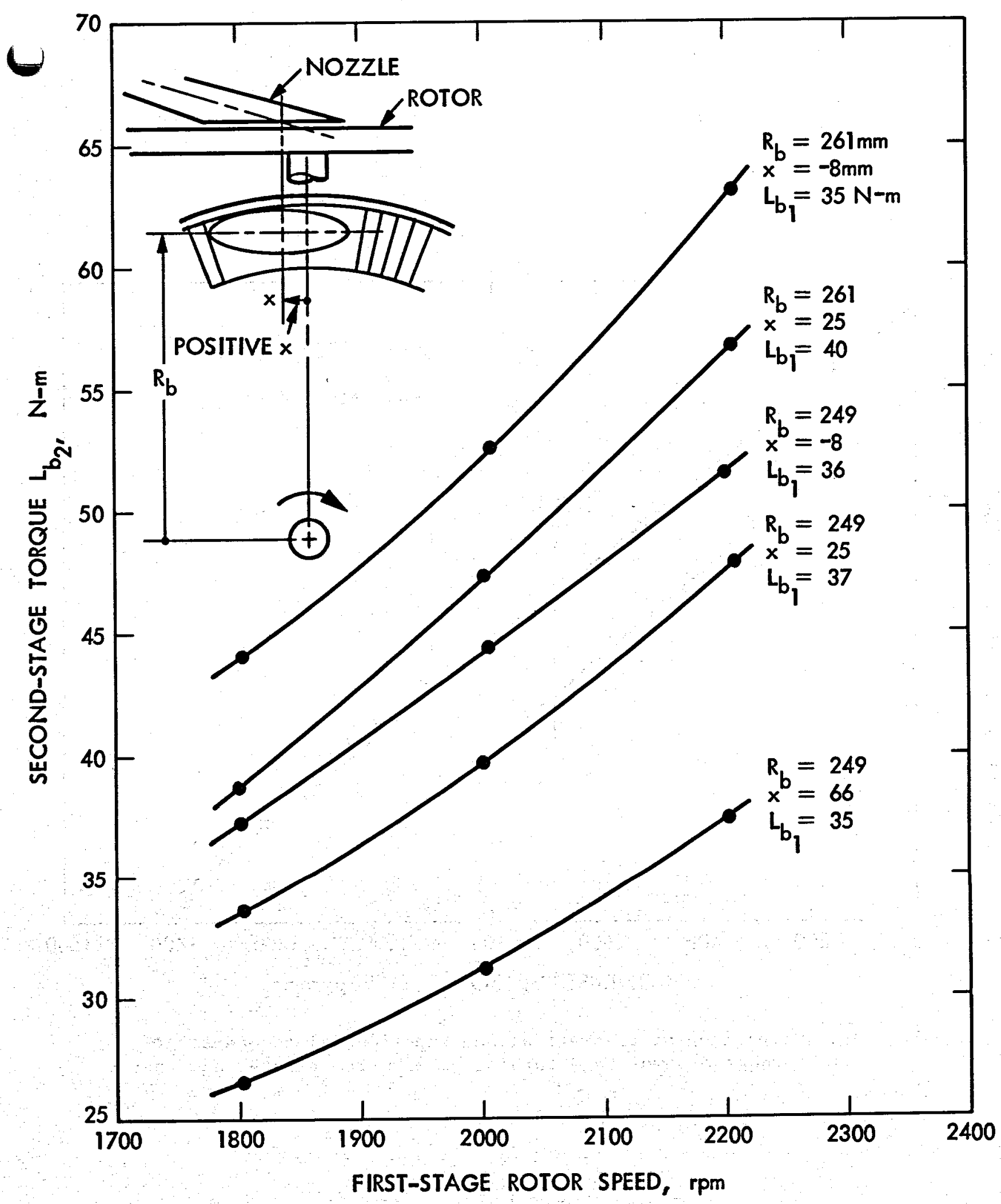

Fig. 35. Effect of nozzle position on second-stage zero-speed torque at 2200-rpm first-stage speed 


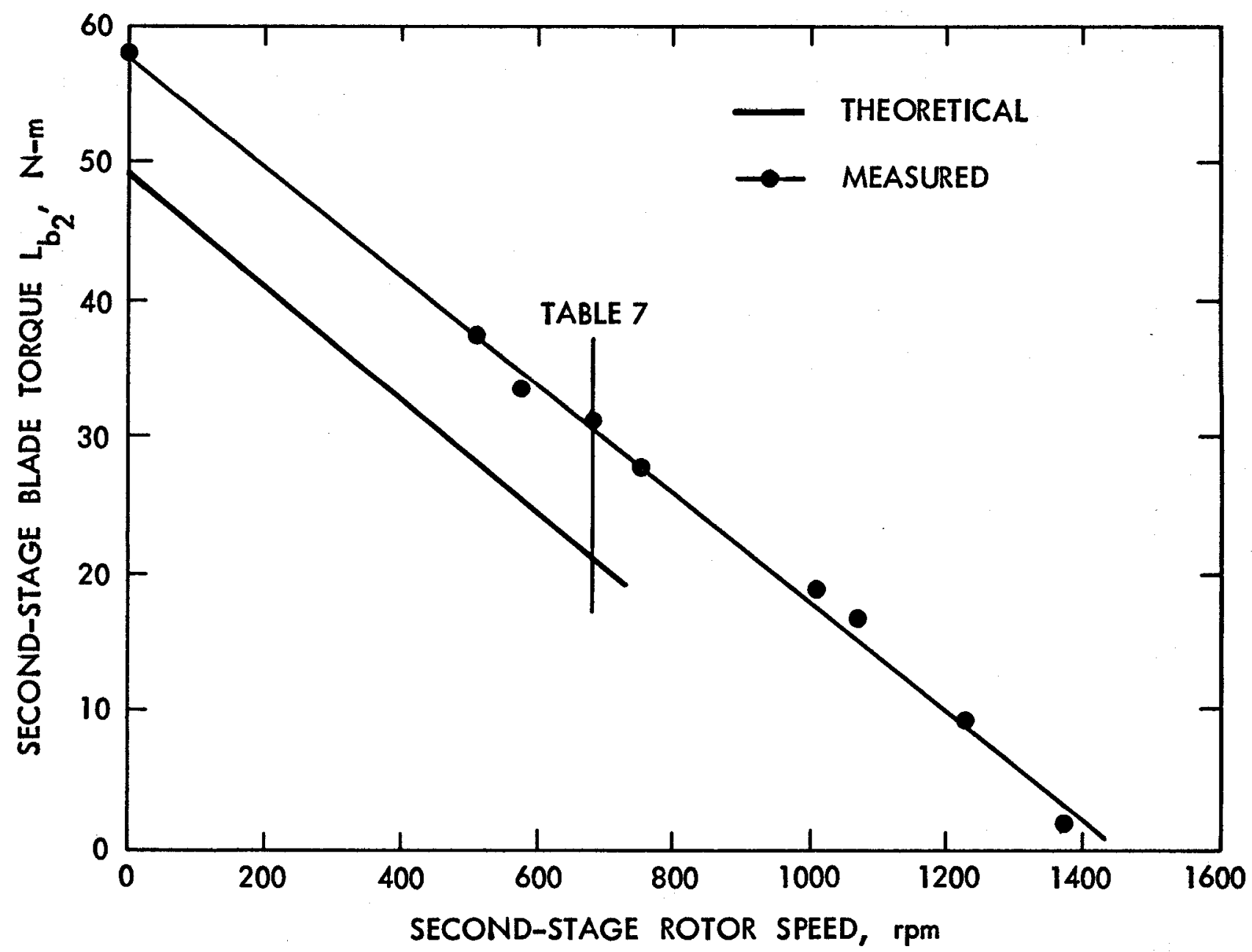

Fig. 36. Comparison of theoretical and experimental second-stage torques of two-stage turbine at 2200-rpm first-stage speed 


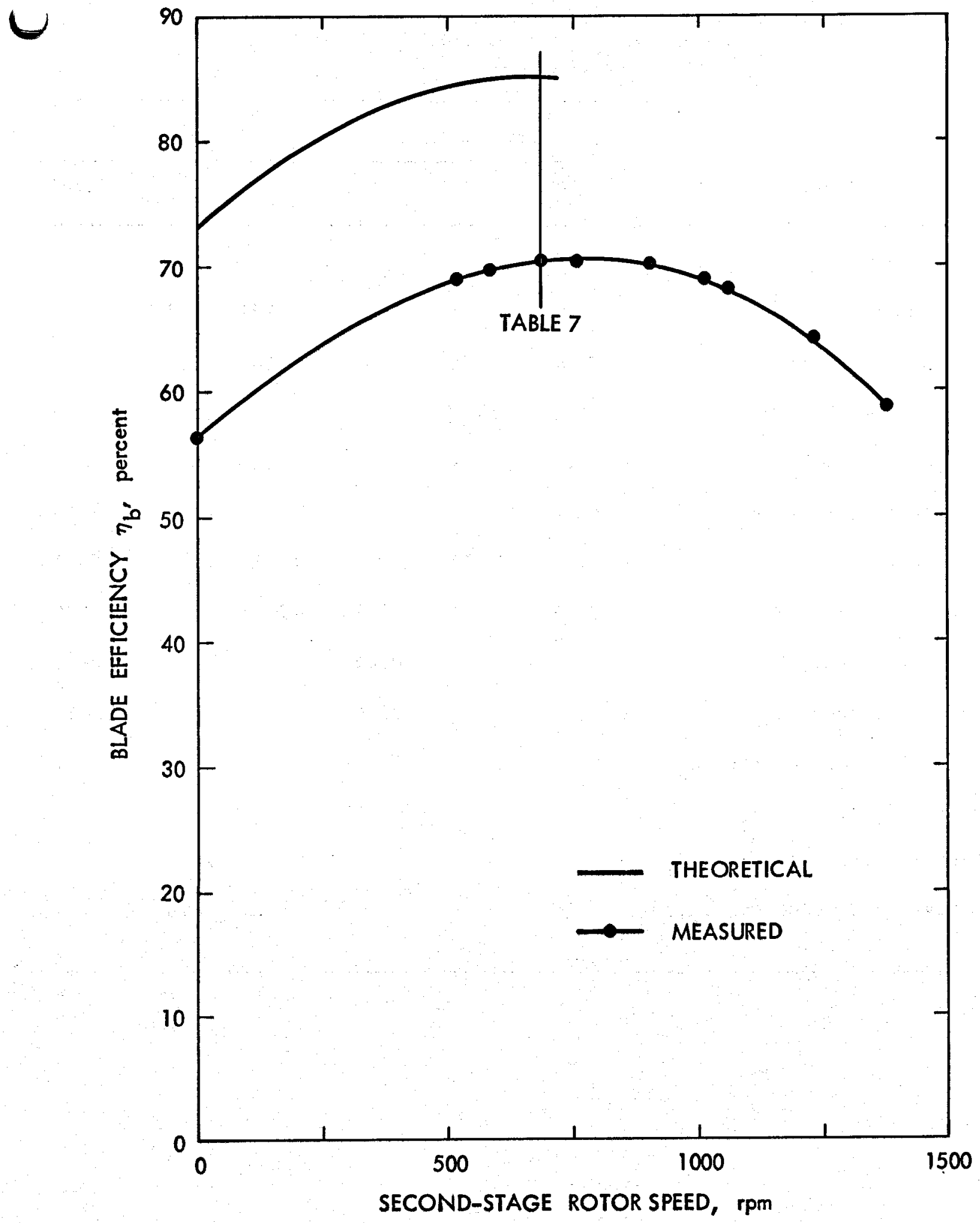

Fig. 37. Comparison of theoretical and experimental efficiencies of two-stage turbine at 2200-rpm first-stage speed 
Table 7. Comparison of theoretical and experimental two-stage turbine performance (Table 1 nozzle conditions)

\begin{tabular}{|c|c|c|c|c|c|c|}
\hline \multirow[b]{2}{*}{ Item } & \multicolumn{3}{|c|}{ Experimental } & \multicolumn{3}{|c|}{ Theoretical } \\
\hline & $\begin{array}{l}\text { First } \\
\text { stage }\end{array}$ & $\begin{array}{c}\text { Second } \\
\text { stage }\end{array}$ & Total & $\begin{array}{l}\text { First } \\
\text { stage }\end{array}$ & $\begin{array}{c}\text { Second } \\
\text { stage }\end{array}$ & Total \\
\hline Nozzle angle, $A_{n}$, deg & 20 & & & 20 & & \\
\hline Rotor radius, $R_{b}$, mm & 261 & 261 & & 261 & 261 & \\
\hline Rotor speed, $N, r p m$ & 2200 & 678 & & 2200 & 678 & \\
\hline Rotor torque, $\mathrm{L}_{\mathbf{r}}, \mathrm{N}-\mathrm{m}$ & 35.5 & 33.6 & & 53.0 & 21.4 & \\
\hline Windage torque, $\mathrm{L}_{w}, \mathrm{~N}-\mathrm{m}$ & 4.5 & -2.4 & & 0.5 & -0.2 & \\
\hline B lade torque, $\mathrm{L}_{b}, \mathrm{~N}-\mathrm{m}$ & 40.0 & 31.2 & & 53.5 & 21.2 & \\
\hline Rotor power, $\mathrm{P}_{\mathbf{r}}, \mathrm{kW}$ & 8.18 & 2.39 & 10.57 & 12.21 & 1.52 & 13.73 \\
\hline B lade power, $\mathrm{P}_{\mathrm{b}}, \mathrm{kW}$ & 9.22 & 2.22 & 11.44 & 12.33 & 1.51 & 13.84 \\
\hline Rotor efficiency, $n_{r}$ & & & 0.648 & & & 0.841 \\
\hline B lade efficiency, $n_{b}$ & & & 0.701 & & & 0.848 \\
\hline Nozzle-blade efficiency, $n_{n b}$ & & & 0.549 & & & 0.664 \\
\hline Turbine efficiency, $n_{t}$ & & & 0.507 & & & 0.659 \\
\hline Relative inlet velocity, $v_{1}, \mathrm{~m} / \mathrm{s}$ & & & & 42.5 & 21.3 & \\
\hline Relative exit velocity, $v_{3}, \mathrm{~m} / \mathrm{s}$ & & & & 31.3 & 8.8 & \\
\hline
\end{tabular}


retarding, for the first stage and negative, or accelerating, for the second stage). The turbine efficiency is 0.51 experimentally and 0.66 theoretically. Although the measured turbine efficiency is not as high as that for the single-stage Refrigerant-22 turbine because of the lower nozzle efficiency, the blade and rotor efficiencies are the highest that have been achieved so far with a two-phase turbine.

\section{Divergence and Stagnation Losses}

An additional source of loss not included in the theoretical torques and efficiencies is the radial spreading of the flow leaving the blades. To see the spreading better, a single blade was tested in the apparatus shown in Fig. 38. Sheet-metal blades similar in shape to those of Rotor 2 (flat contour) were held in a frame. A scoop collected the flow leaving all but the last blade. The flow passing behind the last blade continued on undisturbed except where it hit the support frame.

Figure $38(b)$ shows the spreading of the liquid sheet leaving the test blade. The exit flow consisted of a central sheet of small divergence angle and an outer fan on each side having about a 45-deg divergence angle.

The effect of the spreading exit flow is to reduce the circumferential component of the exit velocity by the cosine of some average divergence angle. In the rotor program, the relative exit velocity is denoted $v_{3} \cdot A$ corrected exit velocity $V_{3}^{\prime}$ can be obtained by specifying a divergence angle A iv such that

$$
v_{3}^{\prime}=v_{3} \cos A_{d i v}
$$

The theoretical zero-speed torque of Rotor 1 in the single-stage tests (Fig. 24) can be brought down to the measured torque by using a divergence angle $\mathrm{A}_{\mathrm{div}}$ of $30 \mathrm{deg}$. For Rotor 2 (Fig. 33), a divergence angle of $30 \mathrm{deg}$ lowers the theoretical zero-speed torque from $124 \mathrm{~N}-\mathrm{m}$ to $119 \mathrm{~N}-\mathrm{m}$, whereas the measured zero-speed torque is only $108 \mathrm{~N}-\mathrm{m}$. However, as was seen from Fig. 32, the angle of discharge of the 1 iquid is less than the 60-deg exit angle of the blades. A line drawn through the estimated center of the exit flow in 
(a)

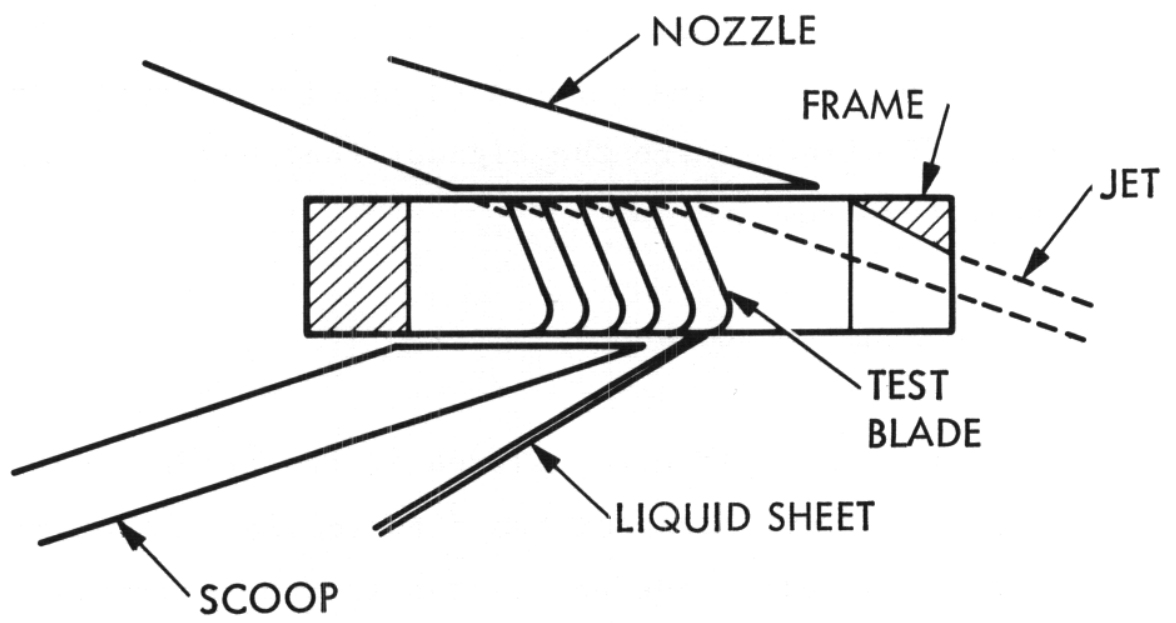

(b)

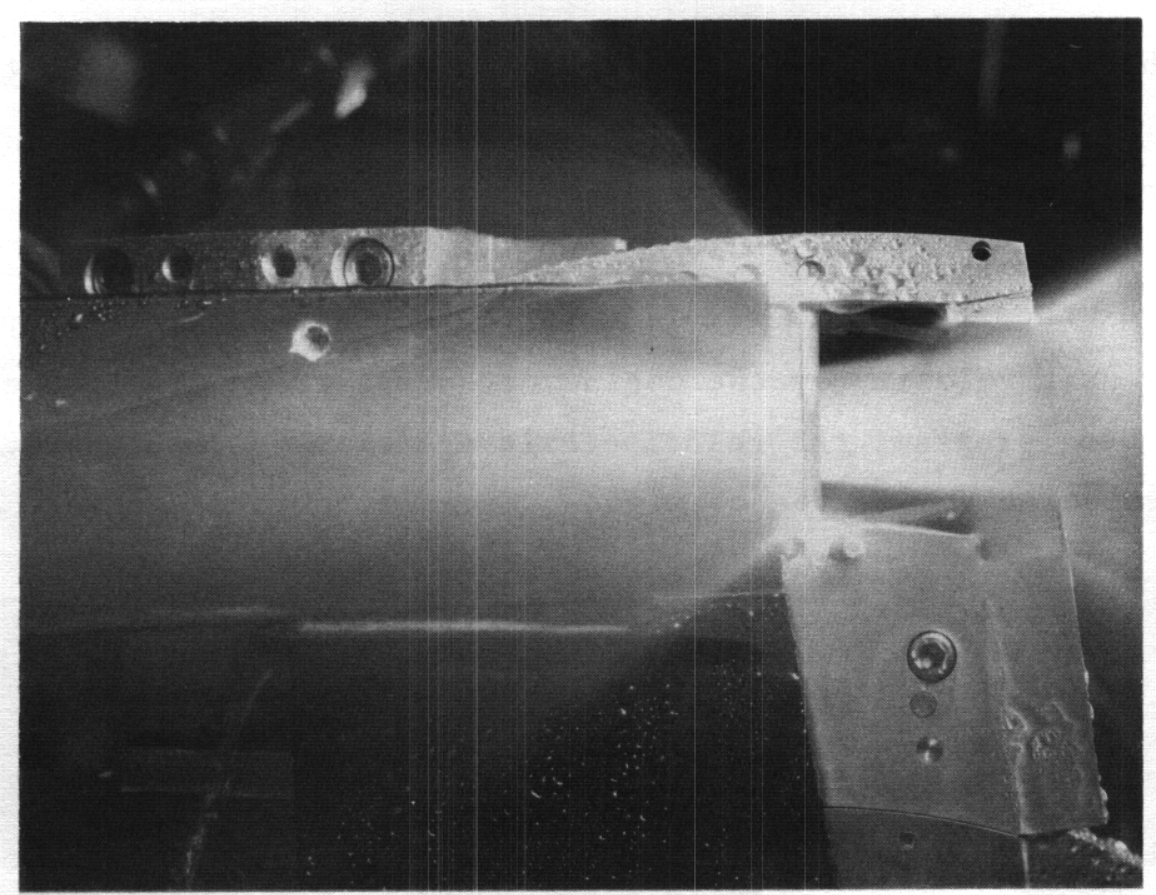

Fig. 38. Exit flow from a single blade: (a) apparatus; (b) flow test 
Fig. 32(b) has an angle of only $40 \mathrm{deg}$ above horizontal. If it is assumed that the liquid is leaving at $40 \mathrm{deg}$ instead of $60 \mathrm{deg}$ and is also spreading at an average divergence angle of $30 \mathrm{deg}$, then the theoretical zero-speed torque is reduced to $111 \mathrm{~N}-\mathrm{m}$, close to the measured value.

A second loss not included in the theory is the stagnation and trapping of a portion of the liquid in the rotor. Observing a rotor in operation, it can be seen that some liquid continues to leave the rotor long after the rotor has passed through the jet. This effect can be seen in Fig. 39, which is a 1-us flash photograph of the flow leaving Rotor 2 at $2250 \mathrm{rpm}$. Streamers of water leave the outer wall of each blade passage after the rotor passes the jet. These streamers persist for about $90 \mathrm{deg}$ of rotation.

Further details of the main flow and the delayed stagnated flow can be seen in Fig. 40. An arm with four blades machined in the shape of those in Rotor 2 ( $f 1 a t$ blade contour) was rotated through the jet at $2200 \mathrm{rpm}$ and photographed at seven successive positions. At the top position, the blades are just starting to enter the flow. In position 2, the liquid sheets are starting to emerge. In positions 3 and 4 , the behavior of the flow that passes straight through the rotor can be seen most clearly: liquid is scooped out of the jet, moved to the near side of the rotor, and released to continue on in its original direction at reduced speed.

In position 5 , it can be seen that some liquid has remained with the rotor. In positions 6 and 7 , this stagnated liquid continues to drain toward the outer walls of the blade passages and spin off, leaving the rotor at full rotor speed.

The amount of liquid leaving the rotor in the main jet was measured by placing a scoop over the exit jet leaving Rotor 2. The outline of the scoop is shown in Fig. 41 . The scoop collected $1.2 \mathrm{~kg} / \mathrm{s}$ of water when the nozzle water flow rate was $1.7 \mathrm{~kg} / \mathrm{s}$. The collected flow rate was constant for rotor speeds from $1250 \mathrm{rpm}$ to $2200 \mathrm{rpm}$. Thus, $0.5 \mathrm{~kg} / \mathrm{s}$ of water, or 30 percent of the flow, was missing from the main exit jet. Further measurements, obtained by moving the scoop, showed that, of this $0.5 \mathrm{~kg} / \mathrm{s}, 0.24 \mathrm{~kg} / \mathrm{s}$ was thrown off the rotor in the first $30 \mathrm{deg}$ of rotation beyond the jet, $0.07 \mathrm{~kg} / \mathrm{s}$ was 


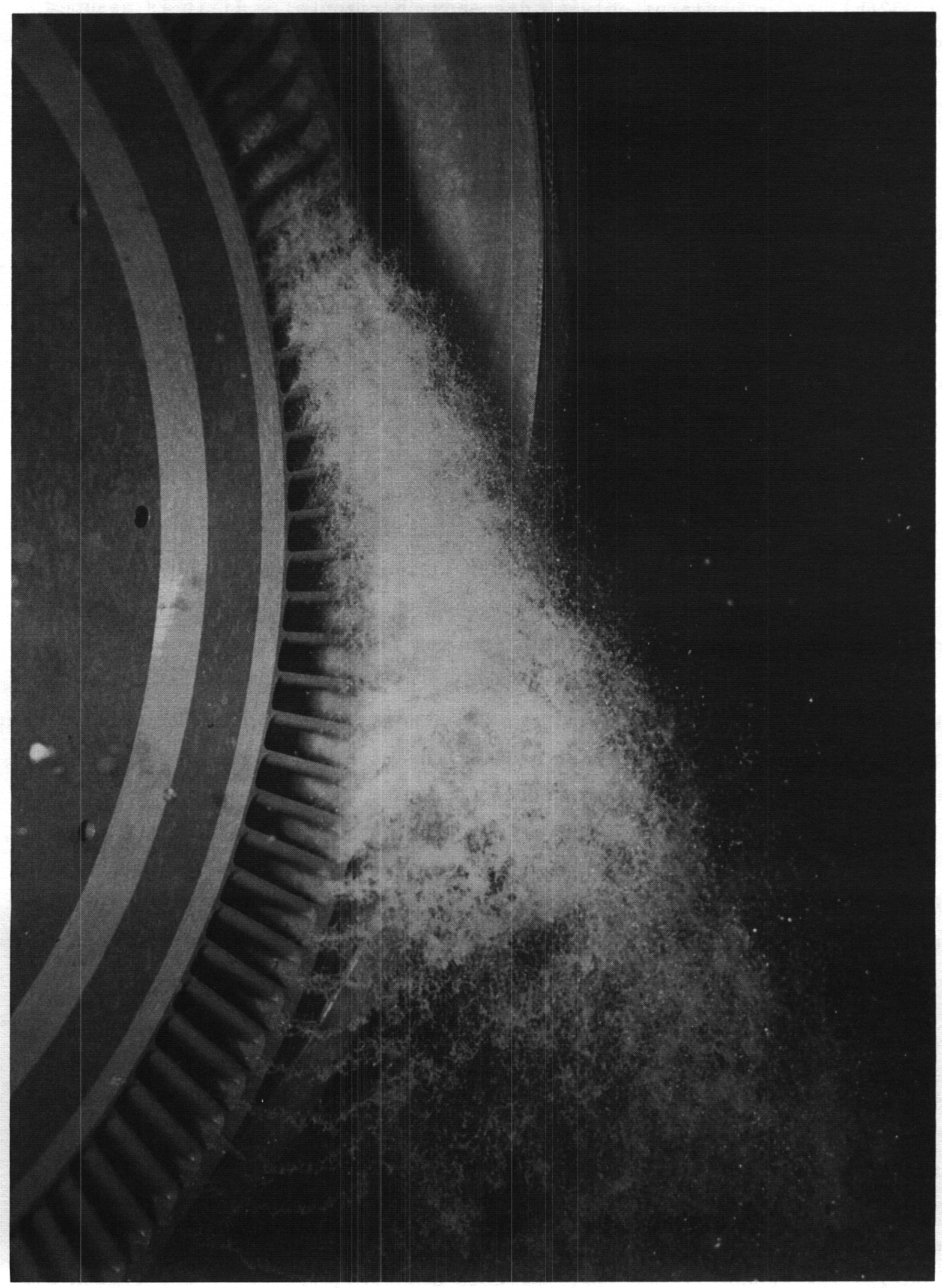

Fig. 39. Exit jet and delayed drainage flow from Rotor 2 


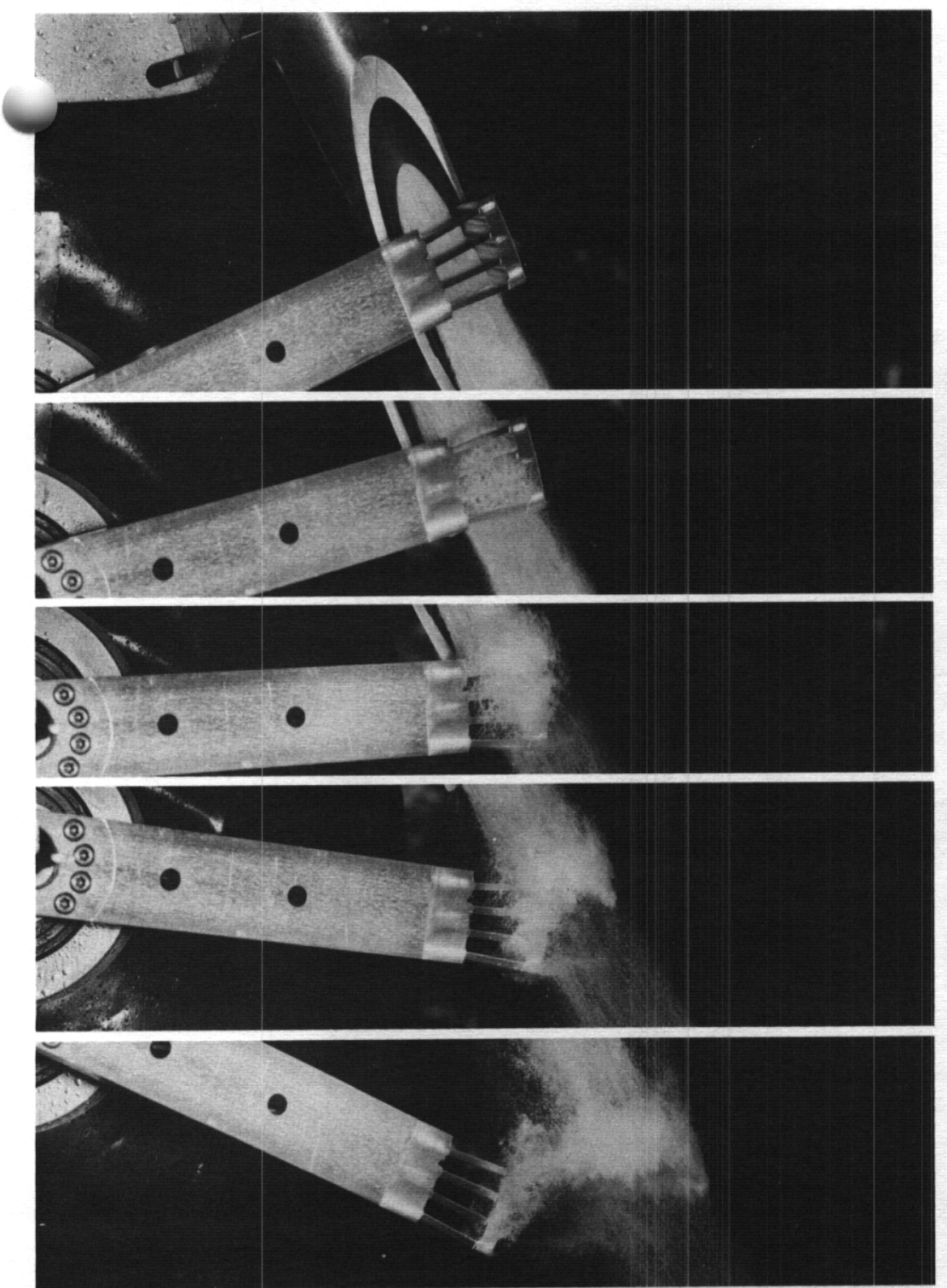

1 - BLADES ENTER JET.

2 - FLOW REACHES BLADE EXIT.

3 - MAIN FLOW LEAVES BLADES.

4- MAIN FLOW CLEARS BLADES

5 - MAIN FLOW CONTINUES IN DIRECTION OF JET. STAGNATED FLOW STARTS TO DRAIN FROM ROTOR

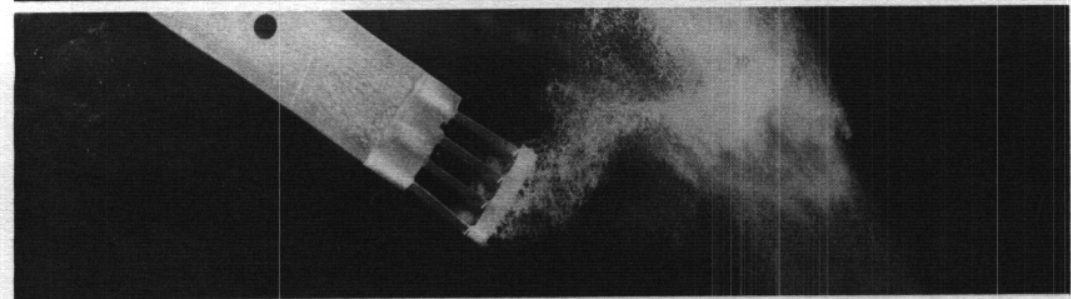

6 - STAGNATED FLOW IS THROWN OFF AT ROTOR SPEED

\section{7 - STAGNATED FLOW CONTINUES TO DRAIN FOR 90 DEG OF ROTATATION}

Fig. 40. Exit flow from bladed arm 


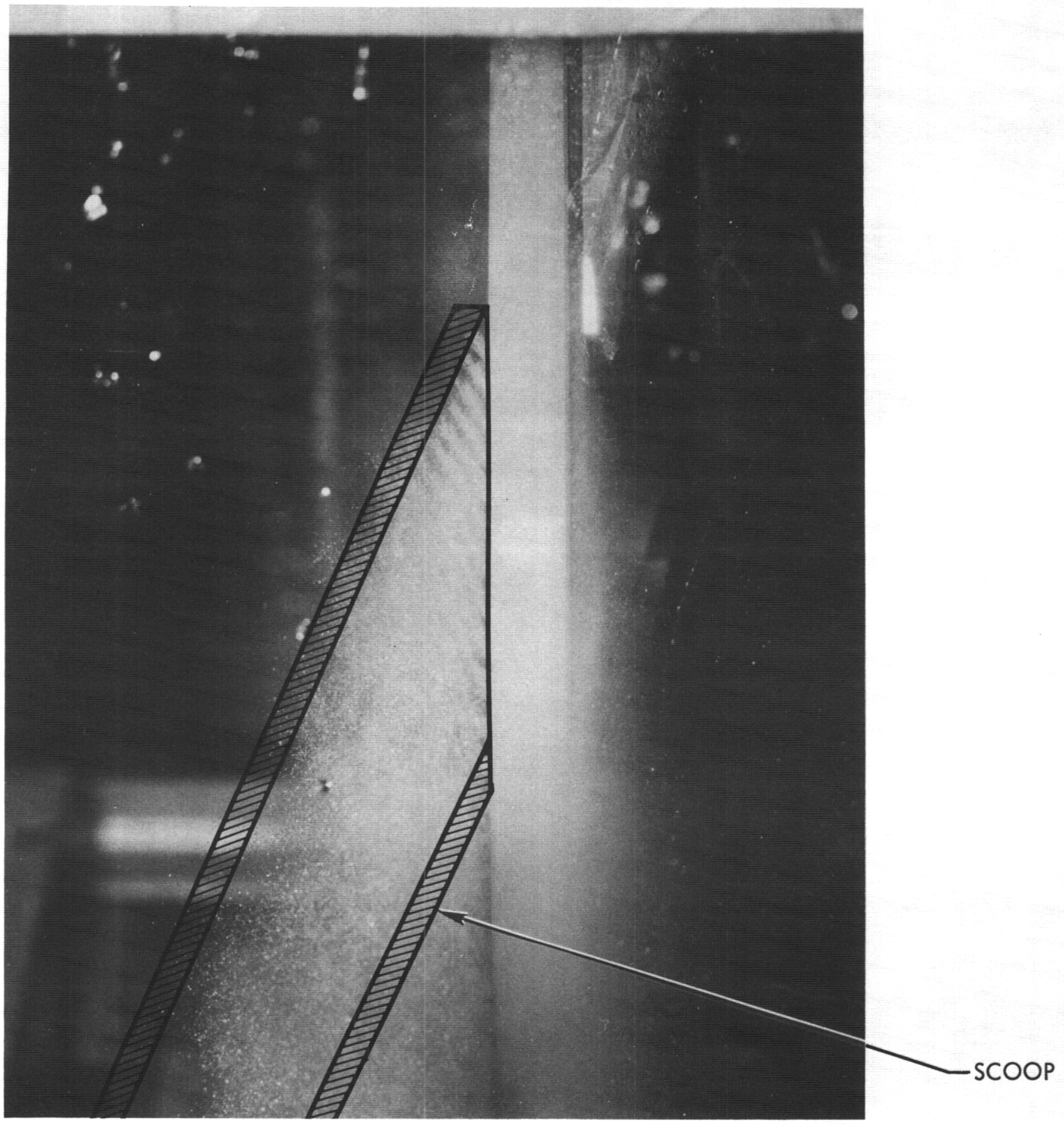

Fig. 41. Rotor 2 exit scoop for flow measurement 
thrown off in the next $90 \mathrm{deg}, 0.05 \mathrm{~kg} / \mathrm{s}$ was thrown off the rotor on the nozzle side near the nozzle, and $0.14 \mathrm{~kg} / \mathrm{s}$ was thrown off the rotor around the remaining circumference.

If, in addition to the exit divergence effect, 25 percent of the flow is considered to be stagnated in the rotor and thrown of $f$ at rotor speed, the theoretical torque of Rotor 2 at $2200 \mathrm{rpm}$ is decreased from $54 \mathrm{~N}-\mathrm{m}$ to $40 \mathrm{~N}-\mathrm{m}$, in agreement with the data. Thus, the flow stagnation effect, combined with the exit flow divergence effect, is sufficient to account for the difference between theoretical and experimental torques.

A major improvement in blade efficiency (from 0.70 to 0.85 for the two-stage water-and-nitrogen turbine) would be possible if the stagnation and divergence effects could be eliminated. This might be possible with more complex blade shapes. On the other hand, the undesired effects might reflect fundamental secondary-flow phenomena that cannot be avoided. Further study of these effects should be the next direction of research.

M. Separator Turbine Concept

The separator turbine (Refs. $3,6,7$ ) is an alternative to the multistage impulse turbine for overcoming the friction problem of two-phase flow. The problem, in essence, is that the large flow area required by the gas phase requires large blade areas that are subjected to the large shear of the liquid phase. The multistage impulse turbine attacks this problem by reducing the relative velocity between the liquid and the blades, thus reducing the shear. The separator turbine attacks the problem by separating out the gas phase, thus reducing the required blade area.

Figure 42 shows the basic arrangement of a separator turbine. The two-phase jet impinges on the inside wall of a rotary separator, causing the liquid to separate out as a liquid layer inside the separator drum. Ideally, the separator drum has the same speed as the jet.

A second rotor, the 1 iquid turbine, is positioned concentrically witbin the rotary separator. The liquid turbine carries one or more U-tube scoops 


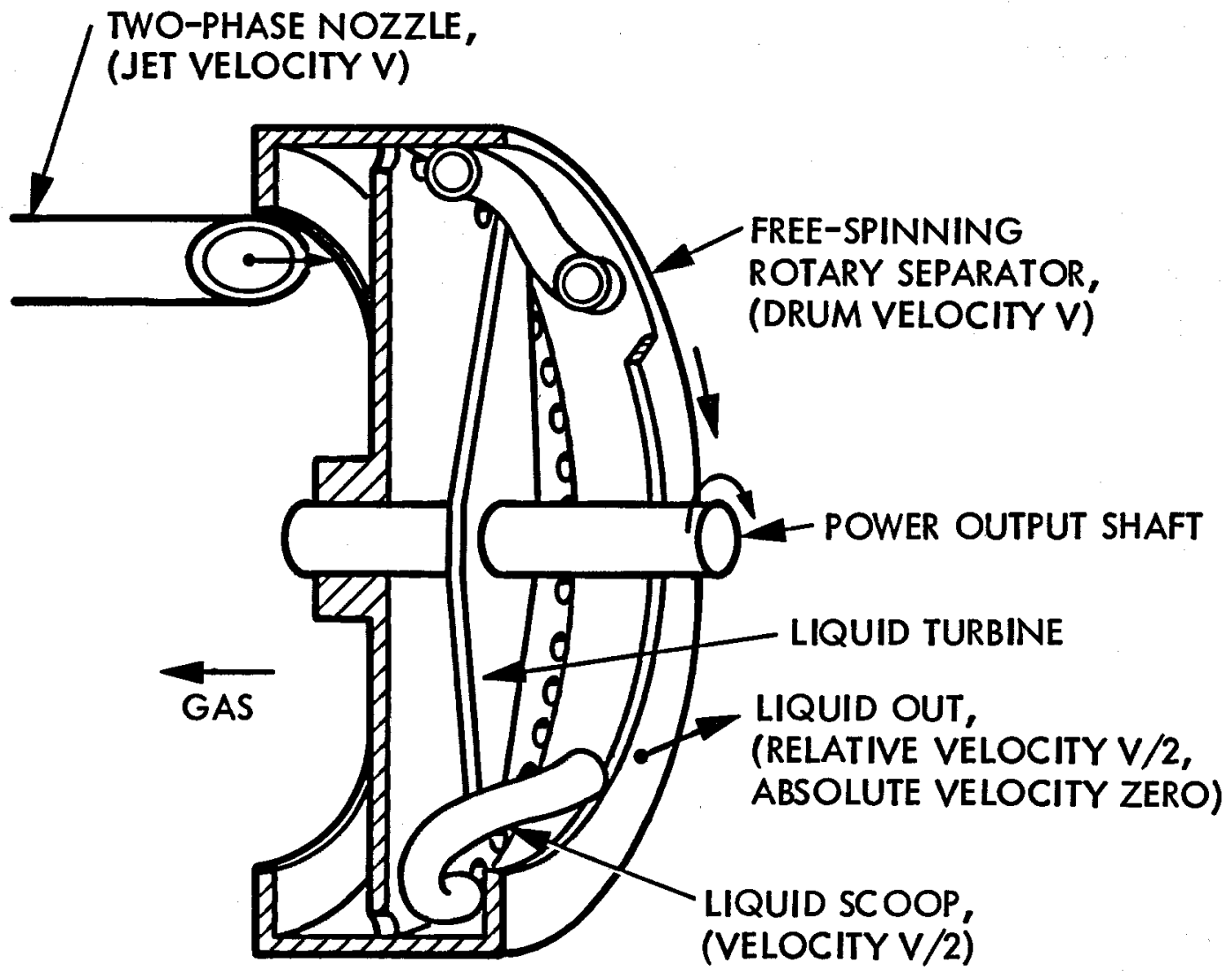

Fig. 42. Separator turbine 
with their inlets immersed in the 1 iquid layer. The 1 iquid enters the U-tubes and is discharged in the opposite direction.

If the U-tubes travel at half the speed of the separator drum, the absolute velocity of the liquid leaving the U-tubes is zero. All of the kinetic energy of the liquid has been converted to shaft power of the liquid turbine. The gas leaving the rotary separator can, in principle, be sent through a gas turbine to recover the gas kinetic energy.

In another variation of the separator turbine, the U-tubes can be replaced by diffusers that feed the liquid to a hollow shaft in the liquid turbine. If the liquid turbine is run at a speed less than half that of the separator drum, the liquid leaving the shaft will be pressurized. At the proper speed, the liquid can be returned to the two-phase nozzle, and the shaft power output will have been reduced by an amount equal to the pumping power for the liquid return.

In principle, the only fluid friction in the separator turbine is in the U-tubes. Since the U-tubes carry only liquid, not two-phase flow, the wall a rea is small and the friction loss is reduced accordingly.

In practice, there is also impact loss of the two-phase jet entering the separator; this loss consists of radial impact on the separator drum and axial impact on the rear wall. There is also external drag on the U-tubes immersed in the 1 iquid layer, and windage 10ss. Appendix $B$ presents the theory of separator turbines, taking these losses into account.

When the separator turbine theory is applied to specific cases, the theoretical efficiency of a separator turbine is no greater than the theoretical efficiency of a single-stage bladed turbine. Figure 43 compares the rotor efficiencies of separator turbines and bladed turbines for a particular steam-and-water mixture. The efficiency of the two-stage impulse turbine is plotted as a function of first-stage rotor speed. The efficiency of the separator turbine is plotted against liquid turbine speed; the separator speed is about twice as great. The efficiency of the liquid turbine is assumed to be very high: 0.9 . 


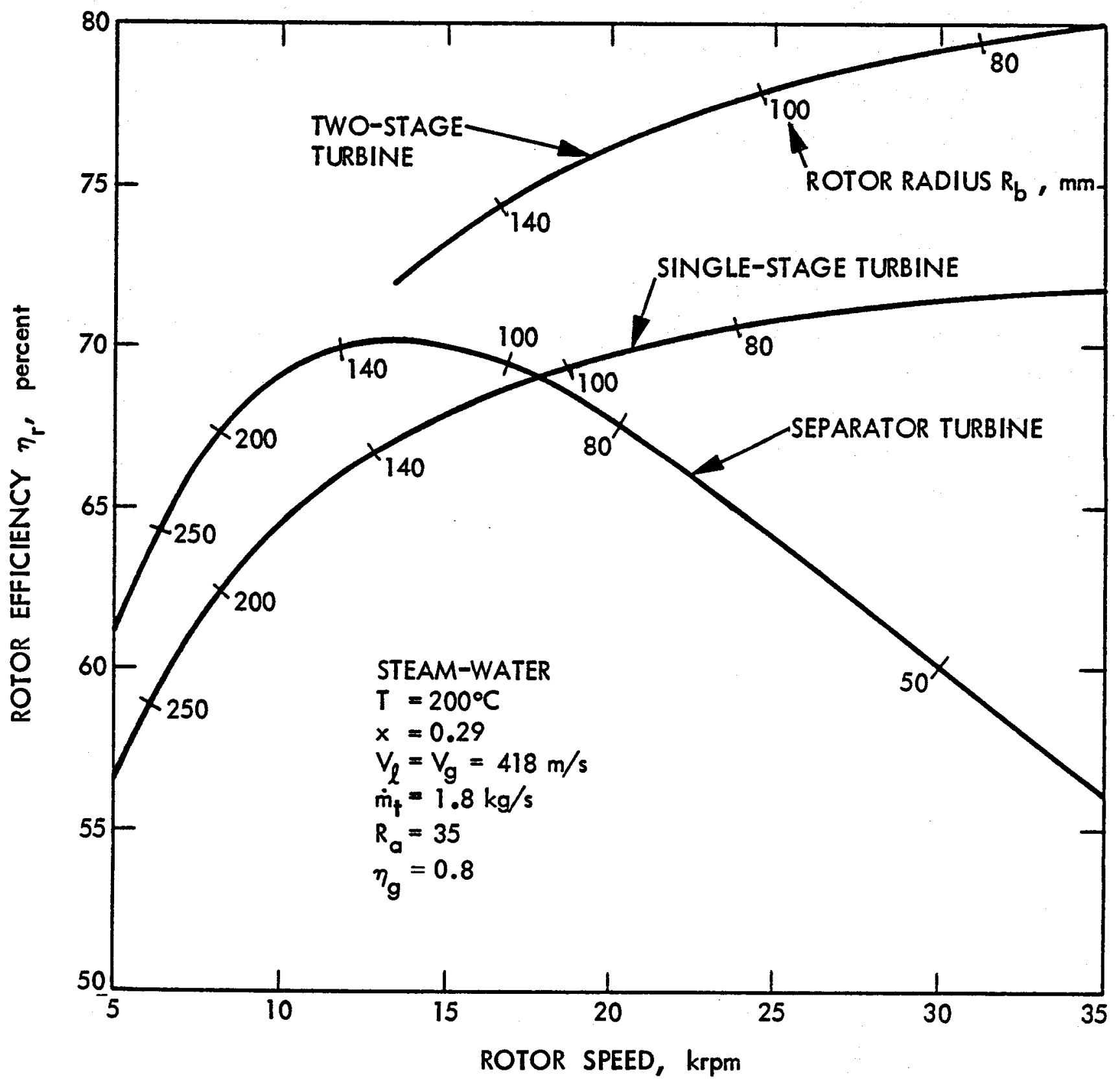

Fig. 43. Comparison of efficiencies of impulse turbine and separator turbine 
At large diameters, the separator turbine is superior to the single-stage impulse turbine because the jet enters the separator with relatively small impact loss, and the assumed U-tube turbine efficiency is higher than the efficiency of the bladed turbine. However, at these large diameters, the windage loss is large. At the other end of the curve, at small diameters, the windage loss of the separator turbine is small, but the impact losses in the separator are large. The peak efficiency of the separator turbine is achieved at a liquid turbine speed of $14,000 \mathrm{rpm}$ (separator speed of $23,000 \mathrm{rpm}$ ).

The basic concept of reducing friction by reducing liquid shear area is a valid approach, but it is not clear how to build a low-loss separator to implement the concept.

\section{N. Turbine Performance Examples}

The nozzle program, coupled with the rotor program, gives a reasonable prediction of two-phase turbine efficiency. The nozzle program gives nozzle efficiencies that are slightly too low, but the rotor program errs in the other direction. It is of interest to see what these programs predict in practical cases.

A geothermal steam-water or "total-flow" turbine has been one of the applications of interest. The theoretical performance of a 5-MW turbine at the flow conditions studied by LLL is presented in Table 8. The flow conditions are taken from Table 1 of Ref. 13.

The nozzle program predicts a nozzle efficiency of 0.89 for nozzles of 1.0-m length. For full admission, 15 nozzles are mounted around the circumference of a rotor of $0.7-\mathrm{m}$ radius and $0.1-\mathrm{m}$ blade height. A single-stage turbine operates at $3600 \mathrm{rpm}$ and has a rotor efficiency of 0.65 ; the turbine efficiency is 0.58 . The turbine efficiency increases to 0.63 with two stages and to 0.66 with three stages. 
Table 8. Theoretical performance of 5-MW steam-and-water turbine (LLL design conditions)

Nozzle inlet

Temperature, $\mathrm{T}_{1},{ }^{\mathrm{O}} \mathrm{C}$

Pressure, $\mathrm{p}_{1}, \mathrm{kPa}$

Flow rate, $\dot{\mathrm{m}}_{\mathrm{t}}, \mathrm{kg} / \mathrm{s}$

Quality, $x_{1}$

Nozzle exit

Pressure, $\mathrm{P}_{2}, \mathrm{kPa}$

Temperature, $\mathrm{T}_{2},{ }^{\circ} \mathrm{C}$

50.1

Drop diameter, $\mathrm{d}_{2}, \mu \mathrm{m}$

Gas density, ${ }^{\circ}, \mathrm{kg} / \mathrm{m}^{3}$

0.084

Area, $A_{2}, \mathrm{~m}^{2}$

0.144

Quality, $x_{2}$

Isentropic velocity, $v_{i}, \mathrm{~m} / \mathrm{s}$

Isentropic power, $P_{i}$, MW

Mean velocity, $\bar{v}, \mathrm{~m} / \mathrm{s}$

681

Liquid velocity, $v_{\ell}, \mathrm{m} / \mathrm{s}$

Gas velocity, $v_{g}, \mathrm{~m} / \mathrm{s}$

Jet power, $P_{\text {jet }}$, MW

Nozzle efficiency, $n_{n}$

0.886

Flow area ratio, $R_{a}$

Rotors

Radius, $R_{b}, m$

0.70

Blade height, $H_{b}$, m

0.10

Gas-phase torque factor, $\eta_{g}$

0.80 
Single-stage turbine

Rotor speed, N, rpm

Relative inlet velocity, $v_{1}, \mathrm{~m} / \mathrm{s}$

Rotor power, $\boldsymbol{P}_{\mathbf{r}}, \mathrm{MW}$

Rotor efficiency, ${ }^{r}$

Turbine efficiency, $n_{t}$

Two-stage turbine

First-stage rotor speed, $\mathrm{N}_{1}$, rpm

Second-stage rotor speed, $\mathrm{N}_{2}$, $\mathrm{rpm}$

First-stage relative inlet velocity, $v_{1}, \mathrm{~m} / \mathrm{s}$

Rotor power, $\mathbf{P}_{\mathbf{r}}, \mathbf{M W}$

Rotor efficiency, ${ }^{n}$

Turbine efficiency, $\eta_{t}$

Three-stage turbine

First-stage rotor speed, $N_{1}, x p m$

Second-stage rotor speed, $\mathrm{N}_{2}, \mathrm{rpm}$.

Third-stage rotor speed, $\mathrm{N}_{3}$, rpm

1770

First-stage relative inlet velocity, $v_{1}, \mathrm{~m} / \mathrm{s}$

Rotor power, $\mathbf{P}_{\mathbf{r}}, \mathrm{MW}$

5.426

Rotor efficiency, ${ }^{n}$

0.741

Turbine efficiency, $n_{t}$

0.657 
The goal of the LLL program was a turbine efficiency of 0.70 ; this does not appear to be attainable with steam-and-water mixtures.

A higher efficiency can be achieved by using an organic working fluid and transferring the heat from the geothermal fluid in a binary cycle. Table 9 presents the theoretical performance of a turbine using Refrigerant 113 (at conditions that correspond to a geothermal fluid of lower temperature and quality than those for the steam-and-water turbine of Table 8).

The turbine efficiency is 0.67 with one stage, 0.71 with two stages, and 0.72 with three stages. Part of the improvement in efficiency with Refrigerant 113 is due to the larger nozzle exit quality (0.64 instead of 0.36), giving higher weight to the assumed gas-phase torque factor of 0.8 . However, the liquid-phase blade efficiency is also improved.

The results of the comparison shown in Fig. 44 are typical of what might be achieved ultimately with two-phase turbines. Single-stage turbines with unfavorable working fluids such as water and steam will have efficiencies 1 imited to the mid-50-percent range. Multistage turbines with more favorable working fluids might achieve efficiencies in the 70 -percent range. Depending on the thermodynamic and practical gains offered by two-phase cycles in a particular case, such turbine efficiencies may be sufficient for useful applications. 
Table 9. Theoretical performance of 5-MW Refrigerant-113 turbine

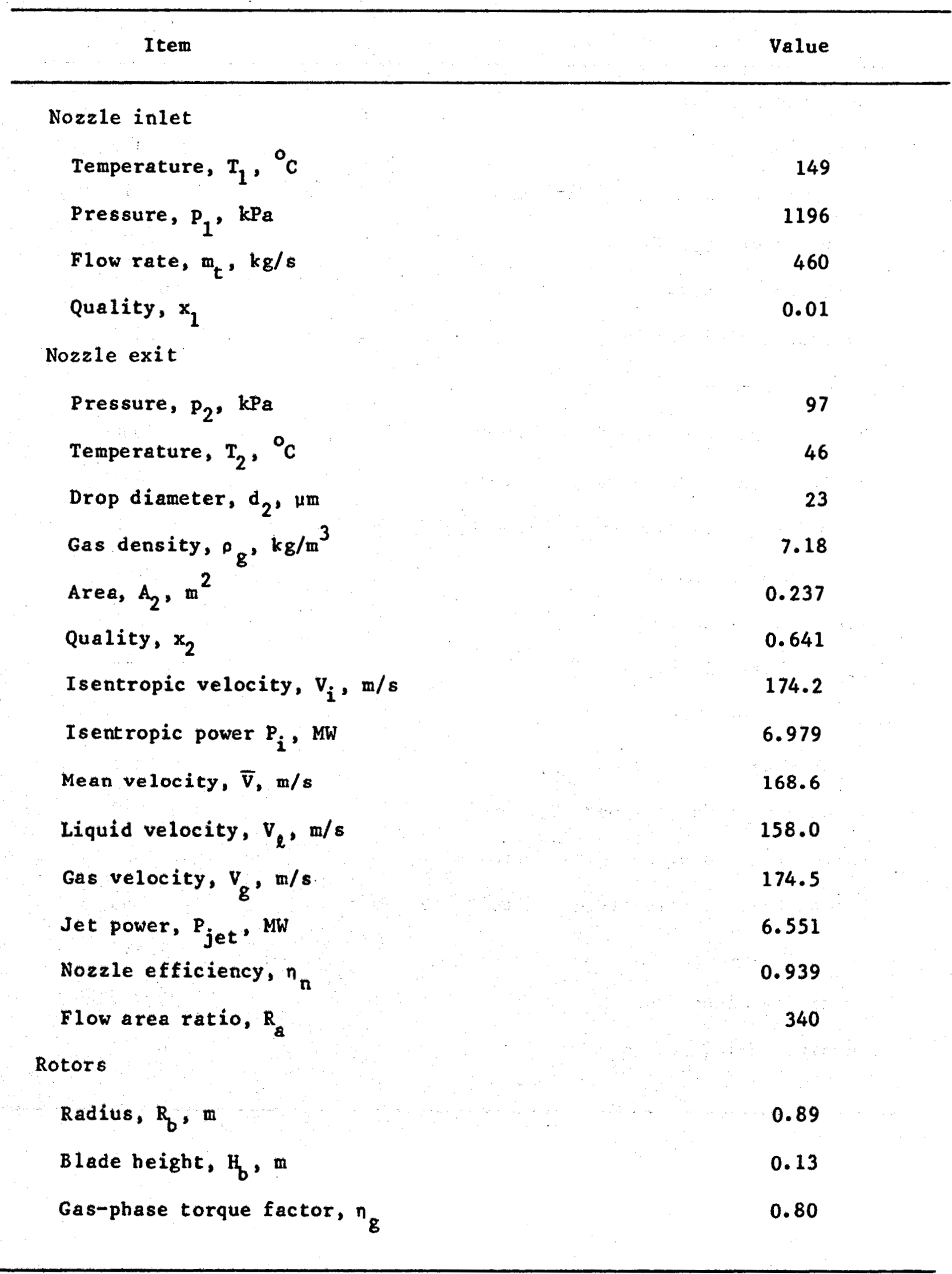


Single-stage turbine

Rotor speed, N, rpm

Relative inlet velocity, $v_{1}, \mathrm{~m} / \mathrm{s}$

Rotor power, $\mathrm{P}_{\mathbf{r}}$, $\mathrm{MW}$

Rotor efficiency, $\eta_{r}$

Turbine efficiency, $n_{t}$

Two-stage turbine

First-stage rotor speed, $N_{1}$, rpm

Second-stage rotor speed, $\mathrm{N}_{2}$, rpm

First-stage relative inlet velocity, $v_{1}, \mathrm{~m} / \mathrm{s}$

Rotor power, $\mathrm{P}_{1}$, MW

Rotor efficiency, $n_{r}$

Turbine efficiency, $n_{t}$

Three-stage turbine

First-stage rotor speed, $N_{1}, r p m$

Second-stage rotor speed, $\mathrm{N}_{2}, \mathrm{rpm}$

Third-stage rotor speed, $\mathrm{N}_{3}, \mathrm{rpm}$

First-stage relative inlet velocity, $v_{1}, \mathrm{~m} / \mathrm{s}$

Rotor power, $\mathbf{P}_{\mathbf{r}}, \mathrm{MW}$

Rotor efficiency, $n_{r}$

Turbine efficiency, $n_{t}$ 


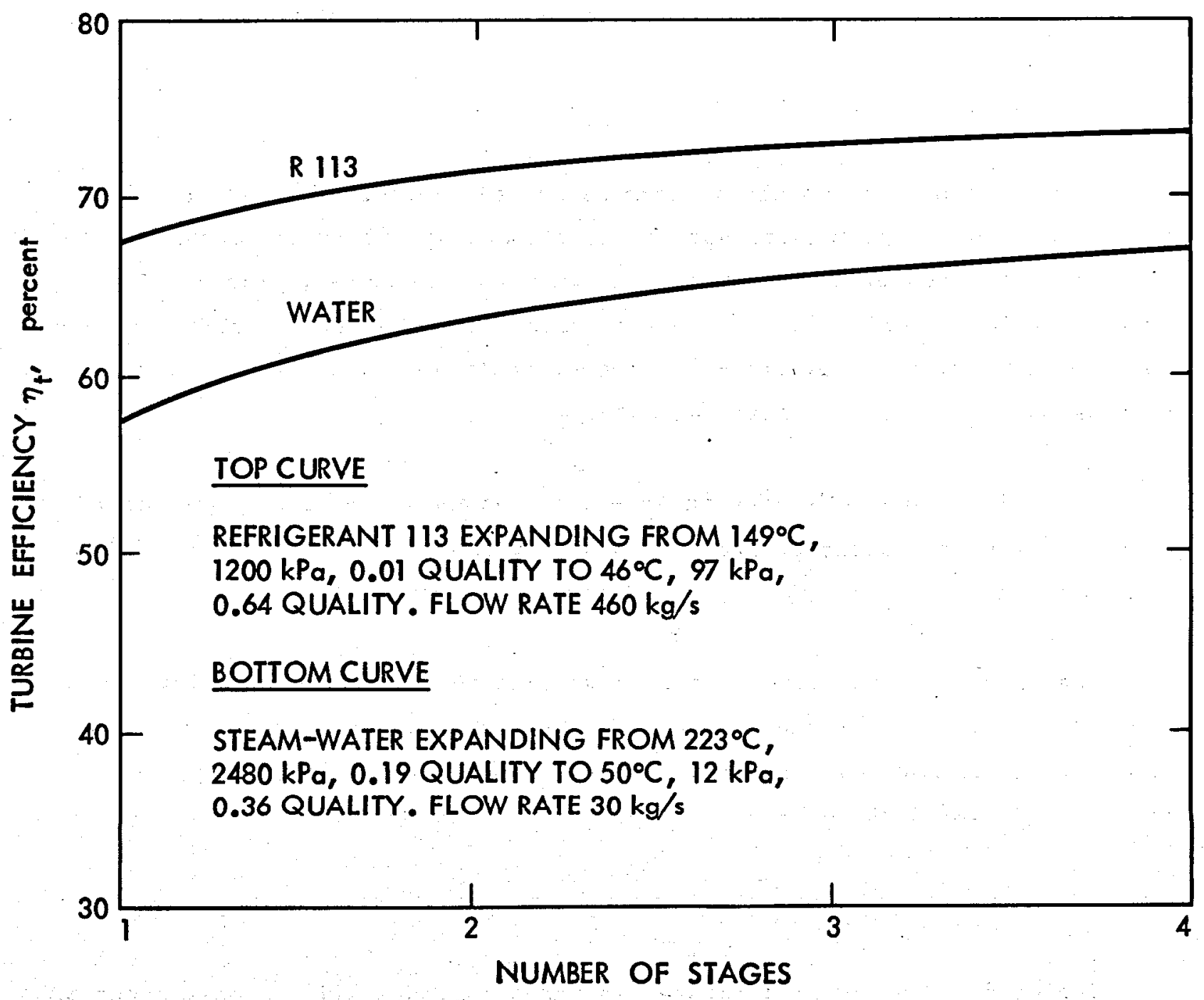

Fig. 44. Theoretical efficiences of 5-MW steam-and-water and Refrigerant-113 turbines 
VI. CONCLUSION

Conclusions can be drawn in two areas: analysis capability for two-phase turbines and, to a lesser extent, practical usefulness of two-pbase turbines.

A. Analysis Capability

The JPL two-phase nozzle program calculates velocities that are within 2 to 4 percent of measurements, but the corresponding efficiency error is 4 to 8 percent. The predicted velocities are lower than measured, probably due to overestimation of drop size. A more sophisticated drop size routine is needed. As an expedient, the critical Weber number could be reduced to a lower number, such as 3 , that would fit existing data.

The rotor program derived in Appendix A gives an upper performance limit. Combined with the nozzle program, it probably shows the best that can be achieved with any given working fluid and operating condition.

The measured rotor efficiencies have been 10 to 15 percent below the calculated values. The cause appears to be flow stagnation and divergence effects. It is not known if these losses can be reduced or if they are fundamental limitations.

\section{B. Application Prospects}

The efficiency of single-stage two-phase turbines will be only about 50 percent, but this is sufficient for replacing the throttling steps in geothermal plants, refrigeration systems, and other systems that use irreversible flashing processes. A two-phase turbine would add power in these applications no matter how inefficient the turbine. However, the value of the added energy output must at least equal the cost of the turbine and associated equipment for the turbine to be economic. This requirement keeps many new energy devices from use, and is a stumbling block for two-phase turbines as well. 
For applications where the two-phase turbine must compete with vapor turbines, there is a difficult efficiency requirement. The efficiency advantage of a two-phase cycle, say for waste-heat recovery or geothermal power where the two-phase cycle improves the matching to the heat source, is only about 15 percent. The efficiency of vapor turbines is about 80 percent. Therefore, a two-phase turbine must have an efficiency of more than 65 percent to give a net gain in cycle efficiency. This is about the upper limit of efficiency for two-phase turbines, and is probably attainable only with organic working fluids. The picture that emerges is that two-phase turbines look promising in organic-fluid waste-heat or geothermal binary cycles where there is a significant thermodynamic advantage in using saturated liquid expansion and where the flow conditions are conducive to the best two-phase turbine efficiency. Two-phase turbines using steam and water expanding to the low pressures required in most applications such as geothermal may be ruled out by low efficiency and possibly erosion.

Perhaps the most attractive prospect for early use of two-phase turbines is the WD cycle where two-phase flow is used only in the nozzle and dry vapor is used in the rotor. 
0

98 
APPENDIX A.

ROTOR MODEL

A. Turbine Geometry

The behavior of the flow in a two-phase turbine rotor will be analyzed for the geometry shown in Fig. A-1.

A two-phase nozzle of width $W_{n}$ and height $H_{n}$ (equal if nozzle is circular) delivers flow at angle $A_{\text {noz }}$ to rotor blades traveling at velocity $v_{b}$. The jet contains liquid of flow rate $\dot{m}_{l}$ traveling at velocity $v_{l}$ and gas of flow rate $\dot{m}_{g}$ traveling at velocity $v_{g^{*}}$

The blades have an inlet section of shallow curvature where the flow impinges and an exit section of sharper curvature where the flow is turned. The inlet radius of curvature is $R_{1}$ and the exit radius of curvature is $R_{2}$. The blade ends with an optional straight extension of length $L_{\text {ext }}{ }^{*}$

A center plane can be drawn through the point where the blade surfaces pass through the axial direction. The blade inlet angle is $A_{1}$ and the blade exit angle is $A_{2}$, measured from the center plane. The inlet curvature $R_{1}$ ends at angle $A_{3}$ past the center plane.

The radius of the rotor at the center of the nozzle is $R_{b}$, and the outside radius of the rotor is $R_{w^{*}}$ The blade spacing at radius $R_{b}$ is $S_{b}$.

The flow parameter that has the dominating effect on liquid friction loss is the ratio of gas flow a rea to liquid flow area $R_{a}$, which is found as follows: The flow area occupied by liquid at the nozzle exit is $\dot{m}_{\ell} / p_{\ell} V_{l}$ " where $\rho_{\ell}$ is the 1 iquid density. The gas flow area is $R_{a}$ times the liquid area, and the total flow area is $\left(1+R_{a}\right)$ times the liquid area. Equating the product of $\left(1+R_{a}\right)$ and liquid flow area to the nozzle exit area $W_{n} H_{n}$ (treating the nozzle as rectangular), the gas/liquid area ratio is given by 


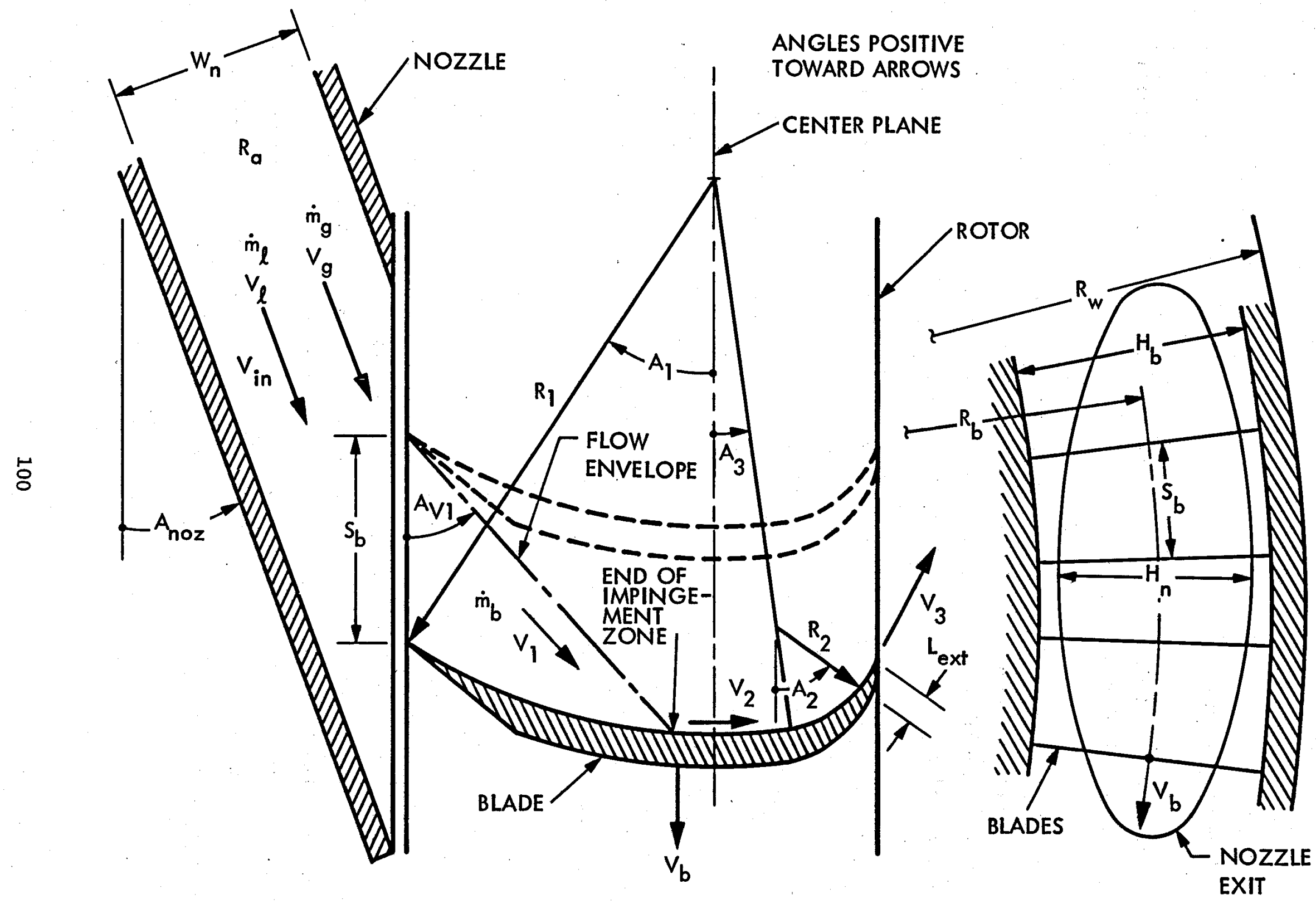

(c)

Fig. A-1. Two-phase turbine geometry

C 


$$
R_{a}=\frac{W_{n}^{H} n_{\ell} V_{\ell}}{\dot{m}_{\ell}}-1
$$

The liquid flow rate $\dot{m}_{b}$ impinging on each blade is equal to the total 1 iquid flow rate $\dot{m}_{\ell}$ times the fraction of the nozzle area intercepted by one blade passage. The nozzle has a projected width in the plane of the rotor equal to $\mathrm{W}_{\mathrm{n}} / \sin \mathrm{A}_{\text {noz }}$. The fraction of the nozzle occupied by one blade passage is equal to the blade spacing $S_{b}$ divided by this projected nozzle width. Hence, the liquid flow rate per blade is

$$
\dot{m}_{b}=\frac{\dot{m}_{l} s_{b} \sin A_{n o z}}{w_{n}}
$$

\section{B. Inlet Velocity Vectors}

Figure A-2 shows the velocity vectors for the liquid flow. Vectors are conveniently handled in the computer as complex numbers. A velocity $v$ at angle A from the positive $x$ axis forms a vector velocity $\vec{v}$. If the magnitude $v$ and angle $A$ are given, the vector can be computed as $\vec{V}=\operatorname{POLAR}(V, A)$, where $\operatorname{POLAR}$ is a function that constructs a complex number having real part $V \cos A$ and imaginary part $V$ sin $A$. Conversely, given a complex number $\vec{V}$, the magnitude and angle of $\vec{V}$ are given by $V=\operatorname{ABS}(\vec{V})$ and $A=\operatorname{PHASE}(\vec{V})$, respectively, where $A B S$ and PHASE are functions that operate appropriately on the complex number $\vec{v}$. (Angles are in degrees in the computer program and will be written in degrees bere.)

The two-phase jet is directed at angle 90 - $A_{\text {noz }}$ (degrees) below the $x$ axis (Anoz 90 above the $x$-axis). The vector inlet velocity is thus

$$
\vec{v}_{\text {in }}=\operatorname{POLAR}\left(V_{\ell}, A_{n o z}-90\right)
$$

The vector blade velocity is

$$
\vec{v}_{b}=\operatorname{POLAR}\left(v_{b},-90\right)
$$




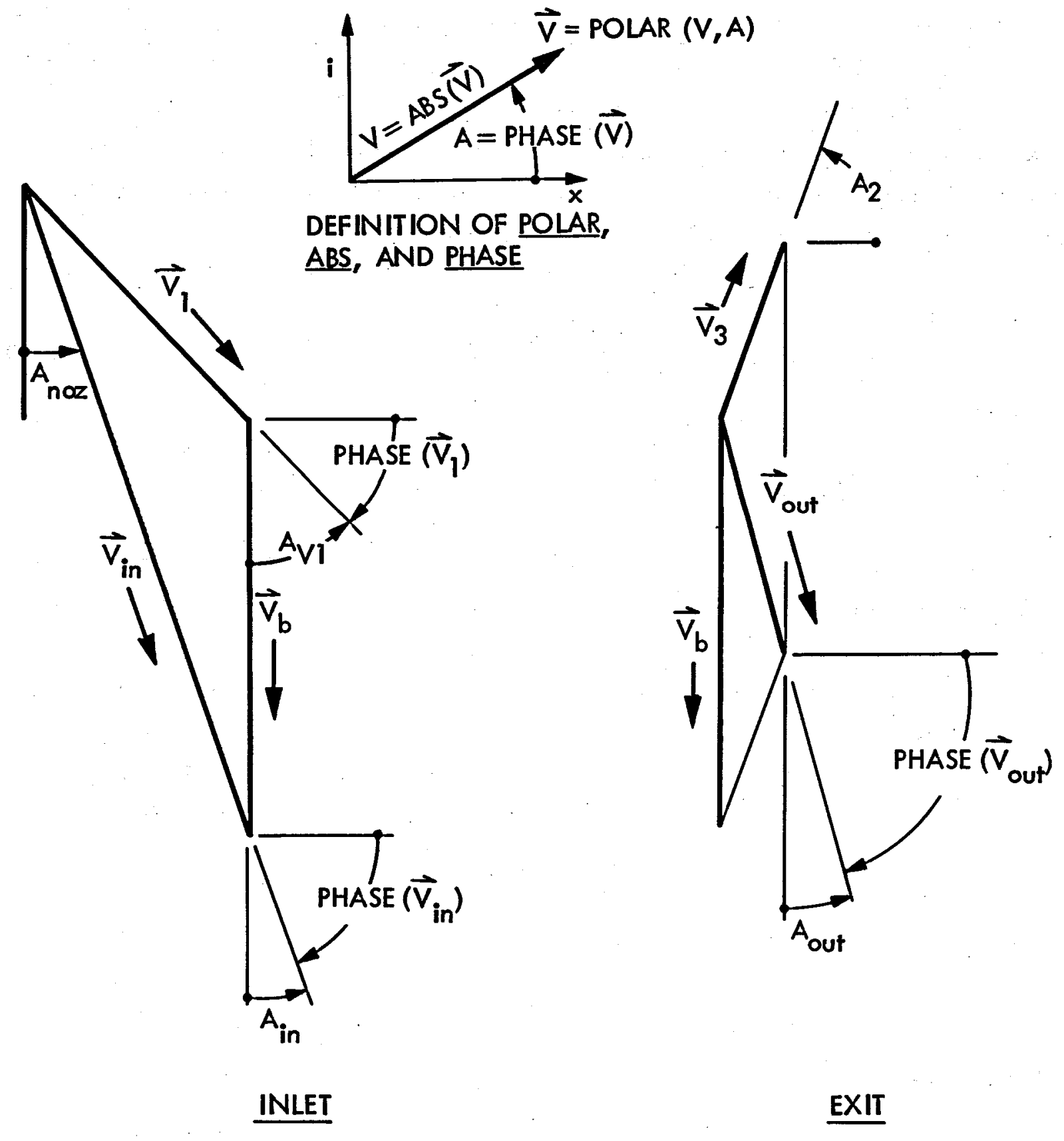

Fig. A-2. Definitions of velocity vectors 
The velocity of the incoming liquid relative to the rotor is the difference between the jet and blade velocities:

$$
\vec{v}_{1}=\vec{v}_{\text {in }}-\vec{v}_{b}
$$

The magnitude of the relative velocity is

$$
v_{1}=\operatorname{ABS}\left(\vec{v}_{1}\right)
$$

and the angle of the relative velocity from vertical is

$$
\mathrm{A}_{1}=\operatorname{PHASE}\left(\vec{v}_{1}\right)+90
$$

noting that PHASE $\left(\vec{v}_{1}\right)$ is negative.

\section{Impingement Geometry}

Figure A-3 shows the impingement geometry of a flow stream entering at distance $Y_{s t}$ above the blade inlet. The flow intersects the blade at angle $A_{x}$ from the center plane. From Fig. $A-3$ it can be seen that angle $A_{x}$ is given by

$$
R_{1} \sin A_{1}=R_{1} \sin A_{x}+\left(R_{1} \cos A_{x}-R_{1} \cos A_{1}+Y_{s t}\right) \tan A_{V 1}(A-8)
$$

Equation $(A-8)$ can be rearranged for iterative solution as follows:

$$
A_{x}=\sin ^{-1}\left(C_{1}-\tan A_{1} \cos A_{x}\right)
$$

where

$$
c_{1}=\sin A_{1}+\left(\cos A_{1}-Y_{s t} / R_{1}\right) \tan A_{1}
$$

The impingment angle of the streamline crossing at $Y_{s t}$ is then given by

$$
\theta=90-A_{V 1}-A_{x}
$$




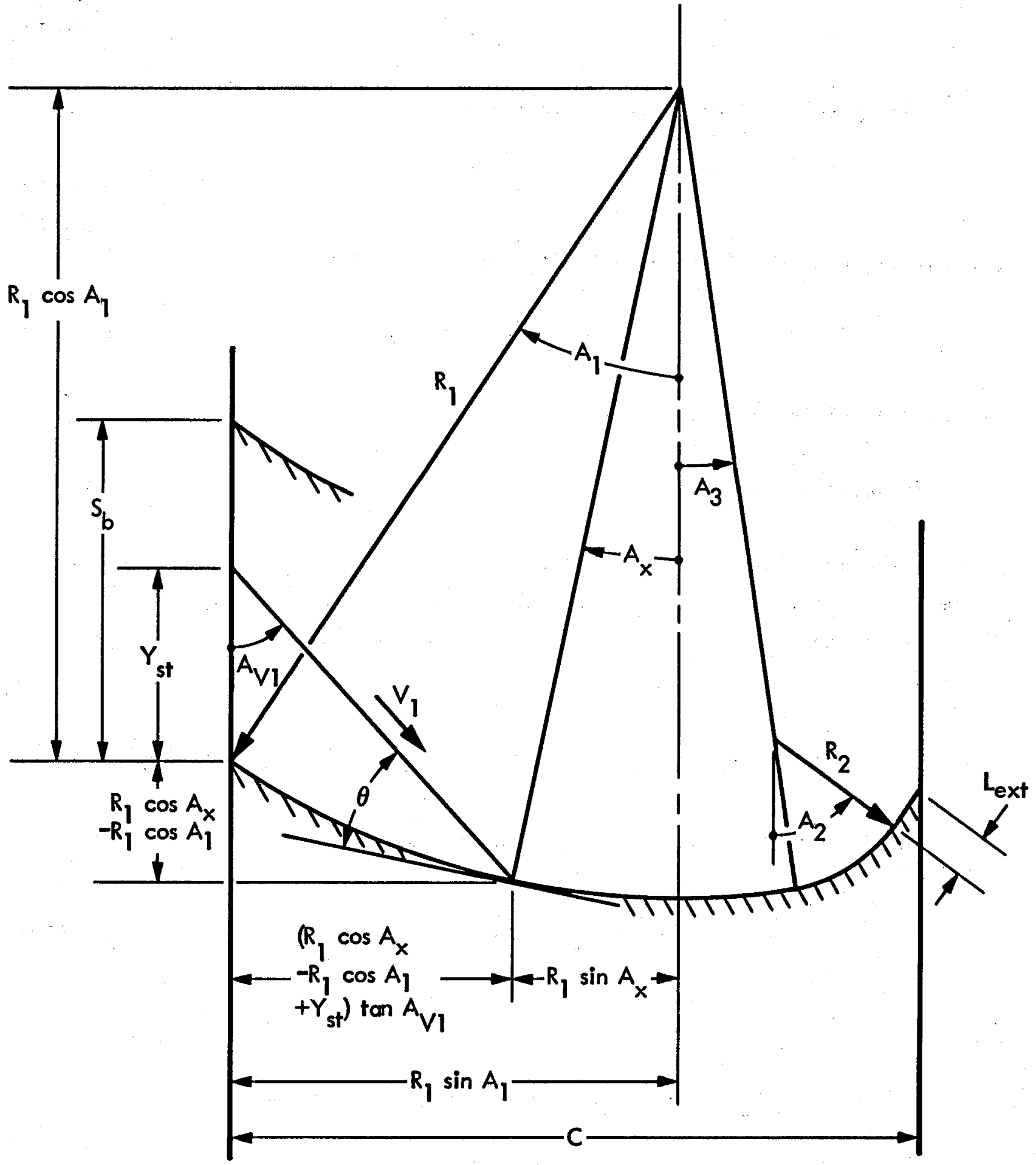

Fig. A-3. Impingement geometry 


\section{Impact Behavior}

When a single liquid jet strikes a surface, both momentum and energy are conserved. The jet splits into two streams that travel away from the point of impact in opposite directions at full velocity (conserving energy) and at differing flow rates (conserving momentum).

When multiple jets or drops strike a surface, only momentum is conserved, because adjacent streams collide with each other and lose kinetic energy through inelastic impact. This effect is familiar from the household water faucets that use screens to divide the flow into multiple streams that dissipate their energy on impact and thus do not splash back.

For two-phase flow striking a turbine blade, the process for the liquid phase can be described as shown in Fig. A-4. The liquid drops strike the blade at angle $\theta$ and velocity $V_{1}$. The row of drops striking the inlet edge of the blade (idealized as a sheet of liquid) splits into a forward flow and a smaller back flow, both flows traveling at velocity $v_{1}$. The second row of drops also splits into a forward flow and a back flow, but the back flow collides with the larger forward flow from the first row of drops and is swept back into the forward direction. Each succeeding row of drops has its back flow swept into the forward direction, and the only back flow from the entire impinging stream is that from the first row of drops.

For a large array of jets, the back flow thus carries a negligible fraction of the total momentum, and the stream leaving the impingement zone has a momentum $\dot{m} v_{2}$ that is essentially equal to the entire forward component of momentum of the incoming jet $\dot{\mathrm{m}} v_{1} \cos \theta$. Thus, the equation for liquid velocity recovery in an impinging two-phase jet, considering impact only, is

$$
v_{2}=v_{1} \cos \theta
$$




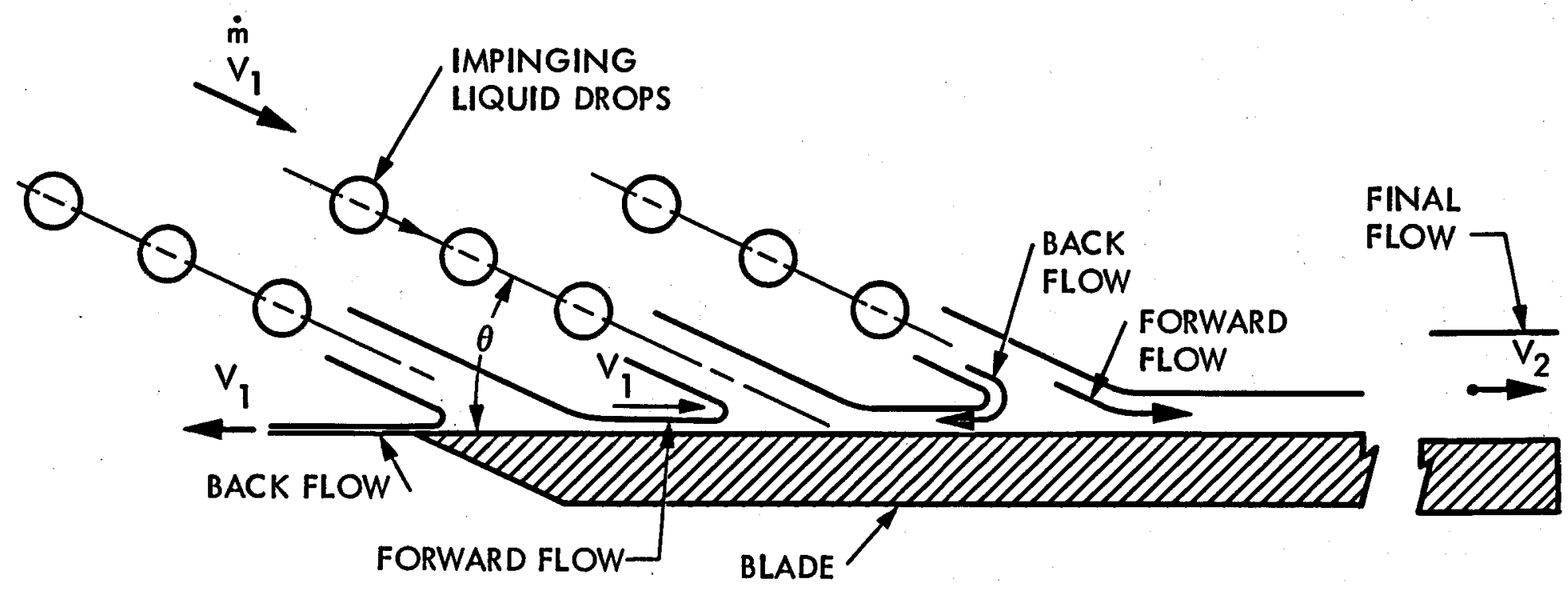

Fig. A-4. Impact behavior 


\section{E. Combined Impact and Friction Loss}

Figure A-5 shows a short section of blade having width $H_{n}$ (that dimension perpendicular to the plane of the figure) and area $\mathrm{dA}$ on which the flow is impinging at angle $\theta$. The liquid flow rate impinging on the blade section is di. The flow rate previously collected is $\dot{m}_{0}$, entering at velocity $v_{0}$.

The flow rate in the film at the midpoint of the blade section is $\dot{\mathrm{m}}_{\mathrm{m}}=\dot{\mathrm{m}}_{0}+\frac{1}{2} \mathrm{~d} \dot{\mathrm{m}}$. If the velocity of the film at the midpoint is $v_{m}$, then the film thickness is

$$
t_{m}=\frac{\dot{m}_{m}}{\rho_{\ell}^{H} v_{m}}
$$

It can be assumed that the wall friction is the same as for flow in a rectangular channel of height $2 t_{m}$ and width $H_{n}$, because the velocity gradient at the film surface is zero as it would be at the center of a rectangular channel. The hydraulic diameter of a rectangular channel is four times the area divided by the wetted perimeter. Thus the hydraulic diameter of the film is

$$
D_{h}=\frac{4\left(2 t_{m} H_{n}\right)}{2\left(2 t_{m}+H_{n}\right)}
$$

Since $t_{m}$ is much smaller than $H_{b}$, the hydraulic diameter is approximately

$$
D_{h}=4 t_{m}
$$

The Reynolds number for pipe flow is

$$
\operatorname{Re}=\frac{\rho_{\ell} v_{\ell} D_{b}}{\mu_{\ell}}
$$

where $\mu_{l}$ is the viscosity of the liquid. 


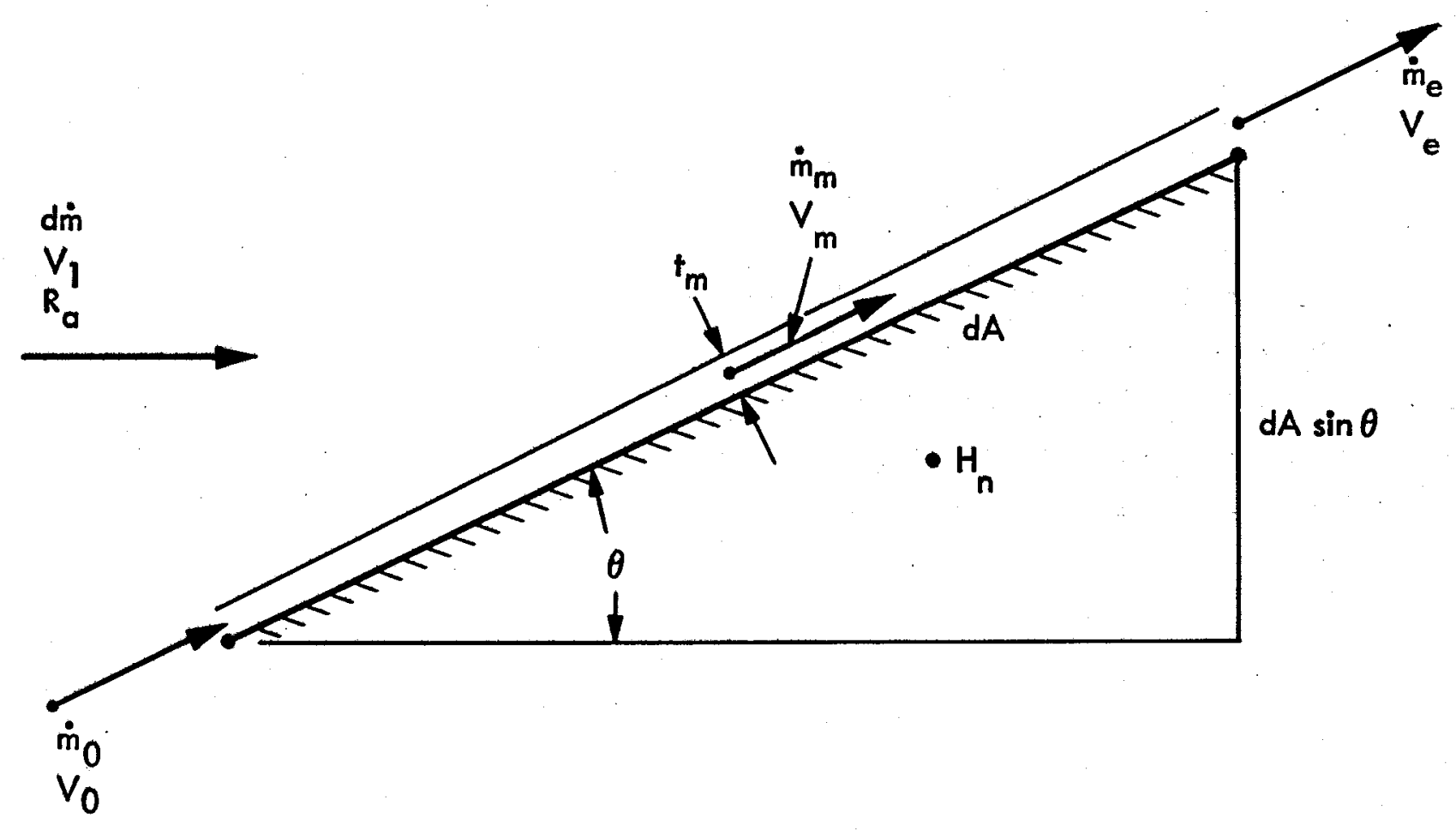

Fig. A-5. Impact and friction on a blade section 
Substituting the hydraulic diameter from Eq. $(A-15)$ and the film thickness from Eq. (A-13), the Reynolds number at the midpoint is

$$
\operatorname{Re}_{\mathfrak{m}}=\frac{4 \dot{\mathrm{m}}_{\mathrm{m}}}{\mathrm{H}_{\mathrm{n}} \mu_{\ell}}
$$

For very low Reynolds numbers the flow is laminar and the friction coefficient is given by

$$
C_{f}=\frac{16}{\operatorname{Re}}
$$

For turbulent flow a convenient expression for friction coefficient, valid over a wide range of Reynolds numbers, is the Von Kármán equation:

$$
c_{f}=\frac{1}{\left[4 \log _{10}\left(2 \operatorname{Re} \sqrt{c_{f}}\right)-1.6\right]^{2}}
$$

The Reynolds number at which Eqs. $(A-18)$ and $(A-19)$ give the same $C_{f}$ is 1034.8, and this Reynolds number is used as the dividing line between the two equations.

The retarding force on the liquid film in the blade section of Fig. (A-5) is the product of dynamic pressure, friction coefficient, and wall area. Any mean velocity $v_{m}$ between inlet velocity $v_{0}$ and exit velocity $v_{e}$ can be used for calculating dynamic pressure since the two velocities approach each other in the limit of small section lengths; exit velocity $v_{e}$ is used for $v$ bere. The friction retarding force can then be written

$$
F=\frac{1}{2} \rho_{\ell} V_{e}^{2} C_{f m} d A
$$

where $C_{f m}$ is the friction coefficient at the middle of the section. 
The flow area of the two-phase stream impinging on the blade section is $\mathrm{dA} \sin \theta$. For unit liquid flow area the gas $f$ low area is $R_{a}$ and the total flow area is $1+R_{a}$, where $R_{a}$ is the gas/liquid area ratio. Hence, the liquid flow rate impinging on the blade section is

$$
d \dot{m}=\frac{\rho_{\ell} v_{1} d A \sin \theta}{1+R_{a}}
$$

Solving Eq. (A-21) for area dA and substituting into Eq.(A-20), the retarding force on the liquid film in the blade section is

$$
F=\frac{v_{e}{ }^{2} C_{f m}\left(1+R_{a}\right) d \dot{m}}{2 v_{1} \sin \theta}
$$

The momentum $d M$ added to the film by the impinging flow $d \dot{m}$, according to $\mathrm{Eq} \cdot(\mathrm{A}-12)$, is the momentum of the impinging stream times $\cos \theta$, or

$$
\mathrm{dM}=\mathrm{d} \dot{\mathrm{m}} \mathrm{v}_{1} \cos \theta
$$

The momentum of the previously-collected flow entering the section along the surface is

$$
\mathrm{M}_{0}=\dot{\mathrm{m}}_{0} \mathrm{~V}_{0}
$$

The momentum of the flow leaving the section is

$$
\mathrm{M}_{\mathrm{e}}=\dot{\mathrm{m}}_{\mathrm{e}} \mathrm{V}_{\mathrm{e}}
$$

The exit momentum is equal to the sum of the inlet momentum and the momentum added by the impinging flow, less the friction force:

$$
M_{e}=M_{0}+d M-F
$$

Substituting the friction force $F$ from $E q .(A-22)$ and the momentums from Eqs. (A-23, A-24, and A-25), the momentum equation becomes 
$\Longleftrightarrow \frac{C_{f m}\left(1+R_{a}\right)}{2 \sin \theta} \frac{d \dot{m}}{\frac{m}{m}}\left(\frac{V_{e}}{V_{1}}\right)^{2}+\frac{v_{e}}{v_{1}}-\left(\frac{d \dot{m}}{m_{e}}\right)\left(1+\frac{\dot{m}_{0} V_{0}}{d \dot{m} v_{1} \cos \theta}\right) \cos \theta=0 \quad(A-27)$

Using the quadratic equation to solve for the ratio $v_{e} / v_{1}$, the result is

$\frac{v_{e}}{v_{1}}=\frac{\sin \theta}{C_{f m}\left(1+R_{a}\right)} \frac{\dot{m}_{e}}{d \dot{m}}\left[\sqrt{1+\frac{2 C_{f m}\left(1+R_{a}\right)}{\tan \theta}\left(\frac{d \dot{m}}{\dot{m}_{e}}\right)^{2}\left(1+\frac{\dot{m}_{0} v_{0}}{d \dot{m} v_{1} \cos \theta}\right)}-1\right]$

This equation gives the liquid film velocity $v_{e}$ leaving a blade section on which two-phase flow of liquid flow rate dim is impinging at angle $\theta$ with liquid velocity $v_{1}$ and gas/liquid flow area ratio $R_{a}$, when the incoming film flow rate is $\dot{m}_{0}$ at velocity $v_{0}$ and the outgoing liquid flow rate is $\dot{\mathrm{m}}_{\mathrm{e}}=\dot{\mathrm{m}}_{0}+\mathrm{d} \dot{\mathrm{m}}$.

Equation (A-28) reduces to the equation used in past work (Reference 2, Figure 6, substituting $A_{2} / A_{s}=\sin \theta$ and $r_{v}=R_{a}$ there) for the velocity leaving a flat plate with no initial surface flow. In that case $\dot{\mathrm{m}}_{0}=0, \mathrm{~d} \dot{\mathrm{m}}=\dot{\mathrm{m}}_{\mathrm{e}}$, and the exit velocity is given by

$$
\frac{v_{e}}{v_{1}}=\frac{\sin \theta}{C_{f m}\left(1+R_{a}\right)}\left[\sqrt{1+\frac{2 C_{f m}\left(1+R_{a}\right)}{\tan \theta}-1}\right]
$$

\section{F. Film Friction Loss}

Following the impingement zone there is additional blade surface to complete the turning of the flow. The Reynolds number for this "film-flow" zone, from $E q \cdot(A-17)$, is

$$
\operatorname{Re}_{\mathrm{f}}=\frac{4 \dot{\mathrm{m}}_{\mathrm{b}}}{\mathrm{H}_{\mathbf{n}^{\mu} \ell}}
$$


where $\dot{m}_{b}$ is the blade flow. The friction coefficient for this Reynolds number as designated $C_{f} f^{*}$

Figure A-6 shows the definition of various surface lengths along the blade. The length to the end of the inlet radius of curvature is

$$
L_{1}=R_{1}\left(A_{1}+A_{3}\right)
$$

The length of the impingement zone is

$$
L_{i m p}=R_{1}\left(A_{1}-A_{x}\right)
$$

where $A_{x}$ is the angle given by $\mathrm{Eq}$. (A-9) for the last streamline of impinging flow (the flow envelope).

The total surface length is

$$
L_{\text {surf }}=L_{1}+R_{2}\left(A_{2}-A_{3}\right)+L_{\text {ext }}
$$

The length of the film-flow zone is

$$
L_{\text {film }}=L_{\text {surf }}-L_{\text {imp }}
$$

As the film decelerates, the friction force in any length $\mathrm{dx}$ is equal to the momentum decrease in that length. The momentum change is

$$
\dot{\mathrm{m}}_{\mathrm{b}} \mathrm{dV}=-\frac{1}{2} \rho_{2} v^{2} \mathrm{C}_{f} \mathrm{f}_{\mathrm{n}}^{\mathrm{H}} \mathrm{dx}
$$

Integrating $\mathrm{Eq}_{\mathrm{g}}(\mathrm{A}-35)$ over the length $\mathrm{L}_{\mathrm{film}}$, the velocity decreases from $v_{2}$ to $v_{3}$ according to

$$
v_{3}=\frac{1}{\frac{1}{v_{2}}+\frac{{ }^{D} C_{f f}^{H}{ }_{n} L_{f i l m}}{2 \dot{m}_{b}}}
$$




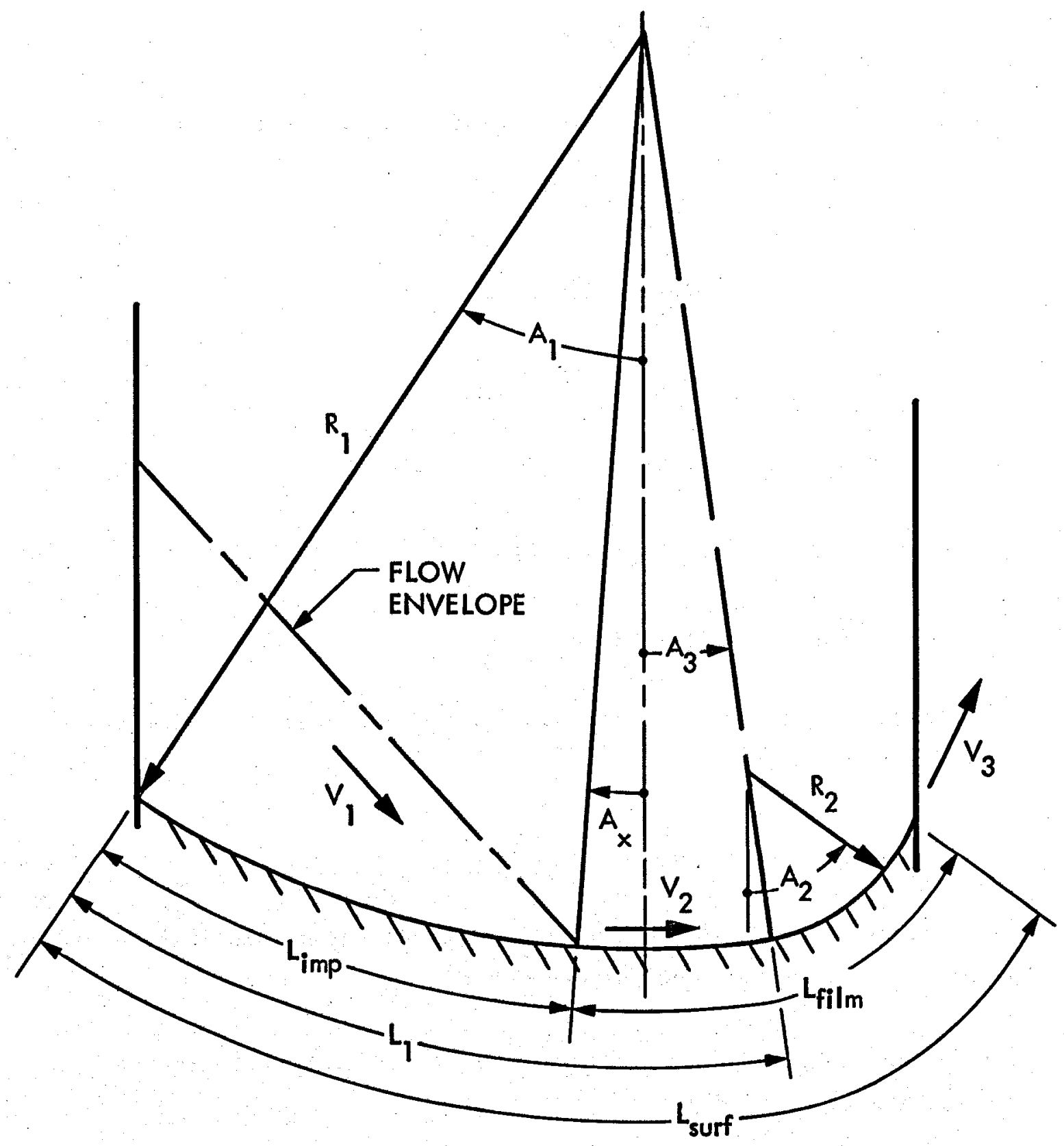

Fig. A-6. Blade lengths 


\section{G. Exit Velocity Vectors}

The exit velocity vectors are shown in Fig. A-2. The vector exit velocity of the liquid relative to the blade is

$$
\vec{v}_{3}=\operatorname{POLAR}\left(\mathrm{V}_{3}, A_{2}\right)
$$

Adding the blade speed, the vector absolute exit velocity is

$$
\overrightarrow{\mathrm{v}}_{\text {out }}=\overrightarrow{\mathrm{v}}_{3}+\overrightarrow{\mathrm{v}}_{\mathrm{b}}
$$

The magnitude of the absolute exit velocity is

$$
v_{\text {out }}=\operatorname{ABS}\left(\vec{v}_{\text {out }}\right)
$$

and the angle of the absolute exit flow from vertical is

$$
A_{\text {out }}=90+\operatorname{PHASE}\left(\overrightarrow{\mathrm{v}}_{\text {out }}\right)
$$

noting that PHASE ( $\vec{\nabla}_{\text {out }}$ ) is negative.

For multistage turbines the exit velocity $\vec{v}_{\text {out }}$ becomes the inlet velocity $\vec{v}_{\text {in }}$ to the next stage.

H. Windage

Mann and Marston (Ref. 16) present correlations for predicting the windage, or disc friction torque, on a bladed rotor.

The Reynolds number of the flow on a disc of radius $R_{w}$ rotating at angular velocity $\omega$ is defined as

$$
R e=\frac{{ }^{\rho} g^{\omega} R_{w}^{2}}{\mu_{g}}
$$

where $\rho_{g}$ is the gas density and $\mu_{g}$ is the gas viscosity. 
If the rotor is one of several stages, then separate Reynolds numbers $\operatorname{Re}_{1}$ and $\mathrm{Re}_{2}$ are calculated for the upstream and downstream sides of each rotor, using the angular velocities relative to the adjacent rotors or to the atmosphere.

The windage torque depends on the thickness of the rotor, which is equal to the blade chord. From Fig. A-3 it can be seen that the blade chord is given by

$$
C=R_{1}\left(\sin A_{1}+\sin A_{3}\right)+R_{2}\left(\sin A_{2}-\sin A_{3}\right)+L_{e x t} \cos A_{2}
$$

The aspect ratio of the blades is $A R=H_{b} / C$, where $H_{b}$ is the blade height (Fig- A-1). Table 3 of Ref. 16 gives moment coefficients $C_{m}$ as a function of aspect ratio for a Reynolds number of $10^{6}$ and a chord/radius ratio $c / R_{w}$ of 0.14 . These coefficients are denoted $C_{m}^{*}$. The table can be fitted by

$$
c_{m}^{*}=0.0067+0.007 \mathrm{AR}^{0.6}
$$

The exponent $\gamma$ of the Reynolds number dependence $\left(c_{m}\right.$ proportional to $\operatorname{Re}^{-\gamma}$ ) is given in the same table, and the values can be fitted by

$$
r=0.21-0.086 \mathrm{AR}
$$

up to $A R=0.7$, beyond which the extrapolation is uncertain and $\gamma$ is held constant at 0.15 .

The moment coefficient $C_{m}$ for a disc of finite thickness is related to the moment coefficient $C_{m_{0}}$ for a disc of zero thickness by $\mathrm{Eq}$. (5) of Ref. 16 :

$$
c_{m}=c_{m_{0}}\left(1+2.3 \frac{C}{R_{w}}\right)
$$


Using the exponent $\gamma$ to correct from $R e=10^{6}$, and factoring out the thickness/radius ratio $c / R_{w}=0.14$ for which Table 3 applies, the zero-thickness moment coefficient as a function of Reynolds number is

$$
c_{m_{0}}=\frac{c_{m}^{*}\left(10^{6} / \operatorname{Re}\right)^{\gamma}}{1+(2.3)(0.14)}
$$

Equation $(A-45)$ can then be applied to find the moment coefficient for the actual thickness/radius ratio $C / R_{w}$.

The windage torque $M$ on one side of the disc is found from Eq. (2) of Ref. 16:

$$
M=0.25 \mathrm{C}_{\mathrm{m}}^{p} \mathrm{~g}^{\omega \mathrm{R}_{\mathrm{w}}}
$$

For a single-stage turbine, $\omega$ is the rotor speed and $M$ is doubled to give the total windage torque $L_{w}$. For multiple stages the relative $w$ values on each side of the disc are calculated and used with the proper signs to give the windage torques $M_{1}$ and $M_{2}$ on the inlet and exit sides, respectively (positive for a retarding torque and negative for an accelerating torque).

\section{Torque, Power, and Efficiency}

The force exerted by the 1 iquid on the blades is equal to the change in liquid momentum in the direction of blade motion. For the angles as defined in Fig. A-2,

$$
F_{\ell}=\dot{m}_{\ell}\left(v_{i n} \cos A_{i n}-v_{\text {out }} \cos A_{\text {out }}\right)
$$

The torque of the 1 iquid phase is the product of the liquid force and the rotor radius:

$$
L_{\ell}=F_{\ell} R_{b}
$$


The gas phase acts independently of the liquid phase, and the gas-phase torque can be calculated by conventional methods. The present program uses the approximation that the gas-phase torque varies linearly from maximum at zero speed to zero at synchronous speed (equal blade and gas speed), with a specified fraction of ideal torque denoted by $\eta_{g}$. The factor $n_{g}$ is also the gas-phase efficiency at half synchronous speed. This assumption gives the following gas-phase torque equation

$$
I_{g}=2{ }_{g} \dot{m} V_{g} R_{b}\left(1-V_{b} / V_{g}\right)
$$

The total blade torque is the sum of the liquid and gas torques, $L_{b}=L_{l}+I_{g}$, and the net rotor torque is the blade torque less the windage torque, $I_{r}=L_{b}-L_{w} \cdot$ The blade output power is

$$
\mathbf{P}_{\mathbf{b}}=\mathbf{L}_{b} \omega
$$

and the net rotor power is

$$
P_{\mathbf{r}}=\mathrm{L}_{\mathbf{r}} \boldsymbol{\omega}
$$

These powers are summed over each stage for a multistage turbine.

The power in the incoming jet is

$$
P_{j e t}=\frac{1}{2}\left(\dot{m}_{\ell} v_{\ell}^{2}+\dot{m}_{g} v_{g}^{2}\right)
$$

The blade efficiency is the ratio of blade power to jet power:

$$
{ }_{b}=\frac{P_{b}}{P_{j e t}}
$$

The rotor efficiency is the ratio of rotor power to jet power:

$$
n_{r}=\frac{P_{r}}{P_{j e t}}
$$


The turbine efficiency is

$$
n_{t}=n_{r} n_{n}
$$

where $\eta_{n}$ is the nozzle efficiency.

J. Divergence and Stagnation Losses

Equations $(A-1)$ through (A-56) define what is meant by "theoretical" in this report. The losses modeled are impact and friction for the liquid, the specified torque factor $\eta_{g}$ for the gas, and the Ref. 16 moment coefficients for windage.

Two additional losses can be calculated in the program. The effect on torque of the spreading of the liquid leaving the blades is calculated by specifying a mean divergence angle $A_{d i v}$ for the exit liquid flow. The relative exit velocity $v_{3}$ is then corrected to

$$
v_{3}^{\prime}=v_{3} \cos A_{d i v}
$$

A fraction $f_{\text {stag }}$ of the 1 iquid can be specified as stagnating in the rotor and leaving at rotor speed. The force exerted by this liquid is

$$
F_{\ell \text { stag }}=\dot{m}_{\ell} f_{\text {stag }}\left(V_{i n} \cos A_{i n}-V_{b}\right)
$$

The force of the main flow is $\left(1-f_{\text {stag }}\right)$ times the force given by Eq. $(A-48)$. The total liquid force is that force plus $F_{\text {latag }}$. The result is 


$$
F_{\ell}=\dot{m}_{\ell}\left[V_{i n} \cos A_{i n}-\left(1-f_{s t a g}\right) V_{\text {out }} \cos A_{\text {out }}-f_{s t a g} V_{b}\right] \quad(A-59)
$$

The inlet velocity to the next stage is assumed to be the weighted average of the main-flow and stagnated-flow velocities:

$$
\vec{v}_{\text {in }_{k+1}}=\left(1-f_{\text {stag }}\right) \vec{v}_{\text {out }_{k}}+f_{\text {stag }} \vec{v}_{b_{k}}
$$

\section{K. Optimization}

The program can be used in an optimization search mode. In this mode the program varies the rotor speeds and (optiona1ly) the blade inlet angles for each stage until the maximum rotor efficiency $n_{r}$ is found.

\section{Program Listing}

A listing of the computer program follows. The subroutine ZPMIN referenced is a library routine for minimization. Decks of the rotor program including ZPMIN are available from JPL.

The nomenclature used in the program is defined in Table A-1. 


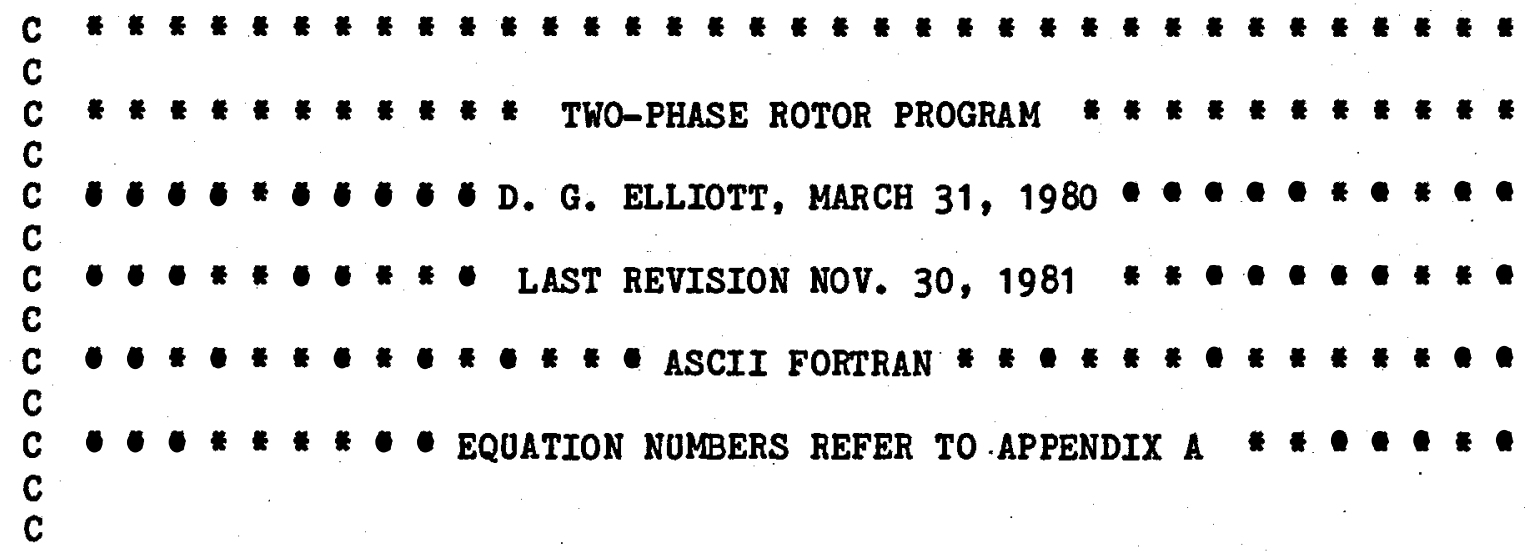

PARAMETER MXSTG $=2$, MXSTEP $=20$ C MAX STAGES AND IMPINGEMENT STEPS PARAMETER $N=M X S T G, N 1=2 * N, N 2=N 1 *(N 1+3), N 3=M X S T E P+1$

C IMPLICIT REAL(L,M)

REAL $A 1(N), A 2(N), A 3(N), R 1(N), R 2(N), \operatorname{RPM}(N), L E X T(N)$ INPOT ARRAYS $\operatorname{REAL} \operatorname{AIN}(N), \operatorname{AOUT}(N), \operatorname{AVi}(N), \operatorname{CFF}(N), \operatorname{FL}(N), \operatorname{L1}(N), \operatorname{LB}(N)$

$\operatorname{REAL} \operatorname{LG}(N), \operatorname{LIMP}(N), \operatorname{LL}(N), \operatorname{LSORF}(N), \operatorname{LR}(N), \operatorname{LW}(N), \operatorname{REF}(N)$

REAL V1(N), V2(N), V3(N), VB(N), VIN(N), $\operatorname{VOUT}(N), \operatorname{WW}(N)$

REAL THETA(N3), X(N1), XBEST(N1), WA(N2), EPSX(10)

C

$\operatorname{COMPLEX~} \operatorname{CV} 1(N), \operatorname{CV} 3(N), \operatorname{CVB}(N), \operatorname{CVIN}(N), \operatorname{CVOUT}(N), \operatorname{POLAR}$

C

NAMELIST /IN/WN, EN, HB, ANOZ, RPM, ML , VL , MG, VG , R1 , R2, LEXT , A1 , A2 , A3,

$\&$

$\&$ SB, RB, RW , RHOL , RHOG , VISCL , VISCG , NSTG , NSTEP, ADIV, NR1, ETAG, ETAN, FSTAG, NINPT, NDET, NOPT, NMON

NAMELIST /OOT1/LB, PB,ETAB, RPM

NAMELIST /OUT2/LR, PR,ETAR,ETAT

NAMELIST /OOT3/LL, LG, LW

NAMELIST /OOT4/A1, VB, VIN, AIN, V1 , AV1, V2,L1, LIMP, LSORF, V3,

$\&$ AOUT, VOUT, WW, RAP1, MB, REF, CFF, TFILM

NAMELIST /OOT5/CV1,CV3, CVB, CVIN,CVOOT

NAMELIST /OOT6/MO,MM, ME, REM, CFM, TERM2, VO, VE

C

C

***:*: FONCTIONS E**:

$\operatorname{XSIN}(A)=\operatorname{SIN}\left(P P^{*} A\right)$ C SINE OF ANGLE 'A' IN DEGREES

$X \cos (A)=\cos \left(P X^{*} A\right)$ C $\operatorname{cosINE}$ OF ANGLE ' $A$ ' IN DEGREES

$\operatorname{XTAN}(A)=\operatorname{TAN}(P X * A)$ C TANGENT OF ANGLE 'A' IN DEGREES

$\operatorname{PHASE}(C)=180 / \operatorname{PI} * \operatorname{ATAN2}(\operatorname{AIMAG}(\mathrm{C})$,

\&SIGN(MAX(ABS(REAL(C)), 1E-38), REAL(C))) EANGLE OF C,DEG CCW FROM X-AXIS

POLAR(AMP, ANG) =CMPLX(AMP $X C O S$ (ANG), AMP*XSIN(ANG)) V VECTOR (AMPL, ANGLE)

C

C

*E:E* CONSTANTS AND DEFAULT INPUTS *E:E:

DATA EPSE/1E-4/,EPSX/10*1E9/,ITMAX/100/ C CONSTANTS FOR SEARCH ROOTINE DATA $A 1 / N * 20 . /, A 2 / N * 60 . /, N S T E P / 20 /$ EDEFAULT INPUTS

$\mathrm{PI}=4.0 * \operatorname{ATAN}(1.0)$

$\mathrm{PX}=\mathrm{PI} / 180$

$P X X=180 / P I$ 


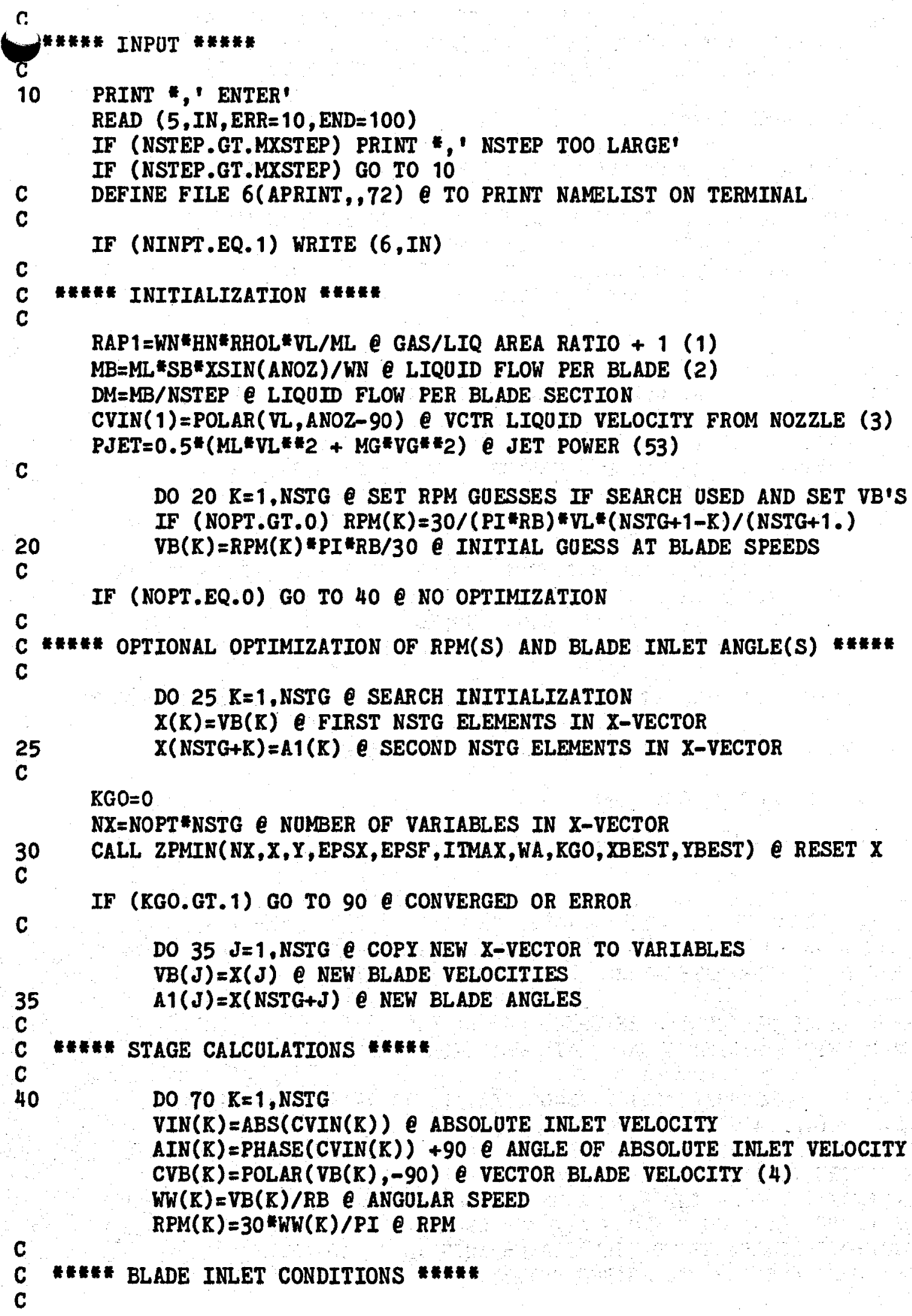


$\operatorname{CV} 1(K)=\operatorname{CVIN}(K)-\operatorname{CVB}(\mathrm{K})$ Q VECTOR RELATIVE INLET VELOCITY (5)

$V 1(K)=A B S(C V 1(K))$ C ABSOLOTE RELATIVE INLET VELOCITY (6)

C

C

$\operatorname{AV1}(\mathrm{K})=\operatorname{PHASE}(\mathrm{CV} 1(\mathrm{~K}))+90$ ANGLE OF RELATIVE INLET VEL (7)

*E: E* IMPINGEMENT ANGLES **E:

$A I 0=A 1(K)+A V 1(K)-90$ INLET IMPINGEMENT ANGLE (BELOW SORFACE) IF (AIO.GE.O) THEN

IF (NOPT.EQ.0) PRINT $\vDash, '$ IMP',AIO,' BELOW SORFACE IN STG', $K$

IF (NOPT.EQ.0) GO TO 10 Q ASK FOR NEW INPOTS

ETAR=0 $Q$ LOW VALOE TO TELL SEARCH THIS IS A BAD ANGLE GO TO 83 \& RETORN TO SEARCH DRIVER

END IF

C

NSTEP $1=$ NSTEP +1

$A X 1=A 1(K)$ INITIAL GOESS AT ANGLE FROM CNTR BACK TO IMP PT

C

DO $55 \mathrm{~J}=1$, NSTEP1 1 FOR EACH STREAM TOBE PLOS LAST STREAMLINE YST $=S B *(J-0.5) / N S T E P$ C CENTER DISTANCE OF STREAM TOBE IF (J.EQ.NSTEP 1) YST $=S B$ Q LAST STREAMLINE $C 1=\operatorname{XSIN}(A 1(K))+(X \operatorname{COS}(A 1(K))-Y S T / R 1(K)) * \operatorname{XTAN}(A V 1(K))$ e (10)

C DO $50 \mathrm{JJ}=1,100$ ITERATE EQ. (9) OP TO 100 TIMES FOR AX $A X=P X X * A S I N(C 1-X T A N(A V 1(K)) * X C O S(A X 1)) @ N E W A X(9)$ IF (ABS(AX-AX1).LT.0.01) GO TO 55 CONV TO 0.01 DEG

50 CALL RGLESI ( $A X 1, A X, J J)$ \& CALL REGULA-FALSI ITERATION

C PRINT *,' DID NOT CONVERGE ON AX IN STAGE', $\mathrm{K}$ AFTER 100 TIMES

C 55 THETA $(J)=90-A \nabla 1(K)-A X$ IMPINGEMENT ANGLE (11)

C

C : E* IMPACT AND FRICTION LOSS

C

C

VO=0 2 DOMMY VALOE OF INLET VELOCITY FOR FIRST SECTION

DO $60 \mathrm{~J}=1$,NSTEP 2 CALCOLATE VELOCITY LEAVING EACH SECTION

$M O=(J-1) \approx D M$ C FLOW RATE AT INLET OF SECTION

$M M=M O+D M / 2$ F FLW RATE AT MIDDLE OF SECTION

C $M E=J * D M$ E FLOW RATE AT END OF SECTION

REM $=4$ *MM (HN*VISCL) 2 REYNOLDS NOMBER (17)

CALL FRIC(REM,CFM) Q CALCOLATE FRICTION COEFFICIENT

C

$\mathrm{Z} 1=(1.0+M 0 * \mathrm{VO} /(\mathrm{DM} * \mathrm{~V} 1(\mathrm{~K}) * \mathrm{XCOS}(\operatorname{THETA}(\mathrm{J})))) *(\mathrm{DM} / \mathrm{ME}) * 2$

$\mathrm{Z2}=\operatorname{XSIN}(\operatorname{THETA}(\mathrm{J})) * M E /($ CFM $* R A P 1 * D M)$

TERM2=2:CFM*RAP1:Z1/XTAN(THETA(J)) \& 2ND TERM IN SQRT

IF (TERM2.LT.1E-12) THEN

IF (NOPT.EQ.0) PRINT \&,' TERM2 TOO SMALL'

IF (NOPT.EQ.0) GO TO 10 ASK FOR NEW INPOTS

ETAR=0 LOW VALOE TO TELL SEARCH THIS IS A BAD ANGLE

GO TO 83 C RETORN TO SEARCH DRIVER

END IF 
${ }^{c}$

60

C

C

C

C

C

C

C

C

C

C

C

C

C

C

\& $\quad-\operatorname{XSIN}(A 3(K)))+\operatorname{LEXT}(K) * X \operatorname{COS}(A 2(K))$ e BLADE CHORD (42)

$V E=V 1(K) * Z 2 *(\operatorname{DSQRT}(1.0 D 0+T E R M 2)-1.0 D O)$ SECTION EXIT VEL (28)

IF (NDET.GE.7) PRINT OOT6

VO=VE $C$ INLET VELOCITY FOR NEXT SECTION

V2(K) $=$ VE $\&$ LIQUID VELOCITY LEAVING IMPINGEMENT ZONE

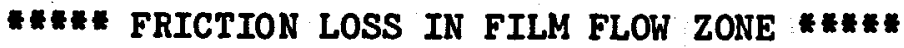

$\operatorname{REF}(K)=4 * M B /(H N * V I S C L)$ REYNOLDS NOMBER IN FILM ZONE (30)

CALL FRIC( REF(K),CFF(K)) C FRICTION COEFF IN FILM ZONE

IF (NOPT.EQ.0.AND.-AX.GT.A3(K)) PRINT*,' IMP BEYOND R1, STG',K

IF (NOPT.GT.1.OR.NR1.EQ.1) $A 3(K)=-A X$ C SET END OF R1 AT LAST STRMLN

$L 1(K)=R 1(K) *(A 1(K)+A 3(K)) * P X$ C LENGTH TO END OF INLET RADIOS (31)

$\operatorname{LIMP}(K)=R 1(K) *(A 1(K)-A X) * P X$ C LENGTH TO END OF IMPINGEMENT ZONE (32)

$\operatorname{LSORF}(K)=L 1(K)+R 2(K) *(A 2(K)-A 3(K)) * P X+L E X T(K)$ C TTL SURF LENGTH (33)

LFILM=LSURF $(K)$-LIMP(K) L LENGTH OF FILM-FLOW ZONE (34)

$V 3(K)=1 /(1 / V 2(K)+0.5$ RHOL $\operatorname{CFF}(K)$ HNELILM/MB ) REL EXIT VEL (36)

TFILM=MB/(RHOL *HN*V3(K)) \& FILM THICKNESS LEAVING BLADE

$V 3(K)=V 3(K) * X C O S(A D I V)$ C CORR FOR FLOW DIVERGENCE IF ADIV>0 (57)

****:* BLADE EXIT CONDITIONS **:**:

$\operatorname{CV} 3(K)=\operatorname{POLAR}(V 3(K), A 2(K))$ Q VCTR RELATIVE EXIT VELOCITY (37)

$\operatorname{CVOOT}(\mathrm{K})=\mathrm{CV} 3(\mathrm{~K})+\mathrm{CVB}(\mathrm{K})$ Q VCTR ABSOLOTE EXIT VELOCITY (38)

$\operatorname{VOUT}(K)=A B S(C V O U T(K))$ ABSOLOTE EXIT VELOCITY . (39)

$\operatorname{AOUT}(K)=90+\operatorname{PHASE}(\operatorname{CVOUT}(K))$ \& ANGLE OF ABSOLUTE EXIT VELOCITY (40)

****: WINDAGE TORQUE *****:

IF (K.EQ.1) WREL $1=V B(K) / R B$ \& REL INLET ANG VEL FIRST STAGE

IF (K.GT.1) WREL $1=(\operatorname{VB}(K)-V B(K-1)) / R B$ C STAGES AFTER FIRST

IF (K.LT.NSTG) WREL2 $=(\mathrm{VB}(K)-\mathrm{VB}(\mathrm{K}+1)) / R B$ C STAGES BEFORE LAST

IF (K.EQ.NSTG) WREL2=VB(K)/RB $P$ REL EXIT ANG VEL LAST STAGE

RE1 =RHOG*ABS(WREL1) *RW*2 /VISCG $O$ REYNOLDS NO., INLET SIDE (41)

RE2 =RHOG*ABS (WREL2) *RW*2 /VISCG Q REYNOLDS NO., EXIT SIDE (41)

RE1 =MAX(RE1,100) C TO PREVENT OVERFLOW IN CMO1 AT ZERO SPEED

RE2 $=M A X(R E 2,100)$ TO PREVENT OVERFLOW IN CMO2 AT ZERO SPEED

$\mathrm{CC}=\mathrm{R} 1(\mathrm{~K}) *(\operatorname{XSIN}(A 1(K))+X \operatorname{SIN}(A 3(K)))+R 2(K) *(X \operatorname{XSIN}(A 2(K))$

$A R=H B / C C$ C ASPECT RATIO OF BLADES

CMSTAR $=0.0067+0.007 * A R * 0.6$ \& FIT TO MANN \& MARSTON TABLE 3 (43)

GAMMA $=$ MAX $(0.21-0.086 * A R, 0.15)$ OFIT TO MANN \& MARSTON TABLE 3 (44)

CM01 $=$ CMSTAR $=((1 E 6 /$ RE1 $) *$ KGAMMA $) /(1+2.3 * 0.14)$ C AT RE1, CC=0 (46)

CMO2 $=$ CMSTAR $*((1 E 6 / R E 2) *$ *GAMMA $) /(1+2.3 * 0.14)$ C AT RE2, CC=0 (46)

CM1 $=\mathrm{CMO1} *\left(1+2.3^{*} \mathrm{CC} / \mathrm{RW}\right)$ B BLADED MOMENT COEFF, INLET SIDE (45)

CM2 $=$ CMO2 $\left(1+2.3^{*} \mathrm{CC} / \mathrm{RW}\right)$ BLADED MOMENT COEFF, EXIT SIDE (45) 


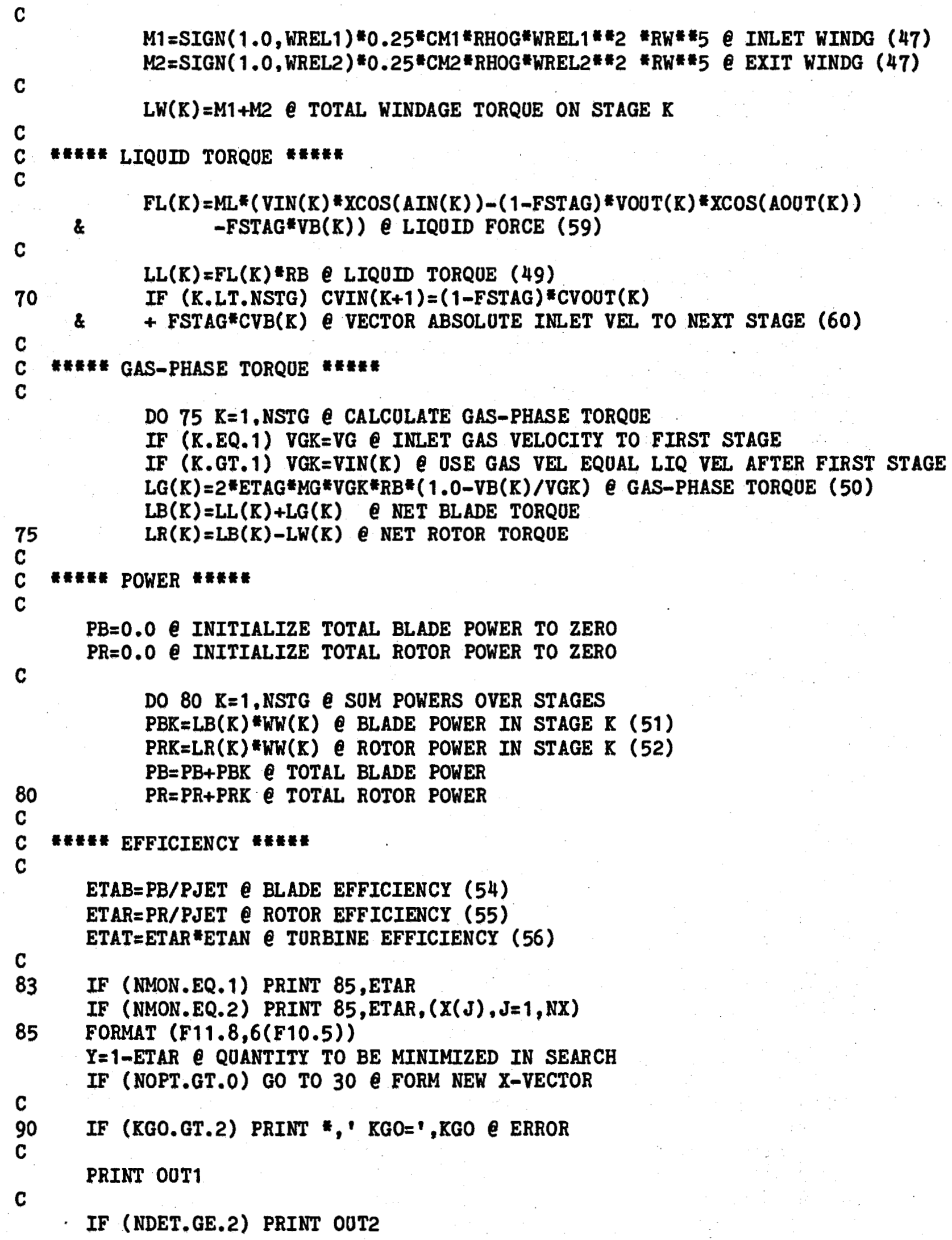




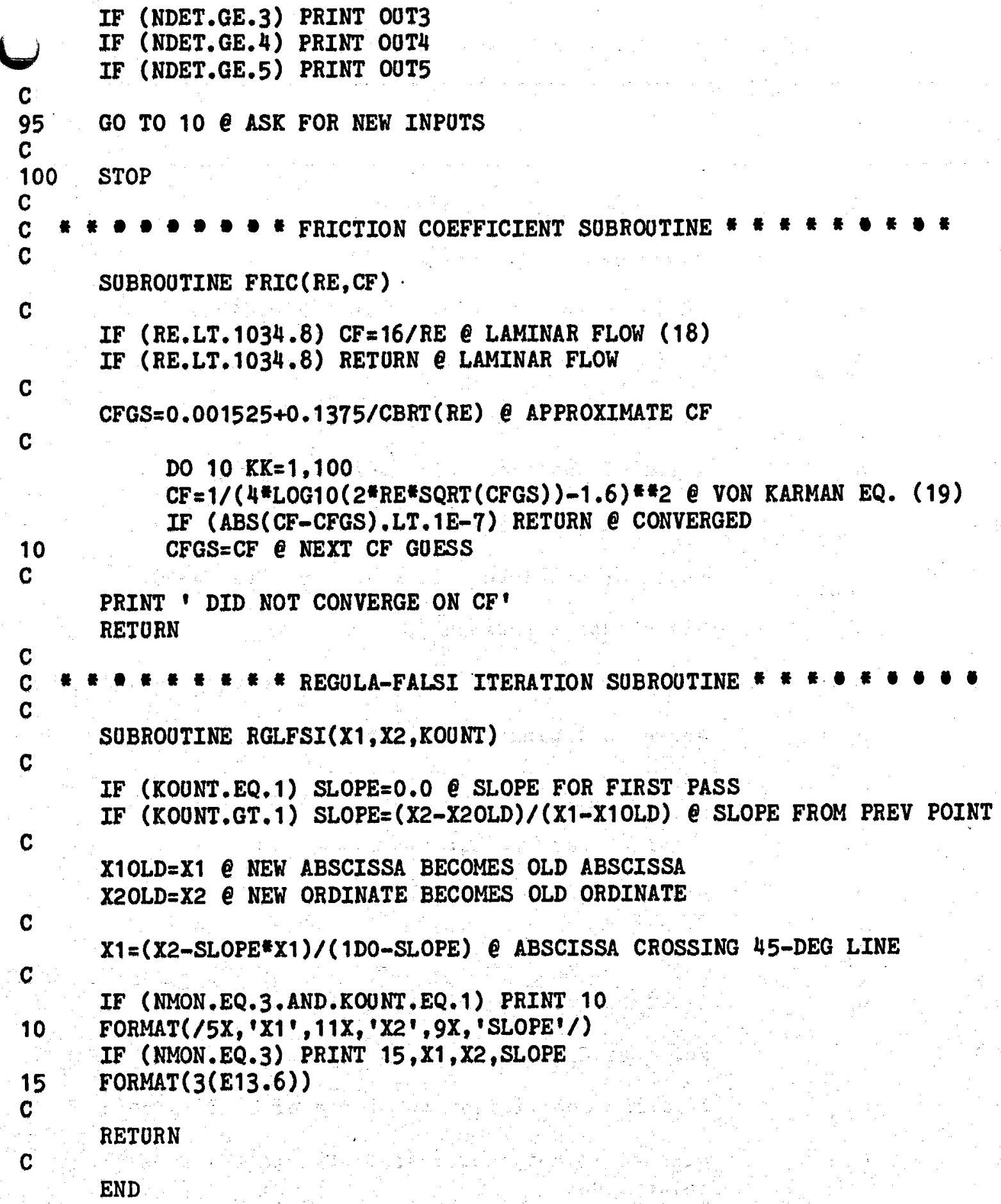


Table A-1. Rotor model nomenclature

\begin{tabular}{|c|c|c|}
\hline Program & Text & Definition \\
\hline Al & $A_{1}$ & blade inlet angle (Fig. A-1) \\
\hline A2 & $A_{2}$ & blade exit angle (Fig. A-1) \\
\hline A3 & $\mathrm{A}_{3}$ & angle to end of inlet radius (Fig. A-1) \\
\hline ADIV & Adiv & average divergence angle of exit flow \\
\hline AIO & & impingement angle at blade inlet \\
\hline AIN & An & angle of absolute inlet velocity (Fig. $A-2$ ) \\
\hline ANOZ & $A_{\text {noz }}$ & nozzle angle (Fig. A-1) \\
\hline AOUT & A out & angle of absolute exit velocity (Fig. A-2) \\
\hline AR & AR & blade aspect ratio $\mathrm{H}_{\mathrm{b}} / \mathrm{C}$ \\
\hline AV1 & ${ }^{A}$ 1 & angle of relative inlet velocity (Figs. $A-1, A-2$ ) \\
\hline $\mathrm{AX}$ & $\mathbf{A}_{\mathbf{x}}$ & angle to impingement point (Fig. $A-3$ ) \\
\hline $\mathrm{AX1}$ & & guess at $\mathrm{AX}$ \\
\hline $\mathrm{Cl}$ & $\mathrm{C}_{1}$ & constant term in Eq. (A-9) \\
\hline $\mathrm{cc}$ & $\mathrm{C}$ & blade chord (Fig. A-3) \\
\hline CF & $\mathrm{c}_{\mathrm{f}}$ & friction coefficient \\
\hline CFF & $\mathrm{C}_{\mathrm{ff}}$ & friction coefficient in film-flow zone \\
\hline CFGS & & guess at $\mathrm{C}_{\mathrm{f}}$ \\
\hline CFM & $\mathrm{C}_{\mathbf{f m}}$ & friction coefficient in middle of blade section \\
\hline CMO 1 & $\mathrm{C}_{\mathrm{m}}$ & $\begin{array}{l}\text { windage moment coefficient at zero thickness, } \\
\text { inlet side }\end{array}$ \\
\hline $\mathrm{CMO} 2$ & $\mathrm{c}_{\mathrm{m}}$ & $\begin{array}{l}\text { windage moment coefficient at zero thickness, } \\
\text { exit side }\end{array}$ \\
\hline
\end{tabular}


Table A-1 (contd)

\begin{tabular}{|c|c|c|}
\hline Program & Text & Definition \\
\hline CM1 & $\mathbf{c}_{\mathbf{m}}$ & windage moment coefficient on inlet side \\
\hline CM2 & $\mathrm{c}_{\mathrm{m}}$ & windage moment coefficient on exit side \\
\hline CMSTAR & $\mathrm{c}_{\mathrm{m}}{ }^{*}$ & $\begin{array}{l}\text { windage moment coefficient for } R_{e}=10^{6} \\
\text { and } C / R_{w}=0.14\end{array}$ \\
\hline CV 1 & $\overrightarrow{\mathrm{v}}_{\mathbf{1}}$ & vector relative inlet velocity (Fig. $A-2$ ) \\
\hline cv3 & $\overrightarrow{\mathrm{V}}_{3}$ & vector relative exit velocity (Fig. $A-2$ ) \\
\hline CVB & $\overrightarrow{\mathbf{v}}_{\mathbf{b}}$ & vector blade velocity (Fig. A-2) \\
\hline CVIN & $\overrightarrow{\mathrm{v}}_{\mathbf{i n}}$ & vector absolute inlet velocity (Fig. $A-2$ ) \\
\hline cVouT & $\overrightarrow{\mathrm{v}}_{\text {out }}$ & vector absolute exit velocity (Fig. $A-2$ ) \\
\hline DM & dm & $\begin{array}{l}\text { liquid flow rate impinging on blade section } \\
\text { (Fig. A-5) }\end{array}$ \\
\hline & $D_{h}$ & hydraulic diameter \\
\hline EPSF & & $\begin{array}{l}\text { convergence criterion on dependent variable } \\
\text { in search routine }\end{array}$ \\
\hline EPSX & & $\begin{array}{l}\text { convergence criterion on independent variable } \\
\text { in search routine }\end{array}$ \\
\hline ETAB & $n_{\mathbf{b}}$ & blade efficiency $P_{b} / P_{j e t}$ \\
\hline ETAG & $n g$ & gas torque factor (peak gas-phase efficiency) \\
\hline ETAN & $n_{n}$ & nozzle efficiency \\
\hline ETAR & $n_{r}$ & rotor efficiency $P_{r} / P_{j e t}$ \\
\hline ETAT & $n_{t}$ & turbine efficiency $n_{r} n_{n}$ \\
\hline FL & $\mathbf{F}_{\boldsymbol{l}}$ & force of liquid phase \\
\hline FSTAG & $f_{\text {stag }}$ & $\begin{array}{l}\text { specified fraction of liquid flow stagnated } \\
\text { in the rotor }\end{array}$ \\
\hline
\end{tabular}


Table A-1 (contd)

\begin{tabular}{|c|c|c|}
\hline Program & Text & Definition \\
\hline GAMMA & $r$ & $\begin{array}{l}\text { exponent of Reynolds number in moment } \\
\text { coefficient }\end{array}$ \\
\hline HB & $\mathrm{H}_{\mathrm{b}}$ & blade height (Fig. A-1) \\
\hline $\mathrm{HN}$ & $H_{n}$ & nozzle height (Fig. A-1) \\
\hline I TMAX & & maximum number of iterations in search routine \\
\hline KGO & & flag used to control search routine \\
\hline L1 & $\mathrm{L}_{1}$ & length to end of inlet radius (Fig. A-6) \\
\hline LB & $\mathrm{L}_{\mathrm{b}}$ & blade torque \\
\hline LEXT & $L_{\text {ext }}$ & length of straight extension (Fig. A-1) \\
\hline LFILM & $\mathrm{L}_{\mathrm{Film}}$ & length of film flow zone (Fig. A-6) \\
\hline LG & $\mathrm{L}_{\mathrm{g}}$ & gas-phase torque \\
\hline L IMP & $\mathrm{L}_{\text {imp }}$ & length of impingement zone (Fig. A-6) \\
\hline LL & $\mathrm{L}_{\ell}$ & 1iquid-phase torque \\
\hline LR & $\mathrm{L}_{\mathbf{r}}$ & rotor torque \\
\hline LSURF & $\mathrm{L}_{\text {surf }}$ & blade surface length (Fig. A-6) \\
\hline LW & $\mathbf{L}_{\mathbf{w}}$ & windage torque \\
\hline MO & $\dot{\mathrm{m}}_{0}$ & $\begin{array}{l}\text { liquid flow rate entering blade section } \\
\text { (Fig. A-5) }\end{array}$ \\
\hline M1 & $M_{1}$ & windage torque on inlet side \\
\hline M2 & $\mathrm{M}_{2}$ & windage torque on exit side \\
\hline MB & $\dot{m}_{b}$ & liquid flow rate on each blade \\
\hline ME & $\dot{\mathrm{m}}_{\mathrm{e}}$ & $\begin{array}{l}\text { liquid flow rate leaving blade section } \\
\text { (Fig. } A-5 \text { ) }\end{array}$ \\
\hline
\end{tabular}


Table A-1 (contd)

\begin{tabular}{|c|c|c|}
\hline Program & Text & Definition \\
\hline & & - \\
\hline MG & $\dot{\mathbf{m}}_{\mathbf{g}}$ & gas flow rate \\
\hline ML & $\dot{\mathrm{m}}_{\boldsymbol{\ell}}$ & liquid flow rate \\
\hline MM & $\dot{\mathrm{n}}_{\mathrm{m}}$ & $\begin{array}{l}\text { liquid flow rate in middle of blade section } \\
\text { (Fig. A-5) }\end{array}$ \\
\hline MXSTEP & & $\begin{array}{l}\text { maximum number of steps for blade impact and } \\
\text { friction calculation }\end{array}$ \\
\hline NDET & & selects level of detail of printout \\
\hline NINPT & & 1 for printout of inputs \\
\hline NMON & & 1 or 2 for monitoring of search \\
\hline NOPT & & $\begin{array}{l}1 \text { for rpm optimization, } 2 \text { for } \mathrm{rpm} \text { and blade } \\
\text { angle optimization }\end{array}$ \\
\hline NR1 & & $\begin{array}{l}\text { selects matching of blade inlet length to } \\
\text { impingement length }\end{array}$ \\
\hline NSTEP & & $\begin{array}{l}\text { number of blade steps for impact and friction } \\
\text { calculation }\end{array}$ \\
\hline NSTEP 1 & & NSTEP +1 \\
\hline NSTG & & number of rotor stages \\
\hline NX & & number of variables to be optimized \\
\hline PB & & total blade power $L_{b} \omega$ \\
\hline PBK & $\mathbf{P}_{\mathbf{b}}$ & blade power in stage $\mathrm{K}$ \\
\hline PI & $\pi$ & 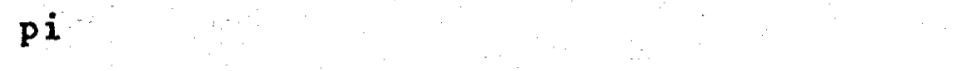 \\
\hline PJET & $P_{\text {jet }}$ & jet power $\frac{1}{2}\left(\dot{\mathrm{m}}_{l} \mathrm{v}_{\ell}^{2}+\dot{\mathrm{m}}_{g} \mathrm{v}_{\mathrm{g}}^{2}\right)$ \\
\hline PR & & total rotor power $L_{r^{w}}$ \\
\hline PRK & $\mathbf{P}_{\mathbf{r}}$ & rotor power in stage $K$ \\
\hline
\end{tabular}


Table A-1 (contd)

\begin{tabular}{|c|c|c|}
\hline Program & Text & Definition \\
\hline $\mathbf{P X}$ & & $\pi / 180$ \\
\hline $\mathbf{P X X}$ & & $180 / \pi$ \\
\hline R1 & $\mathrm{R}_{1}$ & blade inlet radius (Fig. $A-1$ ) \\
\hline R2 & $\mathrm{R}_{2}$ & blade exit radius (Fig. $A-1$ ) \\
\hline & $\mathbf{R}_{\mathbf{a}}$ & gas/liquid flow area ratio \\
\hline RAP1 & & $R_{a}+1$ \\
\hline RB & $\mathbf{R}_{\mathbf{b}}$ & $\begin{array}{l}\text { rotor radius at center of nozzle exit } \\
\text { (Fig. } \mathrm{A}-1 \text { ) }\end{array}$ \\
\hline RE & $\operatorname{Re}$ & Reynolds number \\
\hline RE1 & $\mathrm{Re}_{1}$ & Reynolds number of windage flow on inlet side \\
\hline RE2 & $\mathrm{Re}_{2}$ & Reynolds number of windage flow on exit side \\
\hline REF & $\operatorname{Re}_{\mathbf{f}}$ & Reynolds number of film flow \\
\hline REM & $\operatorname{Re}_{\mathrm{m}}$ & Reynolds number in middle of blade section \\
\hline RHOG & ${ }^{\circ} g$ & gas density \\
\hline RHOL & $\rho_{\ell}$ & liquid density \\
\hline RPM & & rotor speed, revolutions per minute \\
\hline RW & $\mathbf{R}_{\mathbf{w}}$ & outside radius of rotor (Fig. $A-1$ ) \\
\hline SB & $s_{b}$ & blade spacing (Fig. A-1) \\
\hline TERM2 & & $\begin{array}{l}\text { second term under the square root in } \\
\text { Eq. }(A-28)\end{array}$ \\
\hline TFILM & & thickness of liquid film leaving blade \\
\hline & $t_{m}$ & $\begin{array}{l}\text { thickness of liquid film in middle of blade } \\
\text { section (Fig. A-5) }\end{array}$ \\
\hline THETA & $\theta$ & impingement angle (Fig. A-3) \\
\hline
\end{tabular}




\begin{tabular}{|c|c|c|}
\hline Program & Text & Definition \\
\hline vo & $v_{0}$ & $\begin{array}{l}\text { velocity of liquid film entering blade section } \\
\text { (Fig. A-5) }\end{array}$ \\
\hline v1 & $\mathrm{v}_{1}$ & relative inlet velocity (Fig. A-1) \\
\hline V2 & $v_{2}$ & $\begin{array}{l}\text { velocity of liquid leaving impingement zone } \\
\text { (Fig. A-1) }\end{array}$ \\
\hline v3 & $\mathbf{v}_{3}$ & relative exit velocity (Fig. $A-1$ ) \\
\hline VB & $\mathbf{v}_{\mathbf{b}}$ & blade velocity (Fig. $A-1$ ) \\
\hline VE & $\mathbf{v}_{\mathbf{e}}$ & $\begin{array}{l}\text { velocity of liquid leaving blade section } \\
\text { (Fig. A-5) }\end{array}$ \\
\hline VG & $\mathbf{v}_{\mathbf{g}}$ & gas velocity \\
\hline VGK & & inlet gas velocity to stage $K$ \\
\hline VIN & $v_{\text {in }}$ & $\begin{array}{l}\text { absolute inlet velocity (Fig. A-2) } \\
\text { velocity of liquid in middle of blade section } \\
\text { (Fig. A-5) }\end{array}$ \\
\hline VISCG & ${ }^{\mu} \mathbf{g}$ & gas viscosity \\
\hline VISCL & $\mu_{\ell}$ & liquid viscosity \\
\hline VL & $\mathbf{v}_{\ell}$ & liquid velocity \\
\hline VouT & $v_{\text {out }}$ & absolute exit velocity (Fig. $A-2)$ \\
\hline WA & & array used in search routine \\
\hline WN & $\mathbf{w}_{\mathbf{n}}$ & nozzle width (Fig. A-1) \\
\hline WRELI & & $\begin{array}{l}\text { speed of rotor relative to previous stage or } \\
\text { atmosphere }\end{array}$ \\
\hline WREL2 & & $\begin{array}{l}\text { speed of rotor relative to next stage or } \\
\text { atmosphere }\end{array}$ \\
\hline
\end{tabular}


Table A-1 (contd)

\begin{tabular}{|c|c|c|}
\hline Program & Text & Definition \\
\hline WW & $\omega$ & rotor speed, radians per second \\
\hline $\mathrm{x}$ & & array used in search routine \\
\hline XBEST & & array used in search routine \\
\hline $\mathbf{Y}$ & & $\begin{array}{l}1-n_{r}, \text { quantity minimized in optimization } \\
\text { search }\end{array}$ \\
\hline YBEST & & variable used in search \\
\hline YST & $Y_{\text {st }}$ & $\begin{array}{l}\text { distance of streamline from blade inlet } \\
\text { (Fig. A-3) }\end{array}$ \\
\hline $\mathbf{Z 1}$ & & $\begin{array}{l}\text { product of last two factors in second term } \\
\text { under the square root in Eq. (A-28) }\end{array}$ \\
\hline 22 & & product of first two factors in Eq. $(A-28)$ \\
\hline
\end{tabular}




\section{SEPARATOR TURBINE MODEL}

Figure B-1 shows the geometry of the separator turbine. The two-phase flow enters at radius $R_{\text {noz }}$ and angle $A_{\text {noz }}$. The liquid has flow rate $\dot{\mathrm{m}}_{\ell}$ and velocity $v_{\ell}$. The gas has flow rate $\dot{m}_{g}$ and velocity $v_{g}$. The jet power is

$$
\left.P_{j e t}=\frac{3 / 2}{\dot{m}_{\ell} v_{\ell}}{ }^{2}+\dot{\mathrm{m}}_{g} v_{g}^{2}\right)
$$

\section{A. Separator Flow}

The liquid impinges on the inside wall of a rotary separator turning at angular velocity $\omega_{1}$. The liquid forms a spinning liquid layer of radius $R_{\text {sep }}$. The liquid is removed from the separator by a liquid turbine with one or more U-tube scoops turning at angular velocity $\omega_{2}$. The speed of the liquid layer is

$$
v_{\text {sep }}={ }^{w_{1}}{ }^{R} \text { sep }
$$

B. Liquid Turbine Flow

The speed of the scoop is

$$
v_{\text {turb }}=\omega_{2} R_{\text {sep }}
$$

The relative velocity of the liquid entering the scoop is

$$
v_{\text {rel }}=v_{\text {sep }}-v_{\text {turb }}
$$

The relative velocity of the liquid leaving the scoop is $\mathrm{v}_{\mathrm{re}}$. The scoop efficiency can be defined as the square of the ratio of exit ${ }^{2}$ velocity to inlet velocity. Thus, if the scoop efficiency $n_{\text {scoop }}$ is given, the relative exit velocity is 

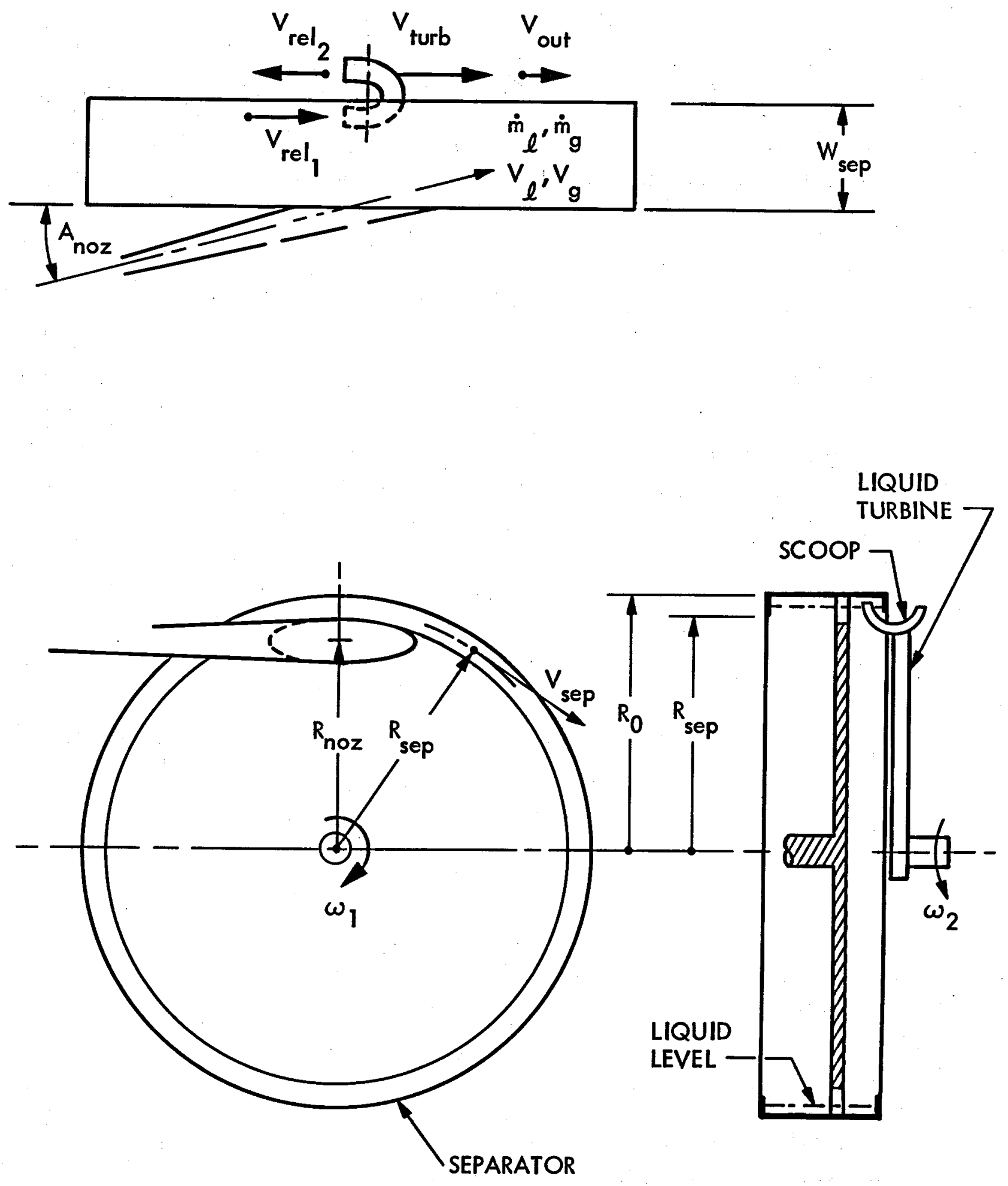

Fig. B-1. Separator turbine 


$$
v_{\mathrm{rel}_{2}}=v_{\mathrm{rel} 1} \sqrt{n_{\text {scoop }}}
$$

The absolute forward exit velocity of the liquid leaving the liquid turbine is

$$
v_{\text {out }}=v_{\text {turb }}-v_{\text {re1 }}
$$

The required inlet area of the scoop, or scoops, is

$$
A_{\text {scoop }}=\frac{\dot{m}_{\ell}}{v_{r e 1_{1}{ }^{{ } \ell}}}
$$

where $\rho_{\ell}$ is the liquid density.

The torque exerted on the scoop by external liquid drag can be expressed as a drag coefficient $C_{d}$ times the product of frontal area and dynamic pressure:

$$
L_{\text {ext }}=\frac{1}{2} C_{d} A_{\text {scoop }} \ell v_{\text {rel }}^{2}{ }_{1}^{R} \text { sep }
$$

c. Liquid Torque

The angular momentum of the liquid leaving the nozzle is

$$
M_{1}=\dot{m}_{\ell} V_{\ell}^{R} R_{n z} \cos A_{n o z}
$$

The angular momentum of the liquid leaving the separator is

$$
M_{2}=\dot{m}_{\ell} v_{\operatorname{sep}^{R}}^{R}
$$

The angular momentum of the liquid leaving the liquid turbine is

$$
M_{3}=\dot{\mathrm{m}}_{\ell} \mathrm{V}_{\text {out }}^{\mathrm{R}} \text { sep }
$$


The separator torque due to the liquid flow is equal to the change in angular momentum of the liquid in the separator minus the external drag of the liquid turbine:

$$
L_{i q}=M_{1}-M_{2}-L_{\text {ext }}
$$

The liquid turbine torque is equal to the change in angular momentum of the liquid in the turbine, plus the external drag.

$$
L_{\text {turb }}=M_{2}-M_{3}+L_{\text {ext }}
$$

D. Windage

The windage torque. of the separator can be calculated from the windage torque formulas of Appendix A, evaluated for a nonbladed disc. The Reynolds number is

$$
\operatorname{Re}=\frac{{ }^{\rho} g_{g}{ }_{1} R_{0}}{{ }_{g}}
$$

where $\rho_{g}$ is the gas density, $R_{0}$ is the separator outside radius, and $\mu_{g}$ is the gas viscosity.

With no blades, the aspect ratio AR is zero. From Eq. (A-43), the moment coefficient for a disc of thickness/radius ratio $=0.14$ at $\operatorname{Re}=10^{6}$ is $C_{m} *=0.0067$. From Eq. $(A-44)$, the exponent of the Reynolds number dependence is $\gamma=0.21$. From $\mathrm{Eq}$. $(\mathrm{A}-46)$, the moment coefficient for a thin disc at $\operatorname{Re}=10^{6}$ is then

$$
c_{m_{0}}=\frac{0.0067\left(10^{6} / \operatorname{Re}\right)^{0.21}}{1+(2.3)(0.14)}
$$


From Eq. $(A-45)$, the moment coefficient for the separator of width $W_{\text {sep }}$ is

$$
c_{m_{0}}=c_{m_{0}}\left(1+2.3 \frac{W_{\text {sep }}}{R_{0}}\right)
$$

From Eq. $(A-47)$, the windage torque is

$$
L_{w}=\frac{1}{2} C_{m^{\rho}} g^{\omega t} 1^{2} R_{0}
$$

The windage torque of the liquid turbine is ignored because of its lower speed.

\section{E. Gas Torque}

The efficiency of power recovery from the gas phase at optimum gas turbine speed is a specified constant, $n_{g^{-}}$. If a separate gas turbine is used that runs at optimum speed, then the gas turbine power is

$$
P_{g t}=\frac{1}{2} \pi g_{g}^{m} v^{2}
$$

If the gas turbine consists of impulse blading attached to the separator at radius $\mathrm{R}_{\mathrm{gt}}$, then ${ }_{\mathrm{g}}$ is the fraction of ideal gas torque at the separator speed. The gas torque is thus

$$
I_{g a s}=2{ }_{g}^{m} v_{g}^{R}{ }_{g t} \cos A_{n o z}\left(1-\frac{\omega_{1}}{w_{s y n c}}\right)
$$

where $\omega_{\text {sync }}$ is the synchronous speed at which the blade speed equals the circumferential component of gas velocity.

$$
\omega_{\text {sync }}=\frac{V_{g} \cos A_{n o z}}{R_{g t}}
$$


F. Power and Efficiency

The total separator torque is

$$
L_{\text {sep }}=L_{1 i q}+L_{\text {gas }}-L_{w}
$$

where $\mathrm{L}_{\text {gas }}$ is zero if a separate gas turbine is used.

In the calculation presented in Fig. 43, $\mathrm{L}_{\text {gas }}$ was zero and the separator speed was adjusted to make $\mathrm{L}_{\text {sep }}$ zero (free-spinning separator).

The separator power output is

$$
P_{\text {sep }}=L_{\text {sep }}{ }^{\omega} 1
$$

The liquid turbine power output is

$$
P_{\text {turb }}=L_{\text {turb }} w_{2}
$$

The total power output is

$$
P_{\text {tot }}=P_{\text {sep }}+P_{\text {turb }}+P_{\text {gt }}
$$

where $P_{g t}$ is zero if the gas turbine is attached to the separator.

The rotor efficiency is

$$
n_{r}=\frac{P_{\text {tot }}}{P_{\text {jet }}}
$$

and the turbine efficiency is

$$
n_{t}=n_{r} n_{n}
$$

where $\eta_{n}$ is the nozzle efficiency. 
1. Elliott, D. G., "Investigation of a Gas-Driven Jet Pump for Rocket Engines," Liquid Rockets and Propellants, Vol. 2, Academic Press, Inc., New York, 1960, pp. 497 - 541 .

2. Elliott, D. G., L. G. Hays, D. J. Cerini, and D. W. Bogdanoff, "Investigation of a Liquid-Metal Magnetohydrodynamic Power System," 5th Intersociety Energy Conversion Engineering Conference, American Nuclear Society, La Grange, Illinois, 1970, pp. 2-64 - 2-73.

3. Elliott, D. G., and L. G. Hays, "Two-Phase Turbine Engines," 11th Intersociety Energy Conversion Engineering Conference, American Institute of Chemical Engineers, New York, 1976, pp. $222-228$.

4. Austin, A. L., G. H. Higgins, and J. H. Howard, The Total Flow Concept for Recovery of Energy from Geothermal Hot Brine Deposits, Report No. UCRL-51366, Lawrence Livermore Laboratory, Livermore, California, Apri1 3, 1973.

5. Austin, A. L., and A. W. Lundberg, The LLL Geothermal Energy Program, A Status Report on the Development of the Total-Flow Concept, Report No. UCRL-50046-77, Lawrence Livermore Laboratory, Livermore, Calif., October 2, 1978.

6. Cerini, D. J., "A Two-Phase Rotary Separator Demonstration System for Geotherma1 Energy Conversion," 12th Intersociety Energy Conversion Engineering Conference, American Nuclear Society, La Grange, Illinois, 1977, pp. $884-892$.

7. Hays, L., and D. J. Cerini, "Progress Report on Rotary Separator Turbine Demonstration Program," Proceedings of the Third Annual Geothermal Conference and Workshop, Electric Power Research Institute, Palo Alto, Calif., October 1979, pp. 3-1 - 3-3. 
8. Steidel, R. F., Jr., H. Weiss, and J. E. Flower, Performance

Characteristics of the Lysholm Engine as Tested for Geothermal Power Applications in the Imperial Valley, Report No. UCRL-80151, Lawrence Livermore Laboratory, Livermore, Calif., August 22, 1977.

9. McKay, R. A., Helical Screw Expander Evaluation Project, Final Report, Jet Propulsion Laboratory, Pasadena, Calif. (to be published).

10. Elliott, D. G., and E. Weinberg, Acceleration of Liquids in Two-Phase Nozzles, Technical Report 32-987, Jet Propulsion Laboratory, Pasadena, Calif., July 1, 1968.

11. Alger, T. W., The Performance of Two-Phase Nozzles for Total Flow Geothermal Impulse Turbines, Report No. UCRL-76417, Lawrence Livermore Laboratory, Livermore, Calif., May 28, 1975.

12. Alger, T. W.,, Droplet Phase Characteristics in Liquid-Dominated Steam-Water Nozzle Flow, Report No. UCRL-52534, Lawrence Livermore Laboratory, Livermore, Calif., August 9, 1978.

13. Comfort, W. J., III, The Design and Evaluation of a Two-Phase Turbine for Low Quality Steam-Water Mixtures, Report No. UCRL-52281, Lawrence Livermore Laboratory, Livermore, Calif., May 16, 1977.

14. Comfort, W. J., III, "Performance of a Total Flow Impulse Turbine for Geothermal Applications," 12th Intersociety Energy Conversion Engineering Conference, American Nuclear Society, La Grange, Illinois, 1977, pp. 893-898.

15. Baker, D. W. C., K. H. Jolliffe, and D. Pearson, "The Resistance of Materials to Impact Erosion Damage," Philosophical Transactions of the Royal Society, Series A, 260, 1966.

16. Mann, R. W., and C. H. Marston, "Friction Drag on Bladed Disks in Housings", Journal of Basic Engineering, December, 1961, pp. $719-723$. 